\title{
A!
}

This is an electronic reprint of the original article.

This reprint may differ from the original in pagination and typographic detail.

Niinivaara, Elina; Cranston, Emily D.

\section{Bottom-up Assembly of Nanocellulose Structures}

Published in:

Carbohydrate Polymers

DOI:

10.1016/j.carbpol.2020.116664

Published: 01/11/2020

Document Version

Peer reviewed version

Published under the following license:

CC BY-NC-ND

Please cite the original version:

Niinivaara, E., \& Cranston, E. D. (2020). Bottom-up Assembly of Nanocellulose Structures. Carbohydrate Polymers, 247, [116664]. https://doi.org/10.1016/j.carbpol.2020.116664

This material is protected by copyright and other intellectual property rights, and duplication or sale of all or part of any of the repository collections is not permitted, except that material may be duplicated by you for your research use or educational purposes in electronic or print form. You must obtain permission for any other use. Electronic or print copies may not be offered, whether for sale or otherwise to anyone who is not an authorised user. 


\section{Journal Pre-proof}

Bottom-up Assembly of Nanocellulose Structures

Elina Niinivaara (Conceptualization) (Writing - original draft) (Writing - review and editing) (Visualization) (Funding acquisition), Emily D. Cranston (Conceptualization) (Writing - original draft) (Writing review and editing) (Visualization) (Supervision) (Project administration) (Funding acquisition)

PII: S0144-8617(20)30838-9

DOI: $\quad$ https://doi.org/10.1016/j.carbpol.2020.116664

Reference: $\quad$ CARP 116664

To appear in: $\quad$ Carbohydrate Polymers

Received Date: $\quad 10$ April 2020

Revised Date: $\quad 4$ June 2020

Accepted Date: $\quad 17$ June 2020

Please cite this article as: Niinivaara E, Cranston ED, Bottom-up Assembly of Nanocellulose Structures, Carbohydrate Polymers (2020), doi: https://doi.org/10.1016/j.carbpol.2020.116664

This is a PDF file of an article that has undergone enhancements after acceptance, such as the addition of a cover page and metadata, and formatting for readability, but it is not yet the definitive version of record. This version will undergo additional copyediting, typesetting and review before it is published in its final form, but we are providing this version to give early visibility of the article. Please note that, during the production process, errors may be discovered which could affect the content, and all legal disclaimers that apply to the journal pertain.

(C) 2020 Published by Elsevier. 


\title{
Bottom-up Assembly of Nanocellulose Structures
}

\author{
Elina Niinivaara ${ }^{1,2}$ and Emily D. Cranston ${ }^{1,3, *}$
}

${ }^{1}$ Department of Wood Science, University of British Columbia, Vancouver, BC, Canada V6T 1Z4

${ }^{2}$ Department of Bioproducts and Biosystems, Aalto University, P.O. Box 16300, FI-0076 Aalto, Espoo, Finland

${ }^{3}$ Department of Chemical and Biological Engineering, University of British Columbia, Vancouver, BC, Canada V6T 1 Z4

${ }^{*}$ Corresponding author.

Email Addresses. elina.niinivaara@ubc.ca (E. Niinivaara), emily.cranston@ubc.ca (E.D. Cranston)

\section{Highlights}

- Bottom-up assembly of cellulose nanocrystal and cellulose nanofibril structures

- Discrete nanocellulose-only particles to bulk nanostructured materials

- Bottom-up assembly techniques and driving forces to produce well-defined structures

- Potential applications and research directions for nanocellulose-only structures

\section{Abstract}

Nanocelluloses, both cellulose nanofibrils and cellulose nanocrystals, are gaining research traction due to their viability as key components in commercial applications and industrial processes. Significant efforts have been made to understand both the potential of assembling nanocelluloses, and the limits and prospectives of the resulting structures. This Review focuses on bottom-up techniques used to prepare nanocellulose-only structures, and details the intermolecular and surface forces driving their assembly. Additionally, the interactions that contribute to their structural integrity are discussed along with alternate pathways and suggestions for improved properties. Six categories of nanocellulose structures are presented: (1) powders, beads, and droplets; (2) capsules; (3) continuous fibres; (4) films; (5) hydrogels; and (6) aerogels and dried foams. Although research on nanocellulose assembly often focuses on fundamental science, this Review also provides insight on the potential utilization of such structures in a wide array of applications.

Keywords Nanocellulose; bottom-up assemblies; structures; cellulose nanocrystals; cellulose nanofibrils 


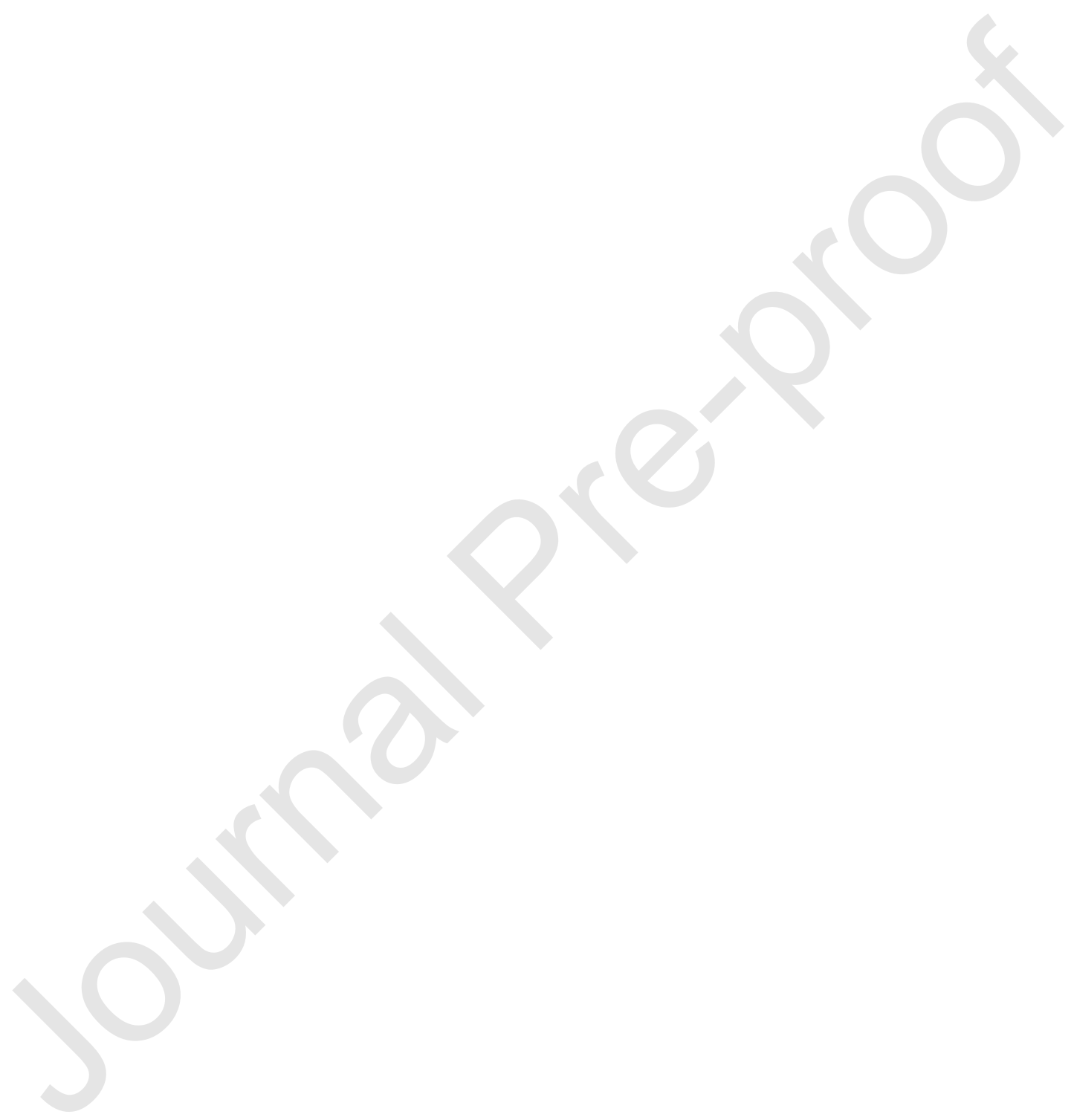




\section{Table of Contents}

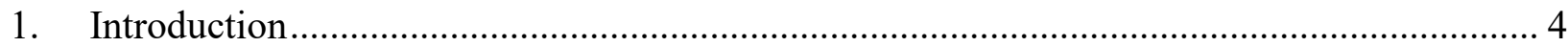

2. Nanocellulose Powders, Droplets and Beads................................................................... 7

2.1. Preparation of Discrete Nanocellulose Particles ............................................................. 8

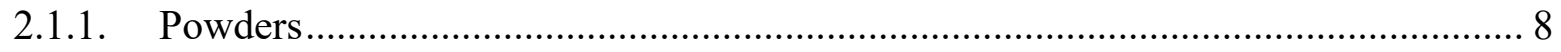

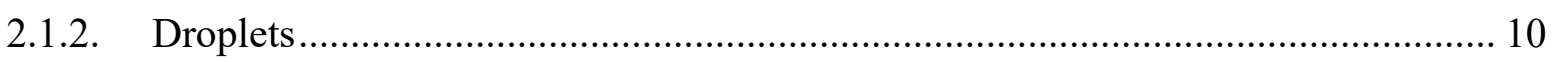

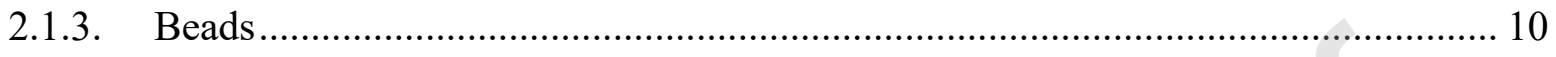

2.2. Potential Applications of Powders, Droplets and Beads .............................................. 12

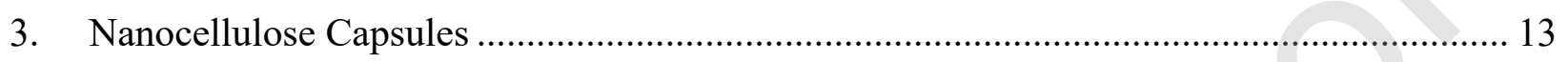

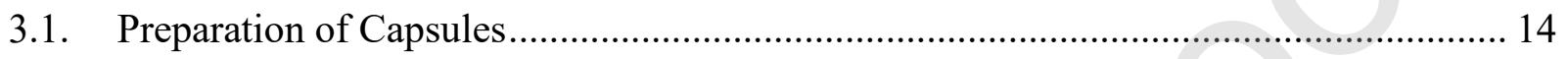

3.2. Potential Applications of Capsules ........................................................................ 15

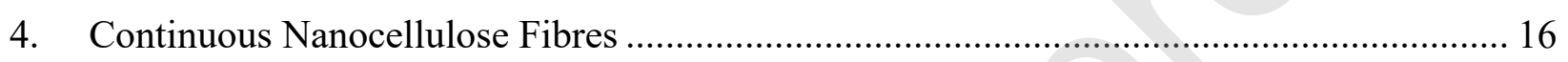

4.1. Preparation of Continuous Fibres....................................................................... 18

4.2. Potential Applications of Continuous Fibres ………….......................................... 20

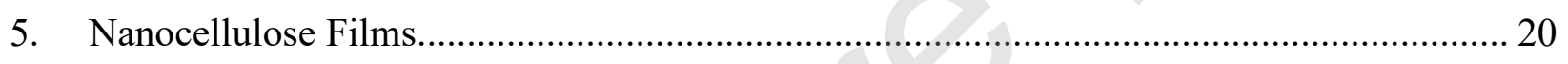

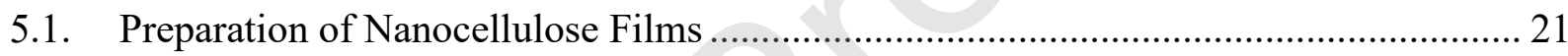

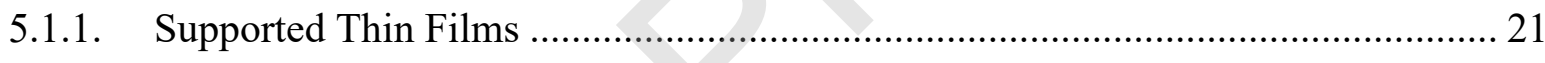

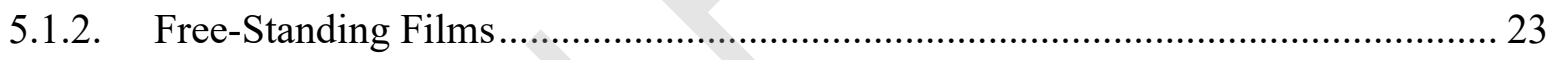

5.2. Potential Applications of Nanocellulose Films ........................................................... 24

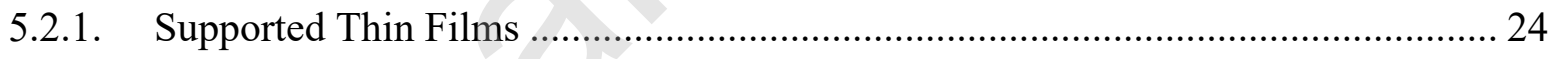

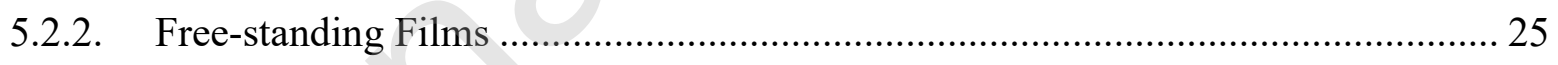

6. Nanocellulose Hydrogels, Aerogels and Dried Foams …………………………............... 26

6.1. Preparation of Hydrogels, Aerogels and Dried Foams ………………………............. 27

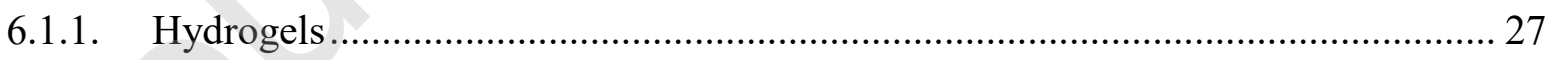

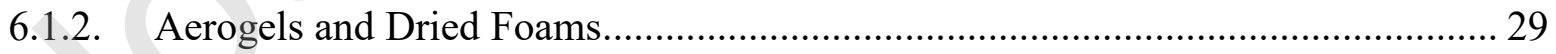

6.2. Potential Applications of Nanocellulose Hydrogels, Aerogels and Foams .................... 31

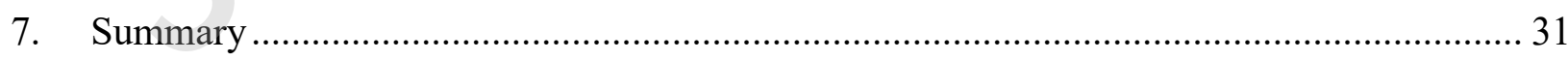

References 


\section{Introduction}

The utilization of nanocelluloses in the production of new functional materials has become a fast-growing area of interest in both research and industry due to the exceptional versatility of these nanoscale materials. Both the physical and chemical adaptability of nanocelluloses make them the ideal substitute for inorganic and petroleum-based materials, in many applications. Additionally, their natural abundance and sustainability, recyclability and inherent biocompatibility allow for nanocelluloses to be implemented not only in industrial applications but also in niche applications such as sensors, pharmaceuticals, food, household products and cosmetics.

Physically, nanocellulose offers a material that has an exceptionally high surface area to volume ratio and exhibits high strength both as crystalline nanoparticles and as entangled fibrillar networks. All of these attributes are beneficial in the bottom-up assembly of nanocellulosic structures, where larger assemblies can be prepared using nanocellulose as the building blocks. The key in designing and fabricating these structures is to understand and control the physical and chemical interactions between nanocellulose particles and fibrils. However, because nanocelluloses range from short, rod-shaped particles (cellulose nanocrystals (CNCs)) to long, flexible fibrils/ribbons (cellulose nanofibrils (CNFs) and bacterial cellulose (BC)) the choice of which type to use in which structure is fully dependent on the desired properties of the final material.

CNFs, for example, are typically implemented in structures that require both strength and flexibility. This type of nanocellulose, with diameters in the nanometer scale and lengths in the micrometer range (Päk̈ko et al., 2007; Sani \& Dahman, 2010; Wågberg et al., 2008), is able to form complex, entangled networks that are often used to form 3-dimensional structures such as hydrogels and aerogels (De France et al., 2017), hierarchical fibres (Clemons, 2016; Lundahl et al., 2017) and films (Kontturi et al., 2006), with, for example, very low gas permeability (Henriksson et al., 2008; Sehaqui et al., 2011). On the other hand, CNCs differ in that they are relatively stiff rod-shaped particles (ca. $3-7 \mathrm{~nm}$ wide and $100-350 \mathrm{~nm}$ long (Beck-Candanedo et al., 2005; Habibi, Lucia, et al., 2010; Reid et al., 2017)) when derived from plant sources) with a specific Young's modulus comparable to that of steel and Kevlar ${ }^{\circledR}$ (with a bending strength of $10 \mathrm{GPa}$, an elastic modulus of $150 \mathrm{GPa}$ and exceptionally high specific modulus when normalized by density) (Eichhorn et al., 2010)) and, exhibit high colloidal stability and interesting optical properties. The use of CNCs in "cellulose-only" materials has proven difficult, due to the brittle nature of the resulting structures. As such, they are more often used in supported thin film/coating applications (Ferrer et al., 2017) and as rheological modifiers, and reinforcing agents in hybrid/composite materials (Hubbe et al., 2008). Recently though, CNCs have also found application in hydrogel and aerogel structures (De France et al., 2017), and even as stabilizers in Pickering emulsions and foams (Gestranius et al., 2017; Kalashnikova et al., 2011, 2012, 2013; Ougiya et al., 1997; Winuprasith \& Suphantharika, 2015). 
From a surface chemistry and functionalization perspective, the potential of nanocelluloses is far reaching. The abundance of hydroxyl groups on the surface of the nanoparticle/fibril allows them to form strong, hydrogen bonded structures when dry, which, owing to the nanoscale size of the cellulose, can lead to densely packed materials. However, the high capacity to form hydrogen bonds also results in the overall hydrophilic nature of nanocelluloses; a property which limits their use in water sensitive applications and reduces their compatibility with non-polar environments. Nonetheless, these hydroxyl groups also facilitate the surface modification of nanocelluloses using well-known carbohydrate and synthetic chemistries. Functionalization routes such as esterification (Braun et al., 2009), acetylation (Cetin et al., 2009), oxidation (Habibi et al., 2006), cationization (Hasani et al., 2008), silylation (Gousse \& Chanzy, 2002), and polymer grafting (Kedzior et al., 2018) have been demonstrated to alter the inherent nature of cellulose, promote otherwise unlikely surface interactions, and impart added functionality. For a more comprehensive take on the multitude of surface modification routes available for nanocellulose, the reader is referred to recent reviews (Heise et al., 2020; Rol et al., 2019; Zoppe et al., 2020).

Table 1 summarizes the contents of this Review, which focuses on the controlled bottom-up assembly of hierarchical nanocellulose-only structures, ordered from discrete particles in the form of powders, beads and droplets, to bulk nanostructured materials. The most common routes to prepare such structures and their potential applications are highlighted. We focus on the fundamental mechanisms and intermolecular and surface forces that govern structure assembly. In this Review, only materials where nanocellulose is the major component or plays the dominant role are presented, despite the importance of hybrids/composites where nanocellulose is an additive or minor component - such materials are reviewed elsewhere (Eichhorn et al., 2010; Moon et al., 2011). Additionally, this Review does not go into detail about the optical properties of CNCs that result from their ability to self-assemble, i.e., form chiral nematic liquid crystals; for in-depth coverage, the reader is referred to comprehensive reviews available in the literature (Abitbol \& Cranston, 2014; Gray, 2016, 2018; Lagerwall et al., 2014; Meseck et al., 2017; Pan et al., 2010; Parker et al., 2018; Tran et al., 2020).

When producing hierarchical nanocellulose assemblies through bottom-up techniques, selfassembly is rarely implemented due to its sensitivity to contaminants and the surrounding environmental conditions, and the long wait times needed for thermodynamically driven ordering and the evaporation of water. Rather, various controlled methods are used to manipulate nanocellulosic materials into defined alignments, shapes and topographies, to produce structures with a specific role and function. In this Review, we will discuss the bottom-up techniques used to assemble the following structures, 1) powders, beads, droplets, 2) capsules, 3) continuous fibres, 4) supported thin and free-standing films, 5) hydrogels, and 6) aerogels and dried foams. These structures are ordered from discrete particles to bulk nanostructured materials. The driving forces that need to be controlled to produce well-defined structures are described in each section, and potential applications and research directions are noted. It is important to keep in mind, 
however, that the utilization of nanocelluloses in commercially relevant applications is an emerging field and as such, the majority of the applications described below are ones which, as of yet, have only been proposed. Regardless, the necessary shift toward greener and more sustainable materials in all commercial products will inevitably result in the implementation of nanocellulose in a broad range of applications, likely in the foreseeable future. 


\section{Nanocellulose Powders, Droplets and Beads}

Nanocellulose can be assembled into hierarchical discrete objects or particles from liquid suspensions following a range of drying methods. Since the particles contain many CNCs or $\mathrm{CNFs}$, they range from hundreds of nanometers to millimeters in size. Some methods give uniform particles with low size polydispersity (i.e., beads) while others are more random (i.e., powders). One of the primary reasons to dry nanocellulose suspensions (in bulk) is to facilitate transportation, shipping and storage, and to increase the range of processing routes for nanocellulose containing materials. For example, to produce melt compounded thermoplastic nanocomposites, adding nanocellulose as a dry powder avoids the complications of adding liquids that may not be compatible with some equipment and furthermore can lead to side reactions with other reactants and promote thermal degradation of cellulose (Kedzior et al., 2016; Oksman \& Mathew, 2014; Peng et al., 2015).

In general, dried nanocellulose is expected to be redispersible in liquid media, meaning that the individual CNCs or CNFs are completely separated, and minimal aggregation of nanoparticles remains after redispersion (Peng et al., 2013). Unless of course, the opposite is required - a material that holds together and is permanently aggregated, in which case, additional chemicals, treatments or crosslinking agents can be added. A great deal of focus has gone into understanding the best drying methods and additives needed to ensure redispersibility. Note that dried CNCs have been shown to be fully redispersible (Beck et al., 2012; Cheng et al., 2015), however work remains with CNFs (Peng, Gardner, et al., 2012), and generally fibrillated celluloses are shipped as dispersions, gels or "pastes", containing as high as $10 \%$ cellulose (90\% water) if redispersion is required (Foster et al., 2018).

Liquid droplets are another form of discrete hierarchical nanocellulose "particles". The production of uniform droplets from nanocellulose suspensions has typically been done using microfluidic devices with the goal of improving the fundamental understanding of cellulosecellulose interactions in the bottom-up assembly of structures, or the self-assembly of CNCs in confined geometries. Alternatively, droplets and microparticles can be produced by dispensing droplets from a pipette/syringe/atomizing nozzle onto superhydrophobic surfaces or into a nondispersing solvent. Drying of uniform droplets to form beads may offer microscale materials with controlled properties and in general, powders and beads may find applications themselves in a variety of liquid formulated products, separation agents, cosmetics (e.g. replacement for plastic microbeads), foods or pharmaceuticals. Table 2 lists the main assembly methods to produce powders, droplets and beads, the key interaction forces during drying and between cellulose, and some characteristic properties of the obtained materials. 


\subsection{Preparation of Discrete Nanocellulose Particles}

\subsubsection{Powders}

As discussed, drying nanocelluloses is considered an essential stage in the commercial development of CNC and CNF applications, manufacturing scale-up and market acceptance. In addition to which, in many cases the use of dried cellulose powders is more efficient than using suspensions or gels, especially when incorporating them into non-polar systems (Peng, Gardner, et al., 2012). The goal of drying is to remove water without permanently losing the nanostructure of CNCs and CNFs and to do so, it is of vital importance to understand the interactions and higher order structures that result from drying. If cellulose comes into contact with itself, strong cellulose-cellulose interactions occur, namely van der Waals forces, hydrogen bonding, and in some situations (the highly debated) hydrophobic interactions (Glasser et al., 2012; Medronho et al., 2012; Nishiyama, 2018). Furthermore, if heated, hornification can also occur. Hornification is the formation of irreversible (or at best, partially reversible) bonds between cellulose hydroxyl groups (Ding et al., 2019). The most common drying methods to obtain powdered nanocelluloses are described below.

Spray drying is the process of atomizing a liquid into small droplets that are then quickly dried with hot gas forming dried particles with a consistent particle size distribution. It is a continuous process that is used industrially in the manufacturing of powders, such as those intended for food, pharmaceutical and detergent products, for example. The forces at play during spray drying are well described in the literature (Peng, Gardner, et al., 2012; Vehring, 2008), and eventually individual cellulose nanoparticles come into molecular contact where hydrogen bonds and van der Waals forces dominate.

When CNCs are spray dried from the sodium salt form (meaning they have been neutralized from the acid form with $\mathrm{NaOH}$ to have $\mathrm{Na}^{+}$counterions on the surface charge groups) they form a uniform white powder of agglomerated nanocrystals with a rounded granular shape (Beck et al., 2012; Khoshkava \& Kamal, 2014a) or spheres (Peng, Gardner, et al., 2012; Z. Zhu et al., 2019), and sizes ranging from 5-30 $\mu \mathrm{m}$ (Figure 1a and Figure 1b). Depending on the spray drying process parameters, particle size and surface roughness can be controlled, and sometimes nanometer-sized particles are also produced. These powders are free-flowing and flour-like and can be redispersed fully when reconstituted in water at low concentrations (where watercellulose hydrogen bonds immediately replace cellulose-cellulose hydrogen bonds) as long as energy is added in the form of ultrasonication to break van der Waals interactions (Beck et al., 2012; Reid et al., 2016). If dried from the acid form, CNCs will not redisperse easily. While spray dried CNC powders can theoretically be redispersed in organic solvents or hydrophobic polymers, their incompatibility with non-polar materials generally means that cellulose-cellulose interactions dominate and nanoparticles remain partially aggregated and not fully dispersed (Khoshkava \& Kamal, 2013, 2014b, 2014a). To improve the compatibility of nanocellulose and 
polymers, "masterbatches" can be prepared (Kargarzadeh et al., 2017), where a high concentration of nanocellulose and polymer are forced together into a powder (produced, for example, by spray drying) which can then be mixed in with more bulk polymer to achieve the final desired nanofiller content. Another compatibilization method has been to spray dry CNCs with lignin, making a more hydrophobic powder but as a result of changes in diffusion during the drying process, the particles have a donut shape instead of being spherical (Z. Zhu et al., 2019).

When CNFs are dried through spray drying, they lead to either spherical particles similar to those formed from $\mathrm{CNCs}$, or if a portion of the long fibrils protrude outside of the atomized droplet, irregular shaped particles are obtained (Figure 1c). These materials are generally not redispersible in water or other solvents.

Freeze drying (or lyophilisation) is a batch process that dries by first freezing, then lowering the pressure and sublimating the ice; it is commonly used in preservation (sometimes of biological tissues and bioactive ingredients) and food processing. The product of freeze drying is not a freeflowing powder but in the case of nanocellulose, it is a thin lamellar flaky structure with laterally agglomerated nanocellulose that may be white or slightly iridescent (Figure 1d) and can be ground to a powder if needed. The flakes are typically a few hundred nanometers thick and ground powders have an irregular shape. The structures produced by freeze drying are highly dependent on the rate of freezing which forces cryogelation between cellulose nanoparticles but leaves large voids or pores where the ice crystals form and are then sublimated. It is believed that the lamellae interact through weak hydrophobic interactions (Peng, Gardner, et al., 2012) contributing to the ease of redispersion of freeze dried CNCs.

A subset of spray drying and freeze drying is freeze spray drying where a nanocellulose suspension is sprayed or dropped into a cryogenic solvent such that the droplets are immediately frozen and then dried by sublimation. Either a fibrillar skeleton morphology (Jimenez-Saelices et al., 2016) or micrometer sized granules (Cai et al., 2014) can be obtained but in both cases, the materials are highly porous (called an aerogel) and retain internal surface area similar to having individualized nanoparticles.

Preparing nanocellulose samples for supercritical drying, or critical point drying (CPD) requires replacing water with a volatile solvent (such as ethanol), then replacing the volatile solvent with liquid $\mathrm{CO}_{2}$. Next, the mixture is heated to supercritical conditions and then $\mathrm{CO}_{2}$ is removed by decompression to atmospheric conditions (Peng et al., 2013; Peng, Gardner, et al., 2012). A number of variations on this sequence and equipment exist, for example, CNCs have been dried using pressurized gas expansion (PGX) to obtain some of the highest porosities reported to date (Osorio et al., 2018). Due to the absence of capillary forces during drying, nanocellulose structures in the wet state are preserved in the dry state. The challenge is fully removing water in the initial stages which has been shown to be easier for CNFs than CNCs (Peng, Gardner, et al., 2012). Overall, supercritical drying may be the most expensive and laborious way to dry nanocellulose but is able to best preserve the nano-dimensions of the 
crystals and fibrils. From a thermal stability standpoint, supercritical drying and freeze drying lead to nanocellulose powders with the lowest onset of thermal degradation and lowest degrees of crystallinity (Peng et al., 2013).

\subsubsection{Droplets}

Microfluidic devices have been implemented to study nanocellulose liquid droplets where the confinement within a droplet, or in a drying/shrinking droplet, gives rise to unique cellulosecellulose interactions (Levin et al., 2018; Y. Li et al., 2016; Parker et al., 2016; Tumarkin \& Kumacheva, 2009). Microfluidic devices for liquid droplet formation are highly versatile, as they allow for accurate control of the size and shape of the droplets and offer a high throughput technique where as many as a million droplets per hour can be produced and parallel assemblies are possible (S. Xu et al., 2005). Within these devices, a nanocellulose suspension (dispersed phase) and an immiscible liquid (continuous phase) are simultaneously passed through micrometer thick channels with varying geometries (depicted in Figure 1e). Junctions, pinches or other physical barriers throughout the device disrupt the flow of the dispersed phase, causing the formation of liquid droplets, which are then collected in the continuous phase. The size of the microfluidic channels is the primary parameter that can be varied to tailor droplet size, and in general, droplets are larger than $50 \mu \mathrm{m}$. While droplets in themselves are not, strictly speaking, bottom-up assemblies of nanocelluloses they are the precursor material for solid, nanocellulose beads, which are formed through drying of said droplets. Moreover, a lot of information about the fundamentals of nanocelluloses, and their potential applications can be learned through droplet technologies.

CNC self-assembly into liquid crystal phases has been tracked in microfluidic droplets either for CNCs alone (Parker et al., 2016, 2018) or for CNCs combined with polymer, metal, carbon or metal oxide nanoparticles (Y. Li et al., 2016). Flow focusing devices led to highly ordered liquid droplets with concentric hierarchical architectures (Y. Li et al., 2016; Parker et al., 2016) that could be dried into low porosity solid particles with vivid iridescence and photonic crystal organization (Y. Li et al., 2016; Parker et al., 2016). Microfluidic channels have also been used to produce uniform CNC droplets with the ability to crosslink, which restricts the self-assembly and densification of CNCs by tethering the particles to each other with an open pore structure (Levin et al., 2018). Due to the fact that CNFs are longer than CNCs and tend to entangle even at low concentrations, there are no literature examples of microfluidic preparation of CNF droplets or beads.

\subsubsection{Beads}

The formation of dried cellulose beads (also called spherical microparticles and microspheres) was first reported as early as the 1950s for a variety of applications including being used as the 
column material in liquid chromatography, water purification, protein immobilization, and as drug delivery vehicles (O’Neill \& Reichardt, 1951). The ability to control the bead size, shape dispersity, porosity, and surface functionality has been widely discussed (Martin et al., 2013). Generally, beads should be wet-stable, and their structure maintained throughout their application. However, the majority of cellulose beads are made from regenerated cellulose (Carrick et al., 2013; Carrick, Larsson, et al., 2014; Carrick, Lindström, et al., 2014; Luo et al., 2009; Luo \& Zhang, 2010), which is not nanocellulose. In many of the examples where nanocellulose is used in microparticles, it is a minor component acting as a reinforcing or crosslinking agent, and is often combined with polymers such as chitosan (Z. Liu et al., 2012), alginate (Mohammed et al., 2015; Supramaniam et al., 2018), xylan (M. Li et al., 2016) or other functional nanoparticles (e.g. magnetic nanoparticles). Again, the focus of this Review is on materials that are primarily nanocellulose and as such, there are only a few examples of nanocellulose-only beads described to date.

In general, solute containing droplets can be "fixed" into more permanent bead structures by drying, ion/solvent/cryo-induced gelation, chemical crosslinking, or thermal/light-activated polymerization. A variety of post-preparation surface functionalization routes also exist (Martin et al., 2013). For nanocellulose systems, drying and cryo-gelation are the most common ways to turn droplets into beads and below we summarize two types of nanocellulose beads: (1) solid nanocellulose beads and (2) porous nanocellulose beads that have internal aerogel structures. The advantages of hierarchical micrometer-sized objects with aerogel structures is that they are extremely lightweight and have specific surface areas approaching that of a nanomaterial, which is good for binding/holding/releasing other components, while being in a convenient format for processing and the development of formulated products ("bulk" aerogels are discussed further in Section 6.1).

In the category of solid nanocellulose beads, examples include drying CNC droplets produced by microfluidics, as mentioned above, to give particles $<200 \mu \mathrm{m}$ in diameter (Y. Li et al., 2016; Parker et al., 2016), or producing semi-spherical geometries of chiral nematic CNC films by using elastomeric molds to template 4-6 mm shapes (Rofouie et al., 2018). Such dried droplets or semi-spheres will hold together if placed in water for at least a short time (minutes to hours), which can be extended if they were dried completely from an acid form CNC suspension or heat treated after drying to induce hornification (Beck et al., 2012; Ding et al., 2019). An alternative route to solid, spherical nanocellulose particles involves oxidizing cellulose nanofibrils from green algae to dialdehyde cellulose that inherently forms 1-20 $\mu \mathrm{m}$ sized beads (Lindh et al., 2014).

Highly porous nanocellulose beads with aerogel "cores" can be produced by adapting some of the procedures for solid beads; for example, by performing a reductive amination with diamine spacers on the green algae oxidized cellulose spheres, beads with 30 times higher specific surface area can be produced with pores in the 10-100 $\mathrm{nm}$ range (Lindh et al., 2016). Following the microfluidic approach, if CNCs are orthogonally functionalized with crosslinking groups 
(e.g. aldehyde and hydrazide groups to form hydrazone crosslinks) and are combined in droplets and then allowed to dry, the removal of water forces CNCs into molecular contact enabling chemical crosslinking (Levin et al., 2018). This crosslinking precludes liquid crystalline selfassembly and instead of producing solid ordered beads, leads to highly macroporous and flexible beads in the 30-110 $\mu \mathrm{m}$ size range that do not redisperse in a range of liquids (Levin et al., 2018).

Two other types of porous nanocellulose beads have been made by depositing droplets and freezing them: in the first case, CNF suspensions were atomized into liquid nitrogen and then freeze dried giving beads in the 60-120 $\mu \mathrm{m}$ range with meso- and macropores, and if produced with an epichlorohydrin resin crosslinker and heat treated after drying, the beads were chemically crosslinked and liquid stable. In the second case, CNF gel droplets were deposited onto superhydrophobic surfaces (to keep an almost perfectly spherical shape) and then oxidized to introduce dialdehyde groups, frozen, thawed, solvent-exchanged to ethanol and then acetone, and air dried (Erlandsson et al., 2016). The final drying induced acetal bond crosslinks, but retained the meso- and macroporous internal structure, and again produced beads that kept their structural integrity in water. Porous beads produced this way are the largest stable and robust structures reported, with sizes in the 1-2 mm range (Erlandsson et al., 2016) (Figure 1f). It is worth noting that structures from CNFs tend to be more wet-stable than CNCs because of significant physical entanglement that occurs naturally in the longer, more flexible nanofibrils, thus making chemical crosslinking less crucial depending on the intended bead applications. One advantage of highly porous beads is the ability to post functionalize them since nanoparticles and polymers can easily coat both the inside and outside of the beads.

\subsection{Potential Applications of Powders, Droplets and Beads}

As mentioned previously, potential applications for powders, droplets and beads span a range of industries. Aside from producing a dried material that can either be redispersed or mixed to give new composite or hybrid materials, biomedical/pharmaceutical, analytical, environmental, and cosmetic uses have been discussed. For example, CNC and CNF beads have been demonstrated in water purification, as sorbents and potentially as replacements for activated carbon to remove dyes and heavy metals from the environment (Mohammed et al., 2015). The ability to load, store and release other nanoparticles and small molecules from porous beads may offer the next advances in controlled release technologies and more specifically, enzyme/protein immobilization (Martin et al., 2013) and drug delivery have been demonstrated (Luo et al., 2009). Another interesting "delivery" approach that has been envisioned, is using cellulose beads to deliver plant growth regulators (M. Li et al., 2016).

Other cosmetic/medical applications may include protective creams/coatings, exfoliating products, blood coagulants (M. Li et al., 2016) and scaffolds for cell growth and tissue engineering (Cai et al., 2014; Levin et al., 2018). In chromatography (e.g. size exclusion, affinity 
or gel filtration chromatography) (Martin et al., 2013) one can imagine using uniform nanocellulose beads as the stationary phase (Luo \& Zhang, 2010) and potentially even as chiral separators (M. Li et al., 2016) or solid phase synthesis supports (Martin et al., 2013).

Microfluidics can offer unprecedented control for the engineering of particles with unusual structural or mechanical properties and due to the interesting optical properties of CNCs, a range of optical devices including optical chirality sorting, optical microresonators (Y. Li et al., 2016), broadband reflectors and circular polarizers (Rofouie et al., 2018) may be possible. Lastly, recent high-tech applications proposed have included nanocellulose beads as components in electrochemical charge storage for energy devices (such as electrodes in supercapacitors), when combined with functional materials like carbon nanotubes and conductive polymers) (Erlandsson et al., 2016).

\section{Nanocellulose Capsules}

In addition to the assemblies described above, nanocelluloses can also be used in encapsulation technologies (Figure 2a). The utilization of capsules covers a wide spectrum of applications from controlled release (Yoo et al., 2017), protection of nano- and microparticles (Ye et al., 2015), to liquid mobility (Svagan et al., 2014, 2016) and separation technologies (Paulraj et al., 2018). Nanocellulose has been shown to be a potential platform as a material in all of the aforementioned applications. The biocompatibility and non-toxicity of nanocellulose makes it ideal for sustained drug release capsules in addition to which the amphiphilic nature of CNCs can enable encapsulation of hydrophobic pharmaceuticals (Mohanta et al., 2014). Furthermore, the controllable porosity of the capsule shell network allows nanocellulose capsules to be loaded with both nano- and macroparticles, whereas their polymer-based counterparts can typically only facilitate the loading of molecules under $10 \mathrm{~nm}$ in diameter (Ye et al., 2015). Importantly, in comparison to the traditionally used encapsulation materials, such as alginate, nanocellulose is of particular interest as a bio-based alternative due to its robustness in low $\mathrm{pH}$, high ionic strength and at elevated temperatures (Huq et al., 2017). Table 3 summarizes the preparation methods for nanocellulose-reinforced capsules. It also reviews the interactions occurring during preparation along with methods by which to lock assembled structures in to place post fabrication.

It should be noted that, while not a nanocellulose-only assembly, emulsions and latexes also warrant mentioning and are "precursors" to capsules in some cases. Due to their small size, intermediate wettability and slightly amphiphilic nature (Kalashnikova et al., 2012), nanocelluloses partition at interfaces, although they are not strictly surface active. For example, nanocelluloses can act either as interface stabilizers or as a network in the continuous phase that restricts droplet coalescence in emulsion and emulsion polymerization systems (Gestranius et al., 
2017; Z. Hu et al., 2015; Jiménez Saelices et al., 2019; Jiménez Saelices \& Capron, 2018; Kalashnikova et al., 2013; Kedzior et al., 2017). Nanocelluloses can also adsorb at latex particle surfaces or reinforce dried latex films used, for example, as coatings and adhesives (Abitbol et al., 2014; Dastjerdi et al., 2017a, 2017b, 2018, 2019; Ouzas et al., 2018, 2019; Pakdel et al., 2020). However, as these structures are outside of the scope of this review, the reader is referred to a comprehensive review on the subject by Kedzior et al., 2020.

\subsection{Preparation of Capsules}

The formation of capsules is largely driven by electrostatic interactions, physical entanglement and crosslinking at interfaces. The most common method to prepare nanocellulose-based capsules is through dip coating (described in detail in Section 5.1.1), where electrostatic interactions lead to the adsorption of nanocellulose (from suspension) onto the surface of an oppositely charged sacrificial template, such as $\mathrm{CaCO}_{3}$ (Paulraj et al., 2018), polystyrene, silica (Ye et al., 2015) or melamine formaldehyde (Mohanta et al., 2014), which can be easily dissolved to leave intact a hollow nanocellulose shell. The potential of both CNCs and CNFs has been investigated in the preparation of capsules prepared through dip coating. However, due to the brittle nature of CNC-only networks, and the relatively hydrophilic nature of cellulose, capsules are typically made from composite materials where the nanocellulose is mixed with a plasticizing polymer such as glycerol and polyethylene glycol (Y. Zhang et al., 2017), xyloglucan and pectin (Paulraj et al., 2018), polyethylenimine (Ye et al., 2015) or alginate (Huq et al., 2012, 2014) (Figure 2b). The role of these plasticizing polymers is to improve flexibility, and to encourage physical entanglement and crosslinking within the capsule shell network. Conversely, nanocellulose can be used as a filler to improve structural integrity and improve the mechanical strength of capsules (Svagan et al., 2014) (Figure 2c). This mechanical strength stems not only from the crystallinity of the cellulose, but also from the abundance of intermolecular hydrogen bonds between nanocellulose crystals (or fibrils) which result from the removal of water from the shell wall structure.

Nanocellulose capsules can also be prepared using Pickering emulsions and subsequent interfacial polymerizations/complexation (Svagan et al., 2014, 2016; Yoo et al., 2017). In this method, as the oil phase polymerizes through an addition polymerization (such as the polymerization of poly urea-urethane) the nanocellulose becomes embedded within the polymeric shell. Using this preparation technique, it is possible to form hollow capsules where carbon dioxide becomes trapped within the capsule, or liquid core capsules where a hydrophobic liquid is encapsulated by the nanocellulose/polymer shell (Svagan et al., 2016; Yoo et al., 2017). Oil containing capsules can also be prepared using a complexation between CNC and methylcellulose stabilized Pickering emulsions and tannic acid, where the tannic acid and methylcellulose form a colloidal complex, which results in the condensation and stiffening of the methylcellulose within the CNC shell network. Interestingly, these tannic acid treated 
$\mathrm{CNC} /$ methyl cellulose oil capsules are so robust that the they can be freeze-dried to a dry powder and then redispersed into water (Z. Hu, Marway, et al., 2016). Although not cellulose-only structures, these structures are only made possible by the partitioning of nanocellulose to the water-oil interface and are then held together by chemical crosslinks resulting from the polymerization/complexation process, and hydrogen bonds inherent to cellulose networks (Svagan et al., 2016).

Although a slightly different approach to bottom-up assembly, it is worth noting that biofabrication has also been used to prepare BC capsules (Greca et al., 2018). In this method, hydrophobic particles are used to stabilize a water droplet in air to create a so-called 'liquid marble' (McHale \& Newton, 2011). These hydrophobic surfaces provide an ideal interface for bacteria to grow and synthesize BC at the air-water interface of the marble, resulting in a templated network of BC fibres held together through inter- and intramolecular hydrogen bonding and van der Waals forces. These capsules can then be isolated by simply washing out the hydrophobic particles, leaving intact a hollow BC capsule upon drying. Interestingly, these structures can also be loaded in situ during BC synthesis with, for example, nano- or microparticles, which results in their encapsulation.

\subsection{Potential Applications of Capsules}

The implementation of nanocellulose-based capsules will likely see a rise in the future, possibly affecting a wide range of applications. A major market in which such capsules could be implemented is in pharmaceuticals. Bio-based capsules show promise in areas such as controlled drug release, tailored drug delivery routes (Mohanta et al., 2014; Y. Zhang et al., 2017), protective cages for small molecules (Greca et al., 2018; Lemahieu et al., 2011; Ye et al., 2015), and drug stabilization (Huq et al., 2014). Additionally, with their ability to encapsulate liquids (Svagan et al., 2016) they could be applied in cosmetics, for the slow release of dyes (Yoo et al., 2017) or other applications requiring liquid mobility. Such capsules could also be used in separation technologies, such as those listed above for powders and beads, and for example, in applications requiring low oxygen permeability. In general, the relative robustness of nanocellulose-reinforced capsules provides a more secure encapsulation technology than many other materials currently available. 


\section{Continuous Nanocellulose Fibres}

Manufactured cellulose-based fibres such as viscose, modal and acetate fibres are by no means a new addition to the application spectrum of cellulosic materials. However, these regenerated cellulose fibres are conventionally made using a tedious combination of cellulose derivatization and subsequent dissolution, extrusion and regeneration processes, which require vast amounts of environmentally harmful chemicals. They have, however, fulfilled the requirement for strong, continuous fibres, for use in, for example, the textile industry and separation technologies, whereas naturally occurring fibres, such a cotton fibres, are typically short and discontinuous, and so exhibit significantly lower mechanical strength (Hooshmand et al., 2015). For context, natural cotton fibres exhibit a Young's modulus $<13 \mathrm{GPa}$ and a tensile strengths as low as 290 $\mathrm{MPa}$ (X. Li et al., 2007), whereas the corresponding value for recently developed, regenerated Ioncell fibres (from cellulose dissolved in ionic liquids) is a modulus up to $34 \mathrm{GPa}$ and tensile strength of almost $900 \mathrm{MPa}$ (Sixta et al., 2015).

Recently, it has been reported that water-based nanocellulose suspensions can be directly spun into continuous fibres with diameters ranging from $100 \mathrm{~nm}$ to $500 \mu \mathrm{m}$, thus circumventing the need for complex chemistries, and providing a strong, greener alternative for numerous applications (Hooshmand et al., 2015; Iwamoto et al., 2011; Lundahl et al., 2016). In many cases, the process of spinning these fibres causes the nanocellulose to align much like that which occurs in nature during the biosynthesis of hierarchical fibres (Clemons, 2016). Whilst celluloseonly fibres can be spun from CNF suspensions, fibres containing CNCs are typically cellulose/polymer composite materials owing the highly brittle nature of CNC-only structures. The use of petroleum-based polymers in these composite fibres can be avoided by combining nanocellulose with a cellulose derivative, however, this requires the same extensive processing as traditional man-made fibres. Beyond the environmental aspect, however, continuous nanocellulose-based fibres are advantageous in that they typically exhibit better mechanical properties than regenerated cellulose fibres, due to the reinforcing nature of nanocellulose as a filler, and its alignment within the fibre (which can also be induced by secondary processing such as stretching, for example) (Endo et al., 2013; Iwamoto et al., 2011). For example, Iwamoto et al. reported Young's moduli as high as $25 \mathrm{GPa}$ for wood-based nanofibrils with corresponding tensile strengths of $320 \mathrm{MPa}$ (Iwamoto et al., 2011), but the best mechanical properties reported to date from nanocellulose are achieved through hydrodynamic alignment, discussed further below, and boasting a modulus of $90 \mathrm{GPa}$ and a tensile strength of ca. 1.6 GPa (Håkansson et al., 2014; Mittal et al., 2018). Again, this is significantly higher than cotton fibres and typical commercial regenerated cellulose fibres like modal (rayon) fibres with a Young's modulus of 15 $\mathrm{GPa}$ and tensile strengths of almost $500 \mathrm{MPa}$ (Adusumalli et al., 2006). Furthermore, their submicron diameters allow these fibres to be spun into mats which have extremely high specific surface areas, controllable porosity and can even be transparent (Giesa \& Buehler, 2013). 
summarizes the typical preparation methods for nanocellulose-based continuous fibres along with the external forces present, which cause the nanocellulose to align (typically) along the axis of the fibre. Summarized are also the forces and interactions present during the formation of these assemblies and those holding the final structure together, in addition to the typical diameters of fibres produced by each method. 


\subsection{Preparation of Continuous Fibres}

Three distinct methods of spinning fibres are used to produce continuous nanocellulose fibres wet spinning, dry spinning and electrospinning. The most common of these techniques is wet spinning where fibres are prepared by extruding an aqueous nanocellulose gel through a nozzle and passing the resulting filament through a solvent coagulation bath (Figure $3 \mathrm{a}$ ). When the extruded filament comes into contact with a cellulose incompatible solvent (such as acetone, ethanol, isopropanol or tetrahydrofuran), the outer wall of the filament will form a skin due to the rapid removal of water through solvent exchange (Walther et al., 2011). This rapid dehydration will induce the formation of hydrogen bonding between cellulose fibrils/crystals and as a result, provides the fibre with good mechanical strength. Cellulose-cellulose interactions can also be improved by modifying the nanocellulose prior to spinning. TEMPO-mediated oxidation and carboxymethylation, for example, have been hypothesized to enhance CNF orientation and promote favourable interactions due to increased surface charge (Håkansson et al., 2014; Iwamoto et al., 2011). Whilst wet spinning of pure CNFs is possible (Hooshmand et al., 2015; Iwamoto et al., 2011; Lundahl et al., 2016; Walther et al., 2011), CNC-based fibres require a polymer matrix. In these cases, or when CNFs are combined with a polymer, nanocellulose is mixed with the polymer (such as polylactic acid (PLA) (Geng et al., 2016) or polyvinyl alcohol (Endo et al., 2013; Uddin et al., 2011)) prior to spinning; reports have shown that the shear forcedriven alignment of the nanocellulose component induces favourable alignment of the polymer component as well (Endo et al., 2013). Irrespective of the polymer matrix used, in order to utilize the full potential of nanocellulose as a reinforcing agent, both homogeneous dispersion of the nanocellulose and favorable cellulose-polymer compatibility are essential.

Nanocellulose fibres can also be prepared using a dry spinning method in which the extruded filament, rather than being passed through a coagulation bath, is dried in the air at elevated temperatures whilst being pulled from an extrusion nozzle (Figure 3b). Similar to wet spinning, the shear forces exerted on the nanocellulose during extrusion result in aligned continuous fibres. As with wet spinning, nanocellulose-only and nanocellulose/polymer composite continuous fibres have been demonstrated using dry spinning processes (S. Chen et al., 2014; Ghasemi et al., 2018; Hooshmand et al., 2015).

Regardless of whether spun wet or dry, the performance of spun nanocellulose fibres is dependent on numerous factors ranging from the concentration and potential pre-treatment of the nanocellulose precursor gel (or suspension), spinning parameters such as shear rate, the speed at which the filament is pulled and fibre drying, along with the presence of potential additives. For a comprehensive review of factors affecting fibre performance, the reader is referred to reference (Lundahl et al., 2017). It should be noted that although spinning can be carried out using specialty equipment, both wet and dry spinning can also be done on a smaller scale using a fairly straightforward syringe pump system (Iwamoto et al., 2011). 
The third spinning technique often implemented to fabricate continuous nanocellulose fibres is electrospinning. However, unlike wet and dry spinning, this technique is typically used to prepare non-woven fibre mats or 1-dimensional mats rather than single spooled fibres (Dong et al., 2012; Hasegawa et al., 1993). Whereas wet and dry spun fibres are frequently CNF-based, electrospinning is more often carried out using CNCs as they cause fewer rheological issues during the spinning process. While nanocellulose-only fibres have not yet been successfully spun, numerous $\mathrm{CNC}$ /polymer combinations are possible to electrospin into mats; these include CNCs spun with polymethyl methacrylate (Dong et al., 2012), cellulose acetate (Vallejos et al., 2012), cotton cellulose (dissolved in a dimethylacetamide/lithium chloride solvent) (He et al., 2014), PLA (Shi et al., 2012), starch (H. Wang et al., 2019) and lignin (Ago, Jakes, et al., 2012; Ago, Okajima, et al., 2012). Figure 3c shows a schematic representation of an electrospinning setup. Briefly, a high voltage is applied to the needle of a syringe out of which the nanocellulose suspension is extruded. At a point where the voltage induced electrostatic repulsion overcomes the surface tension of the suspension, the suspension is ejected in a thin stream towards a metallic collector plate (where the fibre mat is formed). As the stream moves toward the plate it thins and solidifies as a result of the electrically induced elongation forces and simultaneous solvent evaporation (Richard-Lacroix \& Pellerin, 2013). Due to the magnitude of the elongation forces, electrospun fibres exhibit a high order of nanocellulose alignment along the fibre axis (Clemons, 2016).

Aside from traditional spinning techniques, a variety of novel methods to prepare highperformance nanocellulose fibres have recently been reported. One such method is the use of interfacial polyelectrolyte complexation to spontaneously form insoluble polyelectrolyte complexes. In this technique, two oppositely charged polyelectrolytes, when brought into contact, undergo an ionic condensation releasing their corresponding counterions into the system (the increase entropy in the system due to this counterion release is the driving force for complexation to occur) (Drogoz et al., 2007). Combinations of cationic CNCs with anionic TEMPO-oxidized CNFs or carboxylated CNCs have been demonstrated to produce continuous fibres, which are easily extracted from the polyelectrolyte interface by simply lifting the complex out of the nanocellulose suspension (Figure 3d) (K. Zhang \& Liimatainen, 2018). Another novel method by which to form continuous fibres is using flow-focusing devices i.e. hydrodynamic alignment (Håkansson et al., 2014; Mittal et al., 2017, 2018, 2019; Nechyporchuk et al., 2019). In this method, a nanocellulose suspension is passed through a microfluidic device in which the flow of the suspension causes the nanocellulose to align within the confined channels of the device (Figure 3e). Electrostatic repulsion between the nanocellulose fibrils/crystals works to both prevent aggregation and enhance alignment. Just prior to the onset of Brownian motion induced random alignment, the aligned structure is 'frozen' by altering the $\mathrm{pH}$ or ionic strength of the suspension, causing the suspension to gel. This gelled filament is then solvent exchanged in a solvent (or coagulation) bath and allowed to dry to form a solid nanocellulose fibre. The advantage of such a flow-based assembly of continuous fibres is that it is relatively easy to scale, and produces highly orientated fibres with excellent mechanical properties (Håkansson et al., 
2014; Mittal et al., 2018). For reference, flow-focused CNF fibres exhibit tensile strengths as high as $1.6 \mathrm{GPa}$, whereas the respective values for natural cotton fibres are as low as $300 \mathrm{MPa}$ (X. Li et al., 2007), and <350 MPa for wet spun CNF fibres (Lundahl et al., 2016).

\subsection{Potential Applications of Continuous Fibres}

The motivation to use continuous fibres over natural fibres is that they have significantly better mechanical strength due to the lack of discontinuation typically exhibited by the latter (Hooshmand et al., 2015). Furthermore, nanocellulose fibres benefit mechanically not only from the inherent strength of nanocellulose (due to its high crystallinity) but also from the alignment of the nanocellulose fibrils and/or crystals along the fibre axis (Iwamoto et al., 2011). As such, continuous nanocellulose-based fibres have been proposed for a multitude of applications. For example, these fibres could be used as textile yarns in functional active wear or military armour. Not only are they strong and lightweight, but their relatively hydrophilic nature allows them to absorb large amounts of water (Lundahl et al., 2018). This water absorption capacity of these fibres makes them useful in applications such as hygiene products and diapers. Interestingly, when coated with silica nanoparticles (through interfacial complexation), for example, these fibres have been shown to exhibit flame retardant properties, further broadening their application spectrum to safety devices such as fire blankets (Nechyporchuk et al., 2017). From a more mechanical standpoint, continuous nanocellulose fibres could be used as structural reinforcements in advanced composites (Ganster \& Fink, 2006), as a substitute for fibre glass (Goutianos et al., 2006), or in filtration devices, to name a just a few.

Whereas the aforementioned applications are ones utilizing single continuous fibres (Figure $3 \mathrm{f}$ and Figure 3g), electrospun fibre mats (Figure 3h) also have a wide array of possible applications. One such application is the use of these mats in filtration systems (Goetz et al., 2018; Ma et al., 2012). The ability to control, not only the porosity of the mats, but also their surface chemistries, enables them to be used in applications requiring the capture of specific particles/molecules/ions (e.g. water purification). Alternative applications, which benefit from the high surface area and tunability of electrospun mats include supports for catalysis, and biomedical applications such as tissue engineering scaffolds (He et al., 2014) and wound healing, and even sensor and actuators (Clemons, 2016).

\section{Nanocellulose Films}

Nanocellulose films are typically assembled as either supported or free-standing films where supported films (also called "coatings") are ones in which the nanocellulose is attached to the surface of a flat, uniform substrate, whereas free-standing films resemble traditional paper, but 
are significantly thinner. Typically, supported thin films range between $<100 \mathrm{~nm}$ (ultrathin) and $<1000 \mathrm{~nm}$ (thin) in thickness, whereas free-standing films have thicknesses in the micrometer range. Supported thin films of nanocellulose are diverse structures, which can be implemented in a wide array of potential applications such as protective, and antifouling coatings, sensors, drug delivery systems, or they can be used as model systems to gain fundamental understanding about nanocellulose and colloidal systems in general. On the other hand, free-standing films have potential in separation applications as membranes and filters (Metreveli et al., 2014), as transparent substrates for flexible electronics (Hsieh et al., 2013; L. Hu et al., 2013; X. Xu et al., 2016), and as "nanopaper" (Henriksson et al., 2008; Sehaqui et al., 2011). Table 5 lists the main assembly methods and their driving forces along with the dominant forces holding nanocellulose films together and some key properties.

\subsection{Preparation of Nanocellulose Films}

\subsubsection{Supported Thin Films}

Deposition of supported thin films can be carried out using a number of different techniques. The majority of the techniques are ones that utilize the natural tendency of cellulose to assemble at interfaces. These techniques include drop (or solvent) casting, dip coating and Langmuir deposition. Conversely, other thin film deposition techniques, such as spin coating and bar coating, rely on external forces to manipulate the nanocellulose into desired conformations.

Supported thin film preparation using the drop, or solvent, casting method, while being facile and fairly effortless, is uncontrollable and often leads to films with unpredictable properties such as film thickness and surface roughness. The deposition of films through this method is carried out by simply dropping a given volume of a nanocellulose suspension onto a substrate and allowing it to naturally dry into a film through evaporation. Although the degree of control during drop casting is limited, it is possible to control the external parameters effecting film formation. Controlling the atmospheric conditions to allow for slower solvent evaporation and ensuring the film is undisturbed throughout the drying process will provide the best conditions for the formation of uniform films (Beck et al., 2011). Typical phenomena seen during the drying process of solvent cast nanocellulose films are dewetting and the "coffee stain" effect (Teramoto, 2020; Uetani \& Yano, 2013). These occur when the affinity of the cellulosic material toward the substrate is limited, and when the volume of the cast suspension is small.

Simply put, dewetting is the retraction of the suspension to minimize contact with the substrate surface. The effects of dewetting can be seen in the resulting films as unique patterns made up of, for example, coffee rings (Klockars et al., 2019), striations (Niinivaara, Wilson, et al., 2016), or fractals (Niinivaara \& Kontturi, 2014). Recent work has also shown the potential of producing patterned aerogel films, by drop casting a crosslinked hydrogel (further discussed in Section 6.1) 
onto patterned mould, applying pressure and subsequently lyophilizing to remove water (Or et al., 2019).

Whereas the formation of supported thin films through drop casting is governed by the forces occurring during solvent evaporation and the behaviour of the nanocellulose at the air/substrate interface, the formation of films in dip coating is driven by spontaneous adsorption resulting from electrostatics or specific interactions between the surface of the substrate and the nanocellulose. In dip coating (Figure 4a), a substrate is lowered into a nanocellulose suspension, where a layer of material is adsorbed onto the surface of the substrate. Although a tedious process, especially if depositing several layers (i.e., layer-by-layer deposition to form multilayer films (Decher \& Schlenoff, 2002)), dip coating is a straightforward procedure yielding films of controllable thickness (by controlling suspension concentration) with relatively low surface roughness (Cranston, 2013).

Langmuir deposition also relies on the interfacial assembly of nanocelluloses, however at the air/water interface. In this method, the amphiphilic nature of cellulose is utilized to spread a layer of nanocellulose at the air/water interface with its polar moieties in contact with the water, and non-polar ones in contact with the air. Using horizontal barriers sliding over the surface of the water phase, the nanocellulose is then compressed to form a stable, uniform film on the surface of the water. It is important to note that the most important requirement for Langmuir deposition is the ability of the nanocellulose to form these stable films at the air/water interface. While CNCs are able to assemble naturally in this manner (Bertsch et al., 2018) (owing to the hydrophobic edge of their crystal structure (Kalashnikova et al., 2012)) or with the help of surfactants (Habibi et al., 2007; Habibi, Hoeger, et al., 2010), CNFs require a hydrophobic surface functionalization to aid in their assembly at the air/water interface for Langmuir deposition (Xhanari et al., 2011).

Nonetheless, once in the form of a compressed, uniform film at the air/water interface, the nanocellulose is then transferred onto the surface of a substrate. This can be carried out either by passing the substrate perpendicularly (Langmuir-Blodgett deposition) through the film into the water phase and then retracting it (forming a bilayer), or by bringing it into contact parallel (Langmuir-Schaefer deposition) to the film and retracting (forming a monolayer) (Figure 4b). As the deposition of nanocellulose films using this method yields a single layer or bilayer at a time, control of the film thickness is very accurate, however, thin film preparation using Langmuir deposition is slow and requires specialty equipment.

One of the more accessible pieces of equipment for thin film deposition is a spin coater, which is a fast and relatively simple method to produce films of varying thicknesses with high reproducibility (Schubert \& Dunkel, 2003). Spin coating (Figure 4c) utilizes high rotational speeds to dry a droplet of solution or suspension onto the surface of a substrate and can be used with any form of nanocellulose (Ahola et al., 2008; Edgar \& Gray, 2003; Kontturi et al., 2003, 2007; Notley, Eriksson, Wågberg, Beck-Candanedo, et al., 2006). Due to the nature of this 
technique, however, spin coated films are not in thermodynamic equilibrium but in a metastable configuration brought on by the forces involved in the film formation process and the rapid evaporation of the solvent. By varying parameters such as acceleration, rotational speed and suspension concentration, the thickness, uniformity and roughness of the resulting film can be controlled. A fast acceleration and high rotational speed typically result in thin, highly uniform films whereas a high concentration, and therefore viscosity, will lead to thicker films with higher surface roughness. The duration of the spinning cycle is greatly governed by the boiling point and vapour pressure of the solvent used but is also directly affected by atmospheric conditions such as temperature and relative humidity.

The final method by which to prepare supported nanocellulose films is through bar coating (Lavoine et al., 2014) (Figure 4d). In this technique, a volume of nanocellulose suspension is dropped onto the surface of a substrate after which a bar is pushed/or pulled through the suspension horizontally along the surface of the substrate all the while spreading the nanocellulose suspension out evenly. Once it has fully covered the surface of the substrate, the resulting film of nanocellulose is allowed to dry. One of the main advantages of bar coating, is that the shear forces caused by the movement of the bar over the nanocellulose causes the nanocellulose crystals/fibrils to align (Hoeger et al., 2011). An added benefit of this method of coating is that it can be done over significantly large surface areas, however, in comparison to the aforementioned techniques the uniformity of films suffers.

\subsubsection{Free-Standing Films}

Free-standing nanocellulose films are typically prepared by making thick films using drop casting, layer-by-layer deposition, or bar coating, as described above, and then peeling the film from the substrate. Alternatively, they can be made through a simple filtration method (similar to that used in traditional papermaking). The filtration process generates films commonly referred to as "nanopaper" (Henriksson et al., 2008; Sun et al., 2018) where a CNF suspension is vacuum filtered using a filtration aid or membrane and is then recovered and allowed to dry via evaporation or with the aid of an external heat source, such as hot pressing (Österberg et al., 2013) (Figure 5a and Figure 5b) . Whilst vacuum filtered CNC films have also been demonstrated (Q. Chen et al., 2014), free-standing CNC films are more typically produced through simple evaporation processes (Beck et al., 2011). However, due to the brittle nature of CNC-only materials these films have almost no structural integrity and as such necessitate a minor amount of additives such as glycerol (Dorris \& Gray, 2012; M. Xu et al., 2018), surfactants (Bardet et al., 2015; Guidetti et al., 2016) or flexible polymer (e.g. polyethylene glycol (Q. Zhou et al., 2009)) (Figure 5c) to allow for handling or integration into industrial processes. Interestingly, recent reports have shown the potential to produce "nanopaper" through a novel spray coating method, which enables high throughput production of uniform, smooth 
(on the substrate side) films of nanocellulose (Beneventi et al., 2014, 2015; Shanmugam et al., 2017, 2018).

\subsection{Potential Applications of Nanocellulose Films}

\subsubsection{Supported Thin Films}

Supported thin films of nanocelluloses are widely used in fundamental research as model systems (Kontturi et al., 2006) (Figure 5d) to elucidate the viability of nanocellulose as a component in functional materials. Importantly, model systems have been used to mimic the interactions of native cellulose in the plant cell wall (Benselfelt et al., 2016; Notley et al., 2004; Notley \& Norgren, 2006; Stiernstedt et al., 2006; Villares et al., 2015), have provided vital information on cellulose surface interactions (Ahola et al., 2008; Eriksson et al., 2007; Lombardo \& Thielemans, 2019; Notley, Eriksson, Wågberg, Beck, et al., 2006), moisture sensitivity (Ahola et al., 2008; Aulin et al., 2009; Brett et al., 2019; Kittle, 2012; Niinivaara et al., 2015; Niinivaara, Faustini, et al., 2016; Reid et al., 2016), particle binding (Kontturi et al., 2018), and biomedical viability (Jorfi \& Foster, 2015; Orelma et al., 2012) of nanocellulose, to name only a few.

From a more practical standpoint, supported nanocellulose thin films have been implemented in a number of different applications. A significant amount of work has been carried out to demonstrate the potential of thin film coatings in the packaging industry (Ferrer et al., 2017). As mentioned previously, due to the ability of both CNCs and CNFs to form densely packed structures, nanocellulose coatings have the potential to not only provide additional strength to packaging materials but also instill barrier properties (Shanmugam et al., 2019). Such coatings could be implemented in food packaging applications as barriers against either air (oxygen) to prevent food spoilage, for example, or grease. While applicable in barrier applications for hydrophobic components, the hydrophilic nature of cellulose prevents the use of nanocellulose coatings in a number of different applications where moisture sensitivity is an important factor. Water is able to penetrate the nanocellulose network and compete with the intermolecular hydrogen bonds, compromising the structural integrity of the films, significantly diminishing the barrier potential of nanocellulose films. Fortunately, as mentioned earlier, this significant drawback of cellulose can be circumvented through surface functionalization, through which nanocelluloses can be made more compatible for their intended use. For a comprehensive review on nanocellulose in packaging applications, please refer to reference (Hubbe et al., 2017). 
On the other hand, the moisture sensitivity of cellulose can instead be exploited in thin film applications such as in humidity sensors and intelligent packaging. Such applications utilize the swelling and subsequent change in Bragg's reflection (visible colour change) of chiral nematic CNC films (Ping et al., 2013), or changes in thin film interference colors for non-chiral nematic films (Cerclier et al., 2011), upon exposure to humid conditions or enzymes that breakdown cellulose. Such colour indicating films offer a facile and affordable alternative to those currently available to monitor the quality of humidity sensitive goods such as foods, pharmaceuticals and certain chemicals. Another interesting possibility to utilize the chiral nematic behaviour of CNC films is to apply them as anticounterfeit films in security and high-value papers (Pan et al., 2010). Decorative coatings with CNC and CNF films (with and without liquid crystalline order) have also been demonstrated in a number of artistic applications (Figure 5e) (Blonder et al., 2017; Klockars et al., 2019).

The ability to use external forces such as electric (Csoka et al., 2011) and magnetic fields (Sugiyama et al., 1992), and shear forces (Csoka et al., 2011) to tune the alignment of CNCs in suspension and films, shows great promise in a number of different applications. CNC films with tunable long-range order have been proposed as templates in the formation of chiral, mesoporous materials, which can be implemented in antireflective coatings, plasmonic and photonic devices (Giese et al., 2015). Additionally, aligned supported CNC films have also been implemented in the development of bio-based microelectromechanical systems (MEMS), which are used in, for example, the medical, communication and transportation industries (Saha et al., 2018). It has also been speculated, that combined with the piezoelectric properties of nanocellulose films (Rajala et al., 2016), CNC MEMS could be used in actuation and sensing applications (Saha et al., 2018).

\subsubsection{Free-standing Films}

The use of free-standing CNF films as supports in separation applications, such as membranes and other filtration aids, have also been investigated (Metreveli et al., 2014). Due to their high surface area and significant porosity, structures made of nanocellulose, when functionalized appropriately or combined with the correct additives, have the ability to capture small molecules, metal ions, bacteria and other organic pollutants (Carpenter et al., 2015; Voisin et al., 2017).

Recently, the investigation of free-standing CNF "nanopaper" in various applications has gained popularity (Barhoum et al., 2017). Not only are these films highly flexible, but also lightweight and remarkably strong regardless of their porosity (Henriksson et al., 2008). Furthermore, owing to the nanoscale of the cellulose fibres, these structures are extremely densely packed rendering them opaque or even transparent. An interesting use for these film properties is in the field of flexible conductive films (L. Hu et al., 2013) and electronics (Hsieh et al., 2013; X. Xu et al., 2016; Zheng et al., 2013). While cellulose itself is a non-conductive polymer, it shows great promised in being utilized as a transparent and flexible substrate material in the aforementioned applications. Coupled with conductive materials such as carbon nanotubes, graphene, metal 
oxides and conductive polymers CNFs could be used to form highly conductive films capable of for example, energy storage (Zheng et al., 2013). Similarly, CNCs, although too fragile to use as free-standing cellulose-only structures, have the potential to be used as substrates to support more flexible polymers. Such structures have, for example, demonstrated potential as recyclable, organic solar cells (Yinhua Zhou et al., 2013). In general, the application potential of nanocelluloses in functional materials increases exponentially when they are utilized as building blocks in combination with other materials to form nanocomposites; however, such materials are outside the scope of this Review.

\section{Nanocellulose Hydrogels, Aerogels and Dried Foams}

Hydrogels are highly porous 3-dimensional network structures, that are able to hold significant amounts of water whilst maintaining their structural integrity. Networked structures can be held together by physical crosslinks (i.e., weak intermolecular forces that link moieties to each other or entanglement), chemical crosslinks (i.e., covalent bonds between individual CNFs/CNCs and/or to a polymer matrix) (Liang et al., 2020), or a combination of the two. Nanocellulose hydrogels can be either comprised solely of nanocellulose, "nanocellulose-only", or are a combination of hydrophilic polymers reinforced with nanocellulose. Hydrogels have traditionally been used in applications ranging from cosmetics, foods, biomedical devices, absorbents and even in niche technologies such as chromatography and electrophoresis (Chirani et al., 2015). The natural tendency of high aspect ratio nanocellulose to form percolated networks and "gel" makes it ideal for the formation of hydrogels (Pääkko et al., 2007). (Note that aspect ratio is the ratio of a particle's major dimension to minor dimension, length divided by diameter for rods, and by some definitions, anything that is over 1, i.e., not a sphere, is considered high aspect ratio - in general, CNFs have larger aspect ratios than CNCs (Lavoine et al., 2019).) In fact, a large amount of research has been carried out on the viability of both CNCs and CNFs in these structures, as covered in an extensive review summarizing the $200+$ articles available in the literature (De France et al., 2017). The inherent non-toxicity, biodegradability, functionalizability, and high aspect ratio of nanocelluloses are distinctly advantageous in their use as hydrogel materials. While $\mathrm{CNF}$ and $\mathrm{CNC}$-only hydrogels are widely reported, significant research efforts have been made to produce structurally more robust hydrogels (especially in the case of CNC-only gels, which lack physical entanglement due to the rigid-rod like behavior of CNCs). Hydrogels with improved mechanical properties can be prepared by promoting chemical crosslinks through surface modification or through the addition of external crosslinking agents. 
The mechanical strength of hydrogels is an important factor since they are the "precursor" material for preparing aerogels. Typically, aerogels are produced from hydrogel assemblies by substituting the liquid phase (water) with a gas phase (air) through sublimation or supercritical drying (Figure 6a and Figure 6b). Conversely, foams are structures in which air bubbles have been dispersed and stabilized within a liquid or solid structure (generally called aqueous foams or solid foams, respectively). Nonetheless, both aerogels and dried foams are extremely lightweight, high porosity structures ( $>90 \%$ for aerogels and $>50 \%$ for foams (Lavoine \& Bergström, 2017)) in which air is the main component. Aqueous nanocellulose foams in which air bubbles have been dispersed and stabilized in an aqueous nanocellulose suspension have only been reported in a few cases where the surface activity of nanocellulose was improved through functionalization (Cervin et al., 2013; Z. Hu, Xu, et al., 2016). Table 6 summarizes the dominant forces and interactions occurring during gel preparation, the forces that hold them together, and some examples of crosslinking chemistries demonstrated.

\subsection{Preparation of Hydrogels, Aerogels and Dried Foams}

\subsubsection{Hydrogels}

The main contributors to the gelation of unmodified nanocelluloses are physical entanglement (Pääkko et al., 2007), attractive intermolecular cellulose-cellulose interactions such a van der Waals forces, and electrostatic screening or ion-mediated gelation (which destabilizes CNC/CNF colloidal stability (Fall et al., 2011; Nordenström et al., 2017) leading to particle aggregation and often decreasing the percolation threshold) (Figure 6c). It should be noted that in hydrated structures, such as hydrogels, hydrogen bonding between cellulose does not play a vital role (Nishiyama, 2018). Pore sizes in hydrogels are challenging to measure (without drying artefacts) and are generally assumed to be in the nanometer range but can be as large as $10 \mu \mathrm{m}$ for gels templated by ice or sacrificial templates. Entanglement is a dominant gelation mechanism for CNFs but is less likely for shorter rigid CNCs, which generally require surface functionalization, chemical crosslinkers/additives or other polymers to form networked structures. As a result, significantly more work has been carried out on formulating nanocellulose-only gels from the more flexible, higher aspect ratio, CNF materials.

The production of stable hydrogels is a far more simple task than that of forming aerogels. As mentioned, nanocellulose will naturally aggregate to form gels above a threshold concentration, which depends on the medium, the nanocellulose type and dimensions, and the $\mathrm{pH} /$ ionic strength. For plant-derived CNCs in water this is approximately $10 \mathrm{wt} \%$ (Ure et al., 2011) whereas it is significantly lower for CNFs (often under $2 \mathrm{wt} \%$ ) (Foster et al., 2018). This critical concentration can, however, be decreased by screening electrostatic repulsion through an increase in ionic strength or by inducing instability through a decrease in pH (Fall et al., 2011), or by decreasing nanocellulose surface charge density through elevated temperatures (Lewis et 
al., 2016). Multivalent ions have also been demonstrated as effective gelation agents by inducing ionic bridging between CNCs (Chau et al., 2015). These methods, which induce gelation in nanocellulose suspensions, do so through DLVO destabilization (named after Boris Derjaguin, Lev Landau, Evert Verwey and Theodoor Overbeek). The stability of colloids is governed by the DLVO theory, which accounts for the attractive effect of van der Waals forces and the electrostatic repulsion of similarly charged particles (Derjaguin \& Landau, 1941; Verwey \& Overbeek, 1955). In a stable colloid, these two forces are balanced at small separations, however, off-setting this balance by altering ionic strength, concentration, surface charge, $\mathrm{pH}$ or temperature will result in destabilization, and subsequent gelation.

Whilst DLVO destabilization is an effective method by which to induce gelation in nanocellulose suspensions, a number of alternative routes can also be taken to prepare even more robust cellulose-only hydrogels. CNF gelation, for example, can be induced through a homogenization process in which the degree of fibrillation and subsequent mixing (entanglement) of the CNFs are maximized, resulting in strong hydrogel networks (Pääkko et al., 2007). For CNCs, on the other hand, which are unable to physically entangle, strong celluloseonly hydrogels can be prepared through chemical crosslinking. For example, covalent hydrazone crosslinks occur between CNCs surface functionalized with aldehyde and hydrazide groups (Osorio et al., 2018; X. Yang \& Cranston, 2014). Another unique example is that cellulose-only hydrogels can be prepared by physically entrapping CNCs within an entangled cellulose derivative polymer matrix (Y. Wang \& Chen, 2011).

Although cellulose-only hydrogels have been demonstrated, the potential of nanocellulose-based hydrogels is vastly expanded by their incorporation into a hydrophilic polymeric matrix. While these hydrogels are in fact composites, they are worth discussing here as the nanocellulose plays a key role in the mechanical properties of the resulting material. For example, the mechanical properties of polyvinyl alcohol hydrogels can be vastly improved by the simple physical entanglement of CNCs within the polymer matrix (Abitbol et al., 2011). The reinforcing potential of nanocellulose can be enhanced even further by chemically entrapping it within the polymer matrix either through chemical crosslinking or through polymerization (J. Wei et al., 2016; J. Yang et al., 2013) in the presence of the nanocellulose. Through these methods, nanocellulose acts as either the crosslinker between polymer chains or is itself chemically crosslinked to the polymer, which provides the hydrogel with both chemical robustness and physical strength (De France et al., 2017). Regardless of crosslinking mechanism, the nanocellulose component must typically undergo a surface modification in order to promote the formation of covalent bonds between the cellulose and the polymer (Chau et al., 2016; Domingues et al., 2015; García-Astrain et al., 2016; Köhnke et al., 2014; McKee et al., 2014). Typically, these surface modifications include polymer grafts (Atifi et al., 2014; J. Yang et al., 2014; Yiming Zhou et al., 2013), silylation (J. Yang et al., 2014) or the addition of carboxyl (Mihranyan, 2013) or aldehyde groups (Chau et al., 2016). 


\subsubsection{Aerogels and Dried Foams}

As already mentioned, the formation of aerogels essentially involves processing a nanocellulose hydrogel in such a way that the liquid component of the gel is replaced with air while maintaining its structural integrity (Figure 6d) and porous network structure (Figure 6e and Figure 6f). For the preparation of dried foams (Figure 6g) however, an aqueous precursor foam (Figure 6h) must be prepared, which then undergoes the same liquid to gas substitution as the hydrogel precursor in aerogel preparation. It is worth remembering here, that typically, aerogels are produced from hydrogel assemblies by substituting the liquid phase with a gas phase whereas foams are structures in which air bubbles have been dispersed and stabilized within a liquid or solid structure.

The preparation of foams requires nanocellulose to partition at the interface between hydrophobic and hydrophilic substances, which in the case of foams, is the air-water interface. The most common way to prepare a nanocellulose foam is to combine a surfactant and a nanocellulose suspension and agitate or homogenize the mixture. This agitation causes air bubbles to be dispersed into the suspension and become stabilized by surfactant, which then results in the partitioning of the nanocellulose to the "surfactant-coated" air-water interface. Numerous nanocellulose/surfactant combinations have been reported to make stable precursor foams such as TEMPO-oxidized CNFs with a non-ionic surfactant (Gordeyeva et al., 2016), unmodified CNFs with a cationic surfactant (Mariano et al., 2018), and polymer grafted CNCs with non-ionic surfactant (B. Wei et al., 2017). Additionally, surface functionalized CNCs (through amine adsorption) were foamed in water (Cervin et al., 2013, 2016) as was a celluloseonly system where foams were stabilized using CNCs and methyl cellulose ( $\mathrm{Z}$. $\mathrm{Hu}, \mathrm{Xu}$, et al., 2016). Some of these aqueous foams can be dried by oven drying or freeze-drying, however, some collapse upon drying. Foams normally have large pores of over $50 \mu \mathrm{m}$, stemming from the size of the trapped air bubbles - the final structures may have discreet pores or interconnected pores depending on the gas volume and preparation method.

Several techniques have been demonstrated to process nanocellulose hydrogels or solvogels to aerogels such as freeze drying (Lavoine \& Bergström, 2017), CPD (Heath \& Thielemans, 2010; Liebner et al., 2010), and PGX processing (Osorio et al., 2018). Note that freeze drying requires freezing whereas it is an optional pre-processing step with CPD such that cryo-templating (De France et al., 2017; Osorio et al., 2018) is sometimes referred to as an aerogel processing method but freezing alone is not sufficient - it must be followed by a drying step.

In freeze drying (described in Section 2.1.1), the hydrogel or other precursor gel is frozen and then the ice is sublimated, leaving in place a stable, porous, low density aerogel (Lavoine \& 
Bergström, 2017). Freeze drying parameters can be altered in order to control the structure of the resulting aerogel. For example, a slower freezing rate can be used to promote the formation of ice crystals which will exclude the nanocellulose particles from the water phase (Osorio et al., 2018). In this technique, known as cryo-templating, the directional formation of ice crystallites gives form to aerogels with a specific anisotropy (De France et al., 2017). Cryo-templating can be used further to induce anisotropy within an aerogel by controlling the temperature, cold source, and even freezing style of the precursor hydrogel (Y. Chen et al., 2019). Pore sizes in aerogels produced from ice templating followed by drying are normally $>50 \mathrm{~nm}$ and often with large macropores $(\mu \mathrm{m})$ resulting from ice crystals. When spray freeze dried, however, the rapid freezing rate results in nanocellulose aerogels that exhibit pore sizes as low as tens of nanometers (Jimenez-Saelices et al., 2016). In the case of chemically crosslinked nanocellulose aerogels, their pore structure is often bimodal, with mesopores $<20 \mathrm{~nm}$ between individual particles and macropores surrounded by sheets of crosslinked nanocellulose (X. Yang \& Cranston, 2014).

As outlined in Section 2.1.1, supercritical drying or CPD differs from freeze drying in that the liquid filling the gel pores is solvent exchanged with a super critical fluid and then depressurized to ambient conditions, leaving an intact, dry, porous aerogel (Heath \& Thielemans, 2010; Liebner et al., 2010). The basic premise in aerogel formation through PGX processing is very similar to CPD, however, solvent exchange does not need to be carried out in a step-wise process but the hydrogel can be subjected to a mixture of, for example, ethanol and carbon dioxide, which causes a rapid and homogeneous dehydration of the gel upon depressurization (Osorio et al., 2018). Such processes are vital in the removal of water from the nanocellulose structure, as uncontrolled drying causes them to collapse due to capillary pressure resulting from evaporation (Lavoine \& Bergström, 2017). The forces and interactions at play in these drying techniques were discussed in Section 2.1.1 and Table 2. If CPD or PGX is performed on nanocellulose hydrogels without a freezing step, the specific surface area is normally larger and the pores smaller, typically in the $<100 \mathrm{~nm}$ range.

Although not a preparation method per se, it should be noted that a number of aerogel applications require the structure to exhibit a degree of hydrophobicity (such as selective absorption). A relatively facile method to impart specific surface functionalities to aerogel structures is to carry out a post-treatment. For example, gas phase chemistries can be used to esterify the nanocellulose (Fumagalli et al., 2013), or to deposit hydrophobic moieties such as silanes (Jiang \& Hsieh, 2014) or titanium dioxide (Kettunen et al., 2011) through chemical vapour deposition. This can also be considered a type of crosslinking post-treatment. Alternatively, aerogels can be modified using a layer-by-layer assembly (described in Section 5.1.1) for example, to induce conductivity through the adsorption of conductive polymers or nanoparticles (Hamedi et al., 2013). 


\subsection{Potential Applications of Nanocellulose Hydrogels, Aerogels and}

\section{Foams}

Both nanocellulose-only and nanocellulose composite hydrogels have been proposed for a number of potential applications. Nanocellulose hydrogels have primarily found their niche in the biomedical field. For example, as drug delivery systems (Lin et al., 2012), as cell and biomolecule transportation systems (K. Wang et al., 2016), and as biomimetic scaffolds for tissue engineering (Chau et al., 2016; Curvello et al., 2019; Dugan et al., 2010). Additionally, outside of the biomedical field, nanocellulose hydrogels have been explored as selective absorbents (Yiming Zhou et al., 2013, 2014), photonic and optoelectronic materials (Kelly et al., 2013) and in the case of bacterial cellulose, in its hydrogel form, it is used in the dessert, nata de coco.

As with their hydrogel counterparts, nanocellulose-based aerogels have also been proposed for use in a multitude of different applications. One such application is the utilization of these aerogels as support structures to hold, for example, super-capacitor nanoparticles or conductive polymers/particles to function as electrodes/current collectors in energy production and storage (X. Yang et al., 2015) or to improve the processing of organic metal frameworks for water purification applications (H. Zhu et al., 2016). As a result of their large surface area and high porosity, nanocellulose aerogels also have the potential of acting as sorbents (Köse et al., 2020; H. Liu et al., 2017; H. Zhu et al., 2016) provided the aerogel maintains structural integrity upon wetting, which can generally be achieved through chemical crosslinking. Furthermore, aerogels have been demonstrated in shock absorbing materials, as sound and thermal (Kobayashi et al., 2014) insulators and in hygiene products. Interestingly, CNC-based gels have also been used as injectable and space-filling bioscaffolds (Ferreira et al., 2020), and for example, have been shown to speed up bone growth when tested in animal models (Osorio et al., 2019). Nanocellulose foams, on the other hand, have been proposed in applications such a selective adsorption (H. Zhang et al., 2019), thermal insulation (Wicklein et al., 2015), enhanced oil recovery (B. Wei et al., 2017) or even as substitutes for packaging materials traditionally made from polystyrene and polyurethane (Cervin et al., 2013).

\section{Summary}

Nanocellulose, in both its fibrillated and crystalline form, provides an excellent platform with which to address the current (and immediate) necessity to shift away from our reliance on petrochemical-based materials. From investigating the fundamental interactions of bio-based 
materials (e.g., thin films), to building biomedical scaffolds (e.g., hydrogels), reinforcing textiles (e.g., continuous fibres), and even remediating polluted bodies of water (e.g. with absorbent aerogels and foams), the variety of structures which can be assembled from nanocelluloses is broad and far reaching.

Identified in this Review are six classes of nanocellulosic structures assembled using a multitude of bottom-up techniques. Whether assembled through the natural tendency of cellulose to align or partition at interfaces or through the use of external forces, each of these structures are held together by a specific set of underlying interactions, the most prevalent of which (in dry materials) are hydrogen bonds and van der Waals interactions. Nonetheless, the structural integrity of nanocellulosic structures can be vastly improved (especially in cases where water is present) by introducing 'artificial' interactions in the form of physical and/or chemical crosslinking, hornification, electrostatic and hydrophobic interactions, and even by inducing physical entanglement.

Regardless of these available interactions, a key challenge in designing and preparing nanocellulose-only structures is the limitations that their physical structures pose. Where the fibrillar structure of CNFs allows for the preparation of highly entangled networks, the low gelation concentration (and high viscosity) prevents them from being utilized in assembly techniques involving shear forces, such as electrospinning, for example. On the other hand, while the shear thinning and amphiphilic behaviour of $\mathrm{CNCs}$ enable their use in producing continuous fibres, their rigidity results in highly brittle $\mathrm{CNC}$-only structures.

Fortunately, it is possible to overcome a number of these structural issues through the use of nanocelluloses in bio-nanocomposites. Whilst these are outside of scope for this Review, it is worth mentioning that a vast amount of work is currently being carried out in designing and implementing nanocellulose-based composite materials, both polymeric and inorganic in nature. The drawback of these materials, however, is that they typically involve synthetic hydrophobic polymer matrices, which have limited compatibility with cellulose. Numerous surface modification routes for nanocellulose have been reported in the literature to improve this compatibility, however, few industrially feasible, not to mention, green alternatives have been discovered. It seems likely that research focus will remain on investigating the possibility of green surface modifications for nanocellulose, or shift toward finding environmentally sustainable alternative to use as the polymer matrices.

In conclusion, it is important to highlight that the manufacture of both CNFs and CNCs on an industrial scale is still in its early days, and as such, the majority of the potential applications of nanocellulose structures outlined in this Review are not commercially available but remain at the laboratory scale. Furthermore, due to the relatively young age of "the nanocellulose revolution", further work must be carried out to understand the long-term effects of nanocelluloses on the environment and in the body (De France et al., 2019; Roman, 2015), in order to encourage both market and consumer acceptance. 


\section{CRediT authorship contribution statement}

Elina Niinivaara: Conceptualization, Writing - Original Draft, Writing - Review \& Editing, Visualization, Funding acquisition.

Emily Cranston: Conceptualization, Writing - Original Draft, Writing - Review \& Editing, Visualization, Supervision, Project administration, Funding acquisition.

Acknowledgements The authors would like to acknowledge Dr. Feng Jiang for his contributions to this Review. We thank the Natural Sciences and Engineering Research Council of Canada (NSERC) for research support. E.N. would also like to acknowledge the Academy of Finland (grant no. 321801) for funding. 


\section{References}

Abitbol, T., \& Cranston, E. D. (2014). Chiral Nematic Self-Assembly of Cellulose Nanocrystals in Suspensions and Solid Films. In K. Oksman, A. P. Mathew, A. Bismarck, \& O. J. Rojas (Eds.), Handbook of Green Materials Processing Technologies, Properties and Applications Volume 3 (p. 1124). World Scientific Publishing Co. https://doi.org/https://doi.org/10.1142/9789814566469_0035

Abitbol, T., Johnstone, T., Quinn, T. M., \& Gray, D. G. (2011). Reinforcement with cellulose nanocrystals of poly(vinyl alcohol) hydrogels prepared by cyclic freezing and thawing. Soft Matter, 7(6), 2373-2379. https://doi.org/10.1039/c0sm01172j

Abitbol, T., Prevo, B. G., Galli, C., Choudhary, S., Corwin, J., Villalpando-Páez, F., Nguyen, L., Komarov, A., Villalobos, M., Veldhuis, S. C., \& Cranston, E. D. (2014). Comparison of nanocrystalline cellulose and fumed silica in latex coatings. Green Materials, 2(4), 206221. https://doi.org/10.1680/gmat.14.00017

Adusumalli, R. B., Müller, U., Weber, H., Roeder, T., Sixta, H., \& Gindl, W. (2006). Tensile testing of single regenerated cellulose fibres. Macromolecular Symposia, 244, 83-88. https://doi.org/10.1002/masy.200651207

Ago, M., Jakes, J. E., Johansson, L. S., Park, S., \& Rojas, O. J. (2012). Interfacial properties of lignin-based electrospun nanofibers and films reinforced with cellulose nanocrystals. $A C S$ Applied Materials and Interfaces, 4(12), 6849-6856. https://doi.org/10.1021/am302008p

Ago, M., Okajima, K., Jakes, J. E., Park, S., \& Rojas, O. J. (2012). Lignin-based electrospun nanofibers reinforced with cellulose nanocrystals. Biomacromolecules, 13(3), 918-926. https://doi.org/10.1021/bm201828g

Ahola, S., Salmi, J., Johansson, L. S., Laine, J., \& Österberg, M. (2008). Model films from native cellulose nanofibrils. Preparation, swelling, and surface interactions. Biomacromolecules, 9(4), 1273-1282. https://doi.org/10.1021/bm701317k

Atifi, S., Su, S., \& Hamad, W. Y. (2014). Mechanically tunable nanocomposite hydrogels based on functionalized cellulose nanocrystals. Nordic Pulp \& Paper Research Journal, 29(1), 95-104. https://doi.org/10.3183/npprj-2014-29-01-p095-104

Aulin, C., Ahola, S., Josefsson, P., Nishino, T., Hirose, Y., Österberg, M., \& Wågberg, L. (2009). Nanoscale cellulose films with different crystallinities and mesostructures - Their surface properties and interaction with water. Langmuir, 25(13), 7675-7685. https://doi.org/10.1021/la900323n

Bardet, R., Belgacem, N., \& Bras, J. (2015). Flexibility and color monitoring of cellulose nanocrystal iridescent solid films using anionic or neutral polymers. ACS Applied Materials and Interfaces, 7(7), 4010-4018. https://doi.org/10.1021/am506786t

Barhoum, A., Samyn, P., Öhlund, T., \& Dufresne, A. (2017). Review of recent research on flexible multifunctional nanopapers. Nanoscale, 9(40), 15181-15205. https://doi.org/10.1039/c7nr04656a

Beck-Candanedo, S., Roman, M., \& Gray, D. G. (2005). Effect of reaction conditions on the 
properties and behavior of wood cellulose nanocrystal suspensions. Biomacromolecules, 6(2), 1048-1054. https://doi.org/10.1021/bm049300p

Beck, S., Bouchard, J., \& Berry, R. (2011). Controlling the Reflection Wavelength of Iridescent Solid Films of Nanocrystalline Cellulose. Biomacromolecules, 12(1), 167-172. https://doi.org/https://doi.org/10.1021/bm1010905

Beck, S., Bouchard, J., \& Berry, R. (2012). Dispersibility in Water of Dried Nanocrystalline Cellulose. Biomacromolecules, 13(5), 1486-1494. https://doi.org/10.1021/bm300191k

Beneventi, D., Chaussy, D., Curtil, D., Zolin, L., Gerbaldi, C., \& Penazzi, N. (2014). Highly Porous Paper Loading with Microfibrillated Cellulose by Spray Coating on Wet Substrates. Industrial \& Engineering Chemistry Research, 53(27), 10982-10989. https://doi.org/10.1021/ie500955x

Beneventi, D., Zeno, E., \& Chaussy, D. (2015). Rapid nanopaper production by spray deposition of concentrated microfibrillated cellulose slurries. Industrial Crops and Products, 72, 200205. https://doi.org/10.1016/j.indcrop.2014.11.023

Benselfelt, T., Cranston, E. D., Ondaral, S., Johansson, E., Brumer, H., Rutland, M. W., \& Wågberg, L. (2016). Adsorption of Xyloglucan onto Cellulose Surfaces of Different Morphologies: An Entropy-Driven Process. Biomacromolecules, 17(9), 2801-2811. https://doi.org/10.1021/acs.biomac.6b00561

Bertsch, P., Diener, M., Adamcik, J., Scheuble, N., Geue, T., Mezzenga, R., \& Fischer, P. (2018). Adsorption and Interfacial Layer Structure of Unmodified Nanocrystalline Cellulose at Air/Water Interfaces. Langmuir, 34(50), 15195-15202. https://doi.org/10.1021/acs.langmuir.8b03056

Blonder, A., Shoval, S., \& Abitbol, T. (2017). arielle blonder + shira shoval's art piece explores nanocellulose at the eretz israel museum. https:/www.designboom.com/design/arielleblonder-shira-shoval-art-piece-nanocellulose-eretz-israel-museum-09-27-2017/

Braun, B., Dorgan, J. R., Braun, B., \& Dorgan, J. R. (2009). Single-Step Method for the Isolation and Surface Functionalization of Cellulosic Nanowhiskers Single-Step Method for the Isolation and Surface Functionalization of Cellulosic Nanowhiskers. Biomacromolecules, 10(2), 334-341. https://doi.org/10.1021/bm8011117

Brett, C. J., Mittal, N., Ohm, W., Gensch, M., Kreuzer, L. P., Körstgens, V., Månsson, M., Frielinghaus, H., Müller-Buschbaum, P., Söderberg, L. D., \& Roth, S. V. (2019). WaterInduced Structural Rearrangements on the Nanoscale in Ultrathin Nanocellulose Films. Macromolecules. https://doi.org/10.1021/acs.macromol.9b00531

Cai, H., Sharma, S., Liu, W. W., Mu, W., Liu, W. W., Zhang, X., \& Deng, Y. (2014). Aerogel microspheres from natural cellulose nanofibrils and their application as cell culture scaffold. Biomacromolecules, 15(7), 2540-2547. https://doi.org/10.1021/bm5003976

Carpenter, A. W., De Lannoy, C. F., \& Wiesner, M. R. (2015). Cellulose nanomaterials in water treatment technologies. Environmental Science and Technology, 49(9), 5277-5287. https://doi.org/10.1021/es506351r

Carrick, C., Larsson, P. A., Brismar, H., Aidun, C., \& Wågberg, L. (2014). Native and 
Functionalized Micrometre-Sized Cellulose Capsules Prepared by Microfluidic Flow Focusing. RSC Adv., 4(37), 19061-19067. https://doi.org/10.1039/C3RA47803C

Carrick, C., Lindström, S. B., Larsson, P. T., \& Wågberg, L. (2014). Lightweight, Highly Compressible, Noncrystalline Cellulose Capsules. Langmuir, 30(26), 7635-7644. https://doi.org/10.1021/la501118b

Carrick, C., Ruda, M., Pettersson, B., Larsson, P. T., \& Wågberg, L. (2013). Hollow Cellulose Capsules from CO2 Saturated Cellulose Solutions - their Preparation and Characterization. RSC Advances, 3(7), 2462. https://doi.org/10.1039/c2ra22020b

Cerclier, C., Guyomard-Lack, A., Moreau, C., Cousin, F., Beury, N., Bonnin, E., Jean, B., \& Cathala, B. (2011). Coloured Semi-reflective Thin Films for Biomass-hydrolyzing Enzyme Detection. Advanced Materials, 23(33), 3791-3795. https://doi.org/10.1002/adma.201101971

Cervin, N. T., Andersson, L., Ng, J. J. B. S., Olin, P., Bergström, L., \& Waì̌gberg, L. (2013). Lightweight and strong cellulose materials made from aqueous foams stabilized by nanofibrillated cellulose. Biomacromolecules, 14(2), 503-511. https://doi.org/10.1021/bm301755u

Cervin, N. T., Johansson, E., Larsson, P. A., \& Wågberg, L. (2016). Strong, Water-Durable, and Wet-Resilient Cellulose Nanofibril-Stabilized Foams from Oven Drying. ACS Applied Materials and Interfaces, 8(18), 11682-11689. https://doi.org/10.1021/acsami.6b00924

Cetin, N. S., Tingaut, P., Ozmen, N., Henry, N., Harper, D., Dadmun, M., \& Sebe, G. (2009). Acetylation of Cellulose Nanowhiskers with Vinyl Acetate under Moderate Conditions. Macromol. Biosci., 9, 997-1003. https://doi.org/10.1002/mabi.200900073

Chau, M., De France, K. J., Kopera, B., Machado, V. R., Rosenfeldt, S., Reyes, L., Chan, K. J. W., Fo, S., Cranston, E. D., Hoare, T., Kumacheva, E., Förster, S., Cranston, E. D., Hoare, T., \& Kumacheva, E. (2016). Composite Hydrogels with Tunable Anisotropic Morphologies and Mechanical Properties. Chemistry of Materials, 28(10), 3406-3415. https://doi.org/10.1021/acs.chemmater.6b00792

Chau, M., Sriskandha, S. E., Pichugin, D., Thérien-Aubin, H., Nykypanchuk, D., Chauve, G., Méthot, M., Bouchard, J., Gang, O., \& Kumacheva, E. (2015). Ion-Mediated Gelation of Aqueous Suspensions of Cellulose Nanocrystals. Biomacromolecules, 150623113615002. https://doi.org/10.1021/acs.biomac.5b00701

Chen, Q., Liu, P., Nan, F., Zhou, L., \& Zhang, J. (2014). Tuning the Iridescence of Chiral Nematic Cellulose Nanocrystal Films with a Vacuum-Assisted Self-Assembly Technique. Biomacromolecules, 15(11), 4343-4350. https://doi.org/10.1021/bm501355x

Chen, S., Schueneman, G., Pipes, R. B., Youngblood, J., \& Moon, R. J. (2014). Effects of crystal orientation on cellulose nanocrystals-cellulose acetate nanocomposite fibers prepared by dry spinning. Biomacromolecules, 15(10), 3827-3835. https://doi.org/10.1021/bm501161v

Chen, Y., Zhou, L., Chen, L., Duan, G., Mei, C., Huang, C., Han, J., \& Jiang, S. (2019). Anisotropic nanocellulose aerogels with ordered structures fabricated by directional freezedrying for fast liquid transport. Cellulose, 26(11), 6653-6667. 
https://doi.org/10.1007/s10570-019-02557-z

Cheng, D., Wen, Y., Wang, L., An, X., Zhu, X., \& Ni, Y. (2015). Adsorption of polyethylene glycol (PEG) onto cellulose nano-crystals to improve its dispersity. Carbohydrate Polymers, 123, 157-163. https://doi.org/10.1016/j.carbpol.2015.01.035

Chirani, N., Yahia, L., Gritsch, L., Motta, L. F., Chirani, S., \& Fare, S. (2015). History and Applications of Hydrogels. Journal of Biomedical Sciencies, 4(2), 1-23. https://doi.org/10.4172/2254-609x.100013

Clemons, C. (2016). Nanocellulose in Spun Continuous Fibers: A Review and Future Outlook. Journal of Renewable Materials, 4(5), 327-339. https://doi.org/10.7569/jrm.2016.634112

Cranston, E. D. (2013). Polyelectrolyte Multilayer Films Containing Cellulose Nanocrystals. In M. T. Postek, R. J. Moon, A. W. Rudie, \& M. A. Bilodeau (Eds.), Production and Applications of Cellulose Nanomaterials (pp. 82-89). TAPPI.

Csoka, L., Hoeger, I. C., Peralta, P., Peszlen, I., \& Rojas, O. J. (2011). Journal of Colloid and Interface Science Dielectrophoresis of cellulose nanocrystals and alignment in ultrathin films by electric field-assisted shear assembly. Journal of Colloid And Interface Science, 363(1), 206-212. https://doi.org/10.1016/j.jcis.2011.07.045

Curvello, R., Raghuwanshi, V. S., \& Garnier, G. (2019). Engineering nanocellulose hydrogels for biomedical applications. Advances in Colloid and Interface Science, 267, 47-61. https://doi.org/10.1016/j.cis.2019.03.002

Dastjerdi, Z., Cranston, E. D., Berry, R., Fraschini, C., \& Dubé, M. A. (2019). Polymer Nanocomposites for Emulsion-Based Coatings and Adhesives. Macromolecular Reaction Engineering, 13(2), 1-15. https://doi.org/10.1002/mren.201800050

Dastjerdi, Z., Cranston, E. D., \& Dubé, M. A. (2017a). Adhesive Property Modification using Cellulose Nanocrystals. International Journal of Adhesion and Adhesives, submitted.

Dastjerdi, Z., Cranston, E. D., \& Dubé, M. A. (2017b). Synthesis of Poly(n-butyl acrylate/methyl methacrylate)/CNC Latex Nanocomposites via In Situ Emulsion Polymerization. Macromolecular Reaction Engineering, 201700013, 1700013. https://doi.org/10.1002/mren.201700013

Dastjerdi, Z., Cranston, E. D., \& Dubé, M. A. (2018). Pressure sensitive adhesive property modification using cellulose nanocrystals. International Journal of Adhesion and Adhesives, 81(November 2017), 36-42. https://doi.org/10.1016/j.jjadhadh.2017.11.009

De France, K. J., Badv, M., Dorogin, J., Siebers, E., Panchal, V., Babi, M., Moran-Mirabal, J., Lawlor, M., Cranston, E. D., \& Hoare, T. (2019). Tissue Response and Biodistribution of Injectable Cellulose Nanocrystal Composite Hydrogels. ACS Biomaterials Science and Engineering, 5(5), 2235-2246. https://doi.org/10.1021/acsbiomaterials.9b00522

De France, K. J., Hoare, T., \& Cranston, E. D. (2017). Review of Hydrogels and Aerogels Containing Nanocellulose. Chemistry of Materials, 29(11), 4609-4631. https://doi.org/10.1021/acs.chemmater.7b00531

Decher, G., \& Schlenoff, J. B. (2002). Multilayer Thin Films (1st ed., Vol. 1). Wiley-VCH. 
Derjaguin, B. V., \& Landau, L. (1941). Theory of the stability of strongly charge lyophobic sols and of the adhesion of strongly charged particles in solution of electrolytes. Acta Physicochem. URSS, 14(32), 633-662. https://doi.org/10.1016/0079-6816(93)90013-L

Ding, Q., Zeng, J., Wang, B., Tang, D., Chen, K., \& Gao, W. (2019). Effect of nanocellulose fiber hornification on water fraction characteristics and hydroxyl accessibility during dehydration. Carbohydrate Polymers, 207(August 2018), 44-51. https://doi.org/10.1016/j.carbpol.2018.11.075

Domingues, R. M. A., Silva, M., Gershovich, P., Betta, S., Babo, P., Caridade, S. G., Mano, J. F., Motta, A., Reis, R. L., \& Gomes, M. E. (2015). Development of Injectable Hyaluronic Acid/Cellulose Nanocrystals Bionanocomposite Hydrogels for Tissue Engineering Applications. Bioconjugate Chemistry, 26(8), 1571-1581. https://doi.org/10.1021/acs.bioconjchem.5b00209

Dong, H., Strawhecker, K. E., Snyder, J. F., Orlicki, J. A., Reiner, R. S., \& Rudie, A. W. (2012). Cellulose nanocrystals as a reinforcing material for electrospun poly(methyl methacrylate) fibers: Formation, properties and nanomechanical characterization. Carbohydrate Polymers, 87(4), 2488-2495. https://doi.org/10.1016/j.carbpol.2011.11.015

Dorris, A., \& Gray, D. G. (2012). Gelation of cellulose nanocrystal suspensions in glycerol. Cellulose, 19(3), 687-694. https://doi.org/10.1007/s10570-012-9679-3

Drogoz, A., David, L., Rochas, C., Domard, A., \& Delair, T. (2007). Polyelectrolyte complexes from polysaccharides: Formation and stoichiometry monitoring. Langmuir, 23(22), 1095010958. https://doi.org/10.1021/la7008545

Dugan, J. M., Gough, J. E., \& Eichhorn, S. J. (2010). Directing the Morphology and Differentiation of Skeletal Muscle Cells Using Oriented Cellulose Nanowhiskers. Biomacromolecules, 11(9), 2498-2504. https://doi.org/10.1021/bm100684k

Edgar, C. D., \& Gray, D. G. (2003). Smooth model cellulose I surfaces from nanocrystal suspensions. Cellulose, 10, 299-306. https://doi.org/10.1023/A:1027333928715

Eichhorn, S. J., Dufresne, A., Aranguren, M., Marcovich, N. E., Capadona, J. R., Rowan, S. J., Weder, C., Thielemans, W., Roman, M., Renneckar, S., Gindl, W., Veigel, S., Keckes, J., Yano, H., Abe, K., Nogi, M., Nakagaito, A. N., Mangalam, A., Simonsen, J., ... Peijs, T. (2010). Review: current international research into cellulose nanofibres and nanocomposites. Journal of Materials Science, 45(1), 1-33. https://doi.org/DOI 10.1007/s10853-009-3874-0

Endo, R., Saito, T., \& Isogai, A. (2013). TEMPO-oxidized cellulose nanofibril/poly(vinyl alcohol) composite drawn fibers. Polymer, 54(2), 935-941. https://doi.org/10.1016/j.polymer.2012.12.035

Eriksson, M., Notley, S. M., \& Wågberg, L. (2007). Cellulose Thin Films : Degree of Cellulose Ordering and Its Influence on Adhesion. Biomacromolecules, 8(3), 912-919. https://doi.org/10.1021/bm061164w

Erlandsson, J., López Durán, V., Granberg, H., Sandberg, M., Larsson, P. A., \& Wågberg, L. (2016). Macro- and mesoporous nanocellulose beads for use in energy storage devices. 
Applied Materials Today, 5(December), 246-254.

https://doi.org/10.1016/j.apmt.2016.09.008

Fall, A. B., Lindström, S. B., Sundman, O., Ödberg, L., Wågberg, L., Lindstr, S. B., Sundman, O., Odberg, L., \& Lars, W. (2011). Colloidal stability of aqueous nanofibrillated cellulose dispersions. Langmuir, 27(18), 11332-11338. https://doi.org/10.1021/la201947x

Ferreira, F. V., Otoni, C. G., De France, K. J., Barud, H. S., Lona, L. M. F., Cranston, E. D., \& Rojas, O. J. (2020). Porous nanocellulose gels and foams: Breakthrough status in the development of scaffolds for tissue engineering. Materials Today, In Press. https://doi.org/10.1016/j.mattod.2020.03.003

Ferrer, A., Pal, L., \& Hubbe, M. (2017). Nanocellulose in packaging: Advances in barrier layer technologies. Industrial Crops \& Products, 95, 574-582. https://doi.org/10.1016/j.indcrop.2016.11.012

Foster, E. J., Moon, R. J., Bras, J., Camarero-espinosa, S., Chan, K. J., Clift, M. J. D., Cranston, E. D., Eichhorn, S. J., Fox, D. M., Hamad, W. Y., Heux, L., Jean, B., Korey, M., Nieh, W., Ong, K. J., Reid, M. S., Renneckar, S., Roberts, R., \& Shatkin, A. (2018). Current characterization methods for cellulose nanomaterials. Chemical Society Reviews, 47(8), 2609-2679. https://doi.org/10.1039/c6cs00895j

Fumagalli, M., Sanchez, F., Boisseau, S. M., \& Heux, L. (2013). Gas-phase esterification of cellulose nanocrystal aerogels for colloidal dispersion in apolar solvents. Soft Matter, 9(47), 11309-11317. https://doi.org/10.1039/c3sm52062e

Ganster, J., \& Fink, H. P. (2006). Novel cellulose fibre reinforced thermoplastic materials. Cellulose, 13(3), 271-280. https://doi.org/10.1007/s10570-005-9045-9

García-Astrain, C., González, K., Gurrea, T., Guaresti, O., Algar, I., Eceiza, A., \& Gabilondo, N. (2016). Maleimide-grafted cellulose nanocrystals as cross-linkers for bionanocomposite hydrogels. Carbohydrate Polymers, 149, 94-101.

https://doi.org/10.1016/j.carbpol.2016.04.091

Geng, S., Haque, M. M. U., \& Oksman, K. (2016). Crosslinked Poly(vinyl acetate) (PVAc) Reinforced with Cellulose Nanocrystals (CNC): Structure and Mechanical Properties. Composites Science and Technology, 126, 35-42.

https://doi.org/10.1016/j.compscitech.2016.02.013

Gestranius, M., Stenius, P., Kontturi, E., Sjöblom, J., \& Tammelin, T. (2017). Phase behaviour and droplet size of oil-in-water Pickering emulsions stabilised with plant-derived nanocellulosic materials. Colloids and Surfaces A: Physicochemical and Engineering Aspects, 519, 60-70. https://doi.org/10.1016/j.colsurfa.2016.04.025

Ghasemi, S., Tajvidi, M., Gardner, D. J., Bousfield, D. W., \& Shaler, S. M. (2018). Effect of wettability and surface free energy of collection substrates on the structure and morphology of dry-spun cellulose nanofibril filaments. Cellulose, 25(11), 6305-6317. https://doi.org/10.1007/s10570-018-2029-3

Giesa, T., \& Buehler, M. J. (2013). Nanoconfinement and the Strength of Biopolymers. Annual Review of Biophysics, 42(1), 651-673. https://doi.org/10.1146/annurev-biophys-083012- 
130345

Giese, M., Blusch, L. K., Khan, M. K., \& MacLachlan, M. J. (2015). Functional Materials from Cellulose-Derived Liquid-Crystal Templates. Angewandte Chemie International Edition, 54(10), 2888-2910. https://doi.org/10.1002/anie.201407141

Glasser, W. G., Atalla, R. H., Blackwell, J., Brown, M. M., Burchard, W., French, A. D., Klemm, D. O., \& Nishiyama, Y. (2012). About the structure of cellulose: Debating the Lindman hypothesis. Cellulose, 19(3), 589-598. https://doi.org/10.1007/s10570-012-9691-7

Goetz, L. A., Naseri, N., Nair, S. S., Karim, Z., \& Mathew, A. P. (2018). All cellulose electrospun water purification membranes nanotextured using cellulose nanocrystals. Cellulose, 25(5), 3011-3023. https://doi.org/10.1007/s10570-018-1751-1

Gordeyeva, K. S., Fall, A. B., Hall, S., Wicklein, B., \& Bergström, L. (2016). Stabilizing nanocellulose-nonionic surfactant composite foams by delayed $\mathrm{Ca}$-induced gelation. Journal of Colloid and Interface Science, 472, 44-51. https://doi.org/10.1016/j.jcis.2016.03.031

Gousse, Â., \& Chanzy, H. (2002). Stable suspensions of partially silylated cellulose whiskers dispersed in organic solvents. Polymer, 43(9), 2645-2651. https://doi.org/https://doi.org/10.1016/S0032-3861(02)00051-4

Goutianos, S., Peijs, T., Nystrom, B., \& Skrifvars, M. (2006). Development of flax fibre based textile reinforcements for composite applications. Applied Composite Materials, 13(4), 199-215. https://doi.org/10.1007/s10443-006-9010-2

Gray, D. G. (2016). Recent advances in chiral nematic structure and iridescent color of cellulose nanocrystal films. Nanomaterials, 6(11). https://doi.org/10.3390/nano6110213

Gray, D. G. (2018). Order and gelation of cellulose nanocrystal suspensions : an overview of some issues. Philosophical Transactions of the Royal Society A: Mathematical, Physical and Engineering Sciences, 376(2112). https://doi.org/10.1098/rsta.2017.0038.

Greca, L. G., Lehtonen, J., Tardy, B. L., Guo, J., \& Rojas, O. J. (2018). Biofabrication of multifunctional nanocellulosic 3D structures: A facile and customizable route. Materials Horizons, 5(3), 408-415. https://doi.org/10.1039/c7mh01139c

Guidetti, G., Atifi, S., Vignolini, S., \& Hamad, W. Y. (2016). Flexible Photonic Cellulose Nanocrystal Films. Advanced Materials, 28(45), 10042-10047. https://doi.org/10.1002/adma.201603386

Habibi, Y., Chanzy, H., \& Vignon, M. R. (2006). TEMPO-mediated surface oxidation of cellulose whiskers. Cellulose, 13(6), 679-687. https://doi.org/10.1007/s10570-006-9075-y

Habibi, Y., Foulon, L., Aguié-Béghin, V., Molinari, M., \& Douillard, R. (2007). LangmuirBlodgett films of cellulose nanocrystals: Preparation and characterization. Journal of Colloid and Interface Science, 316(2), 388-397. https://doi.org/10.1016/j.jcis.2007.08.041

Habibi, Y., Hoeger, I., Kelley, S. S., \& Rojas, O. J. (2010). Development of Langmuir-Schaeffer Cellulose Nanocrystal Monolayers and Their Interfacial Behaviors. Langmuir, 26(2), 9901001. https://doi.org/10.1021/la902444x 
Habibi, Y., Lucia, L. A., \& Rojas, O. J. (2010). Cellulose Nanocrystals: Chemistry, SelfAssembly, and Applications. Chemical Reviews, 110(6), 3479-3500.

https://doi.org/10.1021/cr900339w

Håkansson, K. M. O., Fall, A. B., Lundell, F., Yu, S., Krywka, C., Roth, S. V., Santoro, G., Kvick, M., Prahl Wittberg, L., Wågberg, L., \& Söderberg, L. D. (2014). Hydrodynamic alignment and assembly of nanofibrils resulting in strong cellulose filaments. Nature Communications, 5, 4018. https://doi.org/10.1038/ncomms5018

Hamedi, M., Karabulut, E., Marais, A., Herland, A., Nyström, G., Wågberg, L., \& W gberg, L. (2013). Nanocellulose aerogels functionalized by rapid layer-by-layer assembly for high charge storage and beyond. Angewandte Chemie - International Edition, 52(46), 1203812042. https://doi.org/10.1002/anie.201305137

Hasani, M., Cranston, E. D., Westman, G., \& Gray, D. G. (2008). Cationic surface functionalization of cellulose nanocrystals. Soft Matter, 4(11), 2238-2244. https://doi.org/10.1039/b806789a

Hasegawa, M., Isogai, A., \& Onabe, F. (1993). Preparation of Low-molecular weight cellulose using phosphoric acid. Carbohydrate Polymers, 20, 279-283. https://doi.org/https://doi.org/10.1016/0144-8617(93)90100-I

He, X., Xiao, Q., Lu, C., Wang, Y., Zhang, X., Zhao, J., Zhang, W., Zhang, X., \& Deng, Y. (2014). Uniaxially aligned electrospun all-cellulose nanocomposite nanofibers reinforced with cellulose nanocrystals: Scaffold for tissue engineering. Biomacromolecules, 15(2), 618-627. https://doi.org/10.1021/bm401656a

Heath, L., \& Thielemans, W. (2010). Cellulose nanowhisker aerogels. Green Chemistry, 12(8), 1448-1453. https://doi.org/10.1039/c0gc00035c

Heise, K., Delepierre, G., King, A., Kostiainen, M., Zoppe, J., Weder, C., \& Kontturi, E. (2020). Chemical modification of cellulose nanocrystal reducing end- groups. Angewandte Chemie. https://doi.org/10.1002/ange.202002433

Henriksson, M., Berglund, L. A., Isaksson, P., \& Lindstro, T. (2008). Cellulose Nanopaper Structures of High Toughness. Biomacromolecules, 9(6), 1579-1585. https://doi.org/https://doi.org/10.1021/bm800038n

Hoeger, I., Rojas, O. J., Efimenko, K., Velev, O. D., \& Kelley, S. S. (2011). Ultrathin film coatings of aligned cellulose nanocrystals from a convective-shear assembly system and their surface mechanical properties. Soft Matter, 7(5), 1957.

https://doi.org/10.1039/c0sm01113d

Hooshmand, S., Aitomäki, Y., Norberg, N., Mathew, A. P., \& Oksman, K. (2015). Dry-Spun Single-Filament Fibers Comprising Solely Cellulose Nanofibers from Bioresidue. ACS Applied Materials and Interfaces, 7(23), 13022-13028.

https://doi.org/10.1021/acsami.5b03091

Hsieh, M., Kim, C., Nogi, M., \& Suganuma, K. (2013). Electrically conductive lines on cellulose nanopaper for flexible electrical devices. Nanoscale, 5(19), 9289-9295.

https://doi.org/10.1039/c3nr01951a 
Hu, L., Zheng, G., Yao, J., Liu, N., Weil, B., Mcgehee, M. D., \& Lars, W. (2013). Transparent and conductive paper from nanocellulose. Energy \& Environmental Science, 6(2), 513-518. https://doi.org/10.1039/c2ee23635d

Hu, Z., Ballinger, S., Pelton, R., \& Cranston, E. D. (2015). Surfactant-enhanced cellulose nanocrystal Pickering emulsions. Journal of Colloid and Interface Science, 439, 139-148. https://doi.org/10.1016/j.jcis.2014.10.034

Hu, Z., Marway, H. S., Kasem, H., Pelton, R., \& Cranston, E. D. (2016). Dried and Redispersible Cellulose Nanocrystal Pickering Emulsions. ACS Macro Letters, 5(2), 185-189. https://doi.org/10.1021/acsmacrolett.5b00919

Hu, Z., Xu, R., Cranston, E. D., \& Pelton, R. H. (2016). Stable Aqueous Foams from Cellulose Nanocrystals and Methyl Cellulose. Biomacromolecules, 17(12), 4095-4099. https://doi.org/10.1021/acs.biomac.6b01641

Hubbe, M. A., Ferrer, A., Tyagi, P., Yin, Y., \& Salas, C. (2017). Nanocellulose in Thin Films, Coatings, and Plies for Packaging Applications: A Review. BioResources, 12(1), 21432233.

Hubbe, M. A., Rojas, O. J., Lucia, L. A., \& Sain, M. (2008). Cellulosic Nanocomposites: A Review. BioResources, 3(3), 929-980. https://doi.org/10.15376/biores.3.3.929-980

Huq, T., Fraschini, C., Khan, A., Riedl, B., Bouchard, J., \& Lacroix, M. (2017). Alginate based nanocomposite for microencapsulation of probiotic: Effect of cellulose nanocrystal (CNC) and lecithin. Carbohydrate Polymers, 168, 61-69.

https://doi.org/10.1016/j.carbpol.2017.03.032

Huq, T., Riedl, B., Bouchard, J., Salmieri, S., \& Lacroix, M. (2014). Microencapsulation of nisin in alginate-cellulose nanocrystal (CNC) microbeads for prolonged efficacy against Listeria monocytogenes. Cellulose, 21(6), 4309-4321. https://doi.org/10.1007/s10570-014-0432-y

Huq, T., Salmieri, S., Khan, A., Khan, R. A., Le Tien, C., Riedl, B., Fraschini, C., Bouchard, J., Uribe-Calderon, J., Kamal, M. R., \& Lacroix, M. (2012). Nanocrystalline cellulose (NCC) reinforced alginate based biodegradable nanocomposite film. Carbohydrate Polymers, 90(4), 1757-1763. https://doi.org/10.1016/j.carbpol.2012.07.065

Iwamoto, S., Isogai, A., \& Iwata, T. (2011). Structure and mechanical properties of wet-spun fibers made from natural cellulose nanofibers. Biomacromolecules, 12(3), 831-836. https://doi.org/10.1021/bm101510r

Jiang, F., \& Hsieh, Y. Lo. (2014). Amphiphilic superabsorbent cellulose nanofibril aerogels. Journal of Materials Chemistry A, 2(18), 6337-6342. https://doi.org/10.1039/c4ta00743c

Jimenez-Saelices, C., Seantier, B., Cathala, B., Grohens, Y., Jiménez-Saelices, C., Seantier, B., Cathala, B., \& Grohens, Y. (2016). Spray freeze-dried nanofibrillated cellulose aerogels with thermal superinsulating properties. Carbohydrate Polymers, 157, 105-113. https://doi.org/10.1016/j.carbpol.2016.09.068

Jiménez Saelices, C., \& Capron, I. (2018). Design of Pickering Micro- and Nanoemulsions Based on the Structural Characteristics of Nanocelluloses. Biomacromolecules, 19(2), 460469. https://doi.org/10.1021/acs.biomac.7b01564 
Jiménez Saelices, C., Save, M., \& Capron, I. (2019). Synthesis of latex stabilized by unmodified cellulose nanocrystals: The effect of monomers on particle size. Polymer Chemistry, 10(6), 727-737. https://doi.org/10.1039/c8py01575a

Jorfi, M., \& Foster, E. J. (2015). Recent advances in nanocellulose for biomedical applications. Journal of Applied Polymer Science, 132(14), 1-19. https://doi.org/10.1002/app.41719

Kalashnikova, I., Bizot, H. H., Bertoncini, P., Cathala, B., \& Capron, I. (2013). Cellulosic nanorods of various aspect ratios for oil in water Pickering emulsions. Soft Matter, 9(3), 952-959. https://doi.org/10.1039/c2sm26472b

Kalashnikova, I., Bizot, H. H., Cathala, B., \& Capron, I. (2012). Modulation of cellulose nanocrystals amphiphilic properties to stabilize oil/water interface. Biomacromolecules, 13(1), 267-275. https://doi.org/10.1021/bm201599j

Kalashnikova, I., Cathala, B., Capron, I., Bizot, H. H., Cathala, B., \& Capron, I. (2011). New pickering emulsions stabilized by bacterial cellulose nanocrystals. Langmuir, 27(12), 74717479. https://doi.org/10.1021/la200971f

Kargarzadeh, H., Mariano, M., Huang, J., Lin, N., Ahmad, I., Dufresne, A., \& Thomas, S. (2017). Recent developments on nanocellulose reinforced polymer nanocomposites: A review. Polymer, 132, 368-393. https://doi.org/10.1016/j.polymer.2017.09.043

Kedzior, S. A., Gabriel, V., Dube, M. A., \& Cranston, E. D. (2020). Nanocellulose in Emulsions and Heterogeneous Water-Based Polymer Systems: A Review. Advanced Materials, In Press.

Kedzior, S. A., Graham, L., Moorlag, C., Dooley, B. M., \& Cranston, E. D. (2016). Poly(methyl methacrylate)-Grafted Cellulose Nanocrystals: One-Step Synthesis, Nanocomposite Preparation, and Characterization. The Canadian Journal of Chemical Engineering, 94(5), 811-822. https://doi.org/10.1002/cjce.22456

Kedzior, S. A., Marway, H. S., \& Cranston, E. D. (2017). Tailoring Cellulose Nanocrystal and Surfactant Behavior in Miniemulsion Polymerization. Macromolecules, 50(7), 2645-2655. https://doi.org/10.1021/acs.macromol.7b00516

Kedzior, S. A., Zoppe, J. O., Berry, R. M., \& Cranston, E. D. (2018). Recent advances and an industrial perspective of cellulose nanocrystal functionalization through polymer grafting. Current Opinion in Solid State and Materials Science, 23(2), 74-91.

https://doi.org/S1359028618301918

Kelly, J. A., Shukaliak, A. M., Cheung, C. C. Y., Shopsowitz, K. E., Hamad, W. Y., \& MacLachlan, M. J. (2013). Responsive photonic hydrogels based on nanocrystalline cellulose. Angewandte Chemie - International Edition, 52(34), 8912-8916. https://doi.org/10.1002/anie.201302687

Kettunen, M., Silvennoinen, R. J., Houbenov, N., Nykänen, A., Ruokolainen, J., Sainio, J., Pore, V., Kemell, M., Ankerfors, M., Lindström, T., Ritala, M., Ras, R. H. A., \& Ikkala, O. (2011). Photoswitchable superabsorbency based on nanocellulose aerogels. Advanced Functional Materials, 21(3), 510-517. https://doi.org/10.1002/adfm.201001431

Khoshkava, V., \& Kamal, M. R. (2013). Effect of surface energy on dispersion and mechanical 
properties of polymer/nanocrystalline cellulose nanocomposites. Biomacromolecules, 14(9), 3155-3163. https://doi.org/10.1021/bm400784j

Khoshkava, V., \& Kamal, M. R. (2014a). Effect of cellulose nanocrystals (CNC) particle morphology on dispersion and rheological and mechanical properties of polypropylene/CNC nanocomposites. ACS Applied Materials and Interfaces, 6, 8146-8157. https://doi.org/10.1021/am500577e

Khoshkava, V., \& Kamal, M. R. (2014b). Effect of drying conditions on cellulose nanocrystal (CNC) agglomerate porosity and dispersibility in polymer nanocomposites. Powder Technology, 261, 288-298. https://doi.org/10.1016/j.powtec.2014.04.016

Kittle, J. D. (2012). Characterization of Cellulose and Chitin Thin Films and Their Interactions with Bio-based Polymers. Characterization of Cellulose and Chitin Thin Films and Their Interactions with Bio-Based Polymers (PhD Dissertation; Virginia Tech), 1-186. http://scholar.lib.vt.edu/theses/available/etd-04122012-080620/

Klockars, K. W., Yau, N. E., Tardy, B. L., \& Majoinen, J. (2019). Asymmetrical coffee rings from cellulose nanocrystals and prospects in art and design. Cellulose, 26(1), 491-506. https://doi.org/10.1007/s10570-018-2167-7

Kobayashi, Y., Saito, T., \& Isogai, A. (2014). Aerogels with 3D Ordered Nanofiber Skeletons of Liquid-Crystalline Nanocellulose Derivatives as Tough and Transparent Insulators.

Angewandte Chemie International Edition, 53(29), 10394-10397.

https://doi.org/10.1002/anie.201405123

Köhnke, T., Elder, T., Theliander, H., \& Ragauskas, A. J. (2014). Ice templated and cross-linked xylan/nanocrystalline cellulose hydrogels. Carbohydrate Polymers, 100, 24-30.

https://doi.org/10.1016/j.carbpol.2013.03.060

Kontturi, E., Johansson, L., Kontturi, K. S., Ahonen, P., Thüne, P. C., \& jann. (2007). Cellulose Nanocrystal Submonolyers by Spin Coating. Langmuir, 23(9674), 9680.

https://doi.org/https://doi.org/10.1021/la701262x

Kontturi, E., Laaksonen, P., Linder, M. B., Nonappa, Gröschel, A. H., Rojas, O. J., \& Ikkala, O. (2018). Advanced Materials through Assembly of Nanocelluloses. Advanced Materials, 30(24), 1703779. https://doi.org/10.1002/adma.201703779

Kontturi, E., Tammelin, T., \& Österberg, M. (2006). Cellulose - Model films and the fundamental approach. Chemical Society Reviews, 35(12), 1287-1304. https://doi.org/10.1039/b601872f

Kontturi, E., Thüne, P. C., \& Niemantsverdriet, J. W. (Hans). (2003). Cellulose Model SurfacesSimplified Preparation by Spin Coating and Characterization by X-Ray Photoelectron Spectroscopy, Infrared Spectroscopy and Atomic Force Microscopy. Langmuir, 19(14), 5735-5741. https://doi.org/https://doi.org/10.1021/la0340394

Köse, K., Mavlan, M., \& Youngblood, J. P. (2020). Applications and impact of nanocellulose based adsorbents. Cellulose, 1, 2967-2990. https://doi.org/10.1007/s10570-020-03011-1

Lagerwall, J. P. F., Schütz, C., Salajkova, M., Noh, J., Park, J. H., Scalia, G., \& Bergström, L. (2014). Cellulose nanocrystal-based materials: From liquid crystal self-assembly and glass 
formation to multifunctional thin films. NPG Asia Materials, 6(1), 1-12. https://doi.org/10.1038/am.2013.69

Lavoine, N., \& Bergström, L. (2017). Nanocellulose-based foams and aerogels: Processing, properties, and applications. Journal of Materials Chemistry A, 5(31), 16105-16117. https://doi.org/10.1039/c7ta02807e

Lavoine, N., Desloges, I., Khelifi, B., \& Bras, J. (2014). Impact of different coating processes of microfibrillated cellulose on the mechanical and barrier properties of paper. Journal of Materials Science, 49(7), 2879-2893. https://doi.org/10.1007/s10853-013-7995-0

Lavoine, N., Durmaz, E., \& Trovagunta, R. (2019). Preparation and Properties of Nanopolysaccharides. In N. Lin, J. Tang, A. Dufresne, \& M. K. C. Tam (Eds.), Advanced Functional Materials from Nanopolysaccharides. Springer, Singapore. https://doi.org/https://doi.org/10.1007/978-981-15-0913-1_1

Lemahieu, L., Bras, J., Tiquet, P., Augier, S., \& Dufresne, A. (2011). Extrusion of nanocellulosereinforced nanocomposites using the dispersed nano-objects protective encapsulation (DOPE) process. Macromolecular Materials and Engineering, 296(11), 984-991. https://doi.org/10.1002/mame.201100015

Levin, D., Saem, S., Osorio, D. A., Cerf, A., Cranston, E. D., \& Moran-mirabal, J. M. (2018). Green Templating of Ultraporous Cross-Linked Cellulose Nanocrystal Microparticles [Research-article]. Chemistry of Materials, 30, 8040-8051. https://doi.org/10.1021/acs.chemmater.8b03858

Lewis, L., Derakhshandeh, M., Hatzikiriakos, S. G., Hamad, W. Y., \& Maclachlan, M. J. (2016). Hydrothermal Gelation of Aqueous Cellulose Nanocrystal Suspensions.

Biomacromolecules, 17(8), 2747-2754. https://doi.org/10.1021/acs.biomac.6b00906

Li, M., Tshabalala, M. A., \& Buschle-Diller, G. (2016). Formulation and characterization of polysaccharide beads for controlled release of plant growth regulators. Journal of Materials Science, 51(9), 4609-4617. https://doi.org/10.1007/s10853-016-9775-0

Li, X., Tabil, L. G., \& Panigrahi, S. (2007). Chemical treatments of natural fiber for use in natural fiber-reinforced composites: A review. Journal of Polymers and the Environment, 15(1), 25-33. https://doi.org/10.1007/s10924-006-0042-3

Li, Y., Jun-Yan Suen, J., Prince, E., Larin, E. M., Klinkova, A., Thérien-Aubin, H., Zhu, S., Yang, B., Helmy, A. S., Lavrentovich, O. D., \& Kumacheva, E. (2016). Colloidal cholesteric liquid crystal in spherical confinement. Nature Communications, 7(1), 12520. https://doi.org/10.1038/ncomms12520

Liang, L., Bhagia, S., Li, M., Huang, C., \& Ragauskas, A. J. (2020). Cross-Linked Nanocellulosic Materials and Their Applications. ChemSusChem, 13(1), 78-87. https://doi.org/10.1002/cssc.201901676

Liebner, F., Haimer, E., Wendland, M., Neouze, M., Schlufter, K., Miethe, P., Heinze, T., Potthast, A., \& Rosenau, T. (2010). Aerogels from Unaltered Bacterial Cellulose : Application of scCO2 Drying for the Preparation of Shaped, Ultra-Lightweight Cellulosic Aerogels. Macromol. Biosci., 10(4), 349-352. https://doi.org/10.1002/mabi.200900371 
Lin, N., Huang, J., \& Dufresne, A. (2012). Preparation, properties and applications of polysaccharide nanocrystals in advanced functional nanomaterials: a review. Nanoscale, 4(11), 3274. https://doi.org/10.1039/c2nr30260h

Lindh, J., Carlsson, D. O., Strømme, M., \& Mihranyan, A. (2014). Convenient One-Pot Formation of 2,3-Dialdehyde Cellulose Beads via Periodate Oxidation of Cellulose in Water. Biomacromolecules, 15(5), 1928-1932. https://doi.org/10.1021/bm5002944

Lindh, J., Ruan, C., Strømme, M., \& Mihranyan, A. (2016). Preparation of Porous Cellulose Beads via Introduction of Diamine Spacers. Langmuir, 32(22), 5600-5607. https://doi.org/https://doi.org/10.1021/acs.langmuir.6b01288

Liu, H., Geng, B., Chen, Y., \& Wang, H. (2017). Review on the Aerogel-Type Oil Sorbents Derived from Nanocellulose. ACS Sustainable Chemistry \& Engineering, 5(1), 49-66. https://doi.org/10.1021/acssuschemeng.6b02301

Liu, Z., Wang, H., Li, B., Liu, C., Jiang, Y., Yu, G., \& Mu, X. (2012). Biocompatible Magnetic Cellulose-Chitosan Hybrid Hel Microspheres Reconstituted from Ionic Liquids for Enzyme Immobilization. Journal of Materials Chemistry, 22(30), 15085. https://doi.org/10.1039/c2jm33033d

Lombardo, S., \& Thielemans, W. (2019). Thermodynamics of adsorption on nanocellulose surfaces. Cellulose, 2, 1-31. https://doi.org/10.1007/s10570-018-02239-2

Lundahl, M. J., Cunha, A. G., Rojo, E., Papageorgiou, A. C., Rautkari, L., Arboleda, J. C., \& Rojas, O. J. (2016). Strength and Water Interactions of Cellulose i Filaments Wet-Spun from Cellulose Nanofibril Hydrogels. Scientific Reports, 6(February), 1-13. https://doi.org/10.1038/srep30695

Lundahl, M. J., Klar, V., Ajdary, R., Norberg, N., Ago, M., Cunha, A. G., \& Rojas, O. J. (2018). Absorbent Filaments from Cellulose Nanofibril Hydrogels through Continuous Coaxial Wet Spinning [Research-article]. ACS Applied Materials and Interfaces, 10(32), 27287-27296. https://doi.org/10.1021/acsami.8b08153

Lundahl, M. J., Klar, V., Wang, L., Ago, M., \& Rojas, O. J. (2017). Spinning of cellulose nanofibrils into filaments: A review. Industrial and Engineering Chemistry Research, 56(1), 8-19. https://doi.org/10.1021/acs.iecr.6b04010

Luo, X., Liu, S., Zhou, J., \& Zhang, L. (2009). In Situ Synthesis of Fe3O4/Cellulose Microspheres with Magnetic-Induced Protein Delivery. Journal of Materials Chemistry, 19(21), 3538. https://doi.org/10.1039/b900103d

Luo, X., \& Zhang, L. (2010). Creation of Regenerated Cellulose Microspheres with Diameter Ranging from Micron to Millimeter for Chromatography Applications. Journal of Chromatography A, 1217(38), 5922-5929. https://doi.org/10.1016/J.CHROMA.2010.07.026

Ma, H., Burger, C., Hsiao, B. S., \& Chu, B. (2012). Nanofibrous microfiltration membrane based on cellulose nanowhiskers. Biomacromolecules, 13(1), 180-186. https://doi.org/10.1021/bm201421g

Mariano, M., Hantao, L. W., da Silva Bernardes, J., \& Strauss, M. (2018). Microstructural 
characterization of nanocellulose foams prepared in the presence of cationic surfactants. Carbohydrate Polymers, 195(April), 153-162.

https://doi.org/10.1016/j.carbpol.2018.04.075

Martin, G., Trygg, J., \& Fardim, P. (2013). Functional Cellulose Beads: Preparation, Characterization, and Applications. Chemical Reviews, 113(7), 4812-4836. https://doi.org/https://doi.org/10.1021/cr300242j

McHale, G., \& Newton, M. I. (2011). Liquid marbles: Principles and applications. Soft Matter, 7(12), 5473-5481. https://doi.org/10.1039/c1sm05066d

McKee, J. R., Appel, E. A., Seitsonen, J., Kontturi, E., Scherman, O. A., \& Ikkala, O. (2014). Healable, stable and stiff hydrogels: Combining conflicting properties using dynamic and selective three-component recognition with reinforcing cellulose nanorods. Advanced Functional Materials, 24(18), 2706-2713. https://doi.org/10.1002/adfm.201303699

Medronho, B., Romano, A., Miguel, M. G., Stigsson, L., \& Lindman, B. (2012). Rationalizing cellulose (in)solubility: Reviewing basic physicochemical aspects and role of hydrophobic interactions. Cellulose, 19(3), 581-587. https://doi.org/10.1007/s10570-011-9644-6

Meseck, G. R., Terpstra, A. S., \& MacLachlan, M. J. (2017). Liquid crystal templating of nanomaterials with nature's toolbox. Current Opinion in Colloid and Interface Science, 29, 9-20. https://doi.org/10.1016/j.cocis.2017.01.003

Metreveli, G., Wågberg, L., Emmoth, E., Belák, S., Strømme, M., \& Mihranyan, A. (2014). A Size-Exclusion Nanocellulose Filter Paper for Virus Removal. Advanced Healthcare Materials, 3(10), 1546-1550. https://doi.org/10.1002/adhm.201300641

Mihranyan, A. (2013). Viscoelastic properties of cross-linked polyvinyl alcohol and surfaceoxidized cellulose whisker hydrogels. Cellulose, 20(3), 1369-1376. https://doi.org/10.1007/s10570-013-9882-X

Mittal, N., Ansari, F., Gowda Krishne, V., Brouzet, C., Chen, P., Larsson, P. T., Roth, S. V., Lundell, F., Wågberg, L., Kotov, N. A., \& Söderberg, L. D. (2018). Multiscale Control of Nanocellulose Assembly: Transferring Remarkable Nanoscale Fibril Mechanics to Macroscale Fibers. ACS Nano, 12(7), 6378-6388. https://doi.org/10.1021/acsnano.8b01084

Mittal, N., Benselfelt, T., Ansari, F., Gordeyeva, K., Roth, S. V., Wågberg, L., \& Söderberg, L. D. (2019). Ion-Specific Assembly of Strong, Tough, and Stiff Biofibers. Angewandte Chemie - International Edition, 58(51), 18562-18569. https://doi.org/10.1002/anie.201910603

Mittal, N., Jansson, R., Widhe, M., Benselfelt, T., Håkansson, K. M. O., Lundell, F., Hedhammar, M., \& Söderberg, L. D. (2017). Ultrastrong and Bioactive Nanostructured BioBased Composites. ACS Nano, 11(5), 5148-5159. https://doi.org/10.1021/acsnano.7b02305

Mohammed, N., Grishkewich, N., Berry, R. M., \& Tam, K. C. (2015). Cellulose nanocrystalsalginate hydrogel beads as novel adsorbents for organic dyes in aqueous solutions. Cellulose, 22(6), 3725-3738. https://doi.org/10.1007/s10570-015-0747-3

Mohanta, V., Madras, G., \& Patil, S. (2014). Layer-by-layer assembled thin films and microcapsules of nanocrystalline cellulose for hydrophobic drug delivery. ACS Applied 
Materials and Interfaces, 6(22), 20093-20101. https://doi.org/10.1021/am505681e

Moon, R. J., Martini, A., Nairn, J., Simonsen, J., \& Youngblood, J. (2011). Cellulose Nanomaterials Review: Structure, Properties and Nanocomposites. Chemical Society Reviews, 40(7), 3941. https://doi.org/10.1039/c0cs00108b

Nechyporchuk, O., Bordes, R., \& Köhnke, T. (2017). Wet Spinning of Flame-Retardant Cellulosic Fibers Supported by Interfacial Complexation of Cellulose Nanofibrils with Silica Nanoparticles. ACS Applied Materials and Interfaces, 9(44), 39069-39077. https://doi.org/10.1021/acsami.7b13466

Nechyporchuk, O., Håkansson, K. M. O., Gowda.V, K., Lundell, F., Hagström, B., \& Köhnke, T. (2019). Continuous Assembly of Cellulose Nanofibrils and Nanocrystals into Strong Macrofibers through Microfluidic Spinning. Advanced Materials Technologies, 4(2), 1-10. https://doi.org/10.1002/admt.201800557

Niinivaara, E. (2016). 2-dimensional assembly of cellulose-based materials [Aalto University]. http://urn.fi/URN:ISBN:978-952-60-6674-5

Niinivaara, E., Faustini, M., Tammelin, T., \& Kontturi, E. (2015). Water vapor uptake of ultrathin films of biologically derived nanocrystals: Quantitative assessment with quartz crystal microbalance and spectroscopic ellipsometry. Langmuir, 31(44), 12170-12176. https://doi.org/10.1021/acs.langmuir.5b01763

Niinivaara, E., Faustini, M., Tammelin, T., \& Kontturi, E. (2016). Mimicking the Humidity Response of the Plant Cell Wall by Using Two-Dimensional Systems: The Critical Role of Amorphous and Crystalline Polysaccharides. Langmuir, 32(8), 2032-2040. https://doi.org/10.1021/acs.langmuir.5b04264

Niinivaara, E., \& Kontturi, E. (2014). 2D dendritic fractal patterns from an amphiphilic polysaccharide. Soft Matter, 10(11), 1801-1805. https://doi.org/10.1039/c3sm52946k

Niinivaara, E., Wilson, B. P., King, A. W. T., \& Kontturi, E. (2016). Parameters affecting monolayer organisation of substituted polysaccharides on solid substrates upon LangmuirSchaefer deposition. Reactive and Functional Polymers, 99, 100-106. https://doi.org/10.1016/j.reactfunctpolym.2015.12.010

Nishiyama, Y. (2018). Molecular interactions in nanocellulose assembly. Philosophical Transactions of the Royal Society of London A: Mathematical, Physical and Engineering Scienceshilosophical Transactions of the Royal Society A: Mathematical, Physical and Engineering Sciences, 376(2112). https://doi.org/10.1098/rsta.2017.0047

Nogi, M., Iwamoto, S., Nakagaito, A. N., \& Yano, H. (2009). Optically Transparent Nanofiber Paper. Advanced Materials, 21(16), 1595-1598. https://doi.org/10.1002/adma.200803174

Nordenström, M., Fall, A., Nyström, G., \& Wågberg, L. (2017). Formation of Colloidal Nanocellulose Glasses and Gels. Langmuir, 33(38), 9772-9780. https://doi.org/10.1021/acs.langmuir.7b01832

Notley, S. M., Eriksson, M., Wågberg, L., Beck-Candanedo, S., \& Gray, D. G. (2006). Surface Force Measurements of Spin-coated Thin Films with Different Crystallinity. Langmuir, 22(7), 3154-3160. https://doi.org/10.1021/la052886w 
Notley, S. M., Eriksson, M., Wågberg, L., Beck, S., \& Gray, D. G. (2006). Surface Forces Measurements of Spin-Coated Cellulose Thin Films with Different Crystallinity. Langmuir, 22(20), 3154-3160. https://doi.org/10.1021/la052886w

Notley, S. M., \& Norgren, M. (2006). Measurement of Interaction Forces between Lignin and Cellulose as a Function of Aqueous Electrolyte Solution Conditions. Langmuir, 22(26), 11199-11204. https://doi.org/10.1021/la0618566

Notley, S. M., Pettersson, B., Wa, L., \& Wågberg, L. (2004). Direct Measurement of Attractive van der Waals' Forces between Regenerated Cellulose Surfaces in an Aqueous Environment. Journal of the American Chemical Society, 126(43), 13930-13931. https://doi.org/https://doi.org/10.1021/ja045992d

O’Neill, J. J., \& Reichardt, E. P. (1951). US Patent 2,543,928, .

Oksman, K., \& Mathew, A. P. (2014). Melt Compounding Process of Cellulose Nanocomposites. In K. Oksman, A. P. Mathew, A. Bismarck, O. J. Rojas, \& M. Sain (Eds.), Handbook of Green Materials (p. 1124). World Scientific Publishing Co. https://doi.org/10.1142/9789814566469_0019

Or, T., Saem, S., Esteve, A., Osorio, D. A., De France, K. J., Vapaavuori, J., Hoare, T., Cerf, A., Cranston, E. D., \& Moran-Mirabal, J. M. (2019). Patterned Cellulose Nanocrystal Aerogel Films with Tunable Dimensions and Morphology. ACS Applied Nano Materials. https://doi.org/10.1021/acsanm.9b00640

Orelma, H., Filpponen, I., Johansson, L., Österberg, M., \& Rojas, O. J. (2012). Surface Functionalized Nanofibrillar Cellulose (NFC) Film as a Platform for Immunoassays and Diagnostics. Biointerphases, 7(61). https://doi.org/10.1007/s13758-012-0061-7

Osorio, D. A., Lee, B. E. J., Kwiecien, J. M., Wang, X., Shahid, I., Hurley, A. L., Cranston, E. D., \& Grandfield, K. (2019). Cross-linked cellulose nanocrystal aerogels as viable bone tissue scaffolds. Acta Biomaterialia, 87, 152-165. https://doi.org/10.1016/j.actbio.2019.01.049

Osorio, D. A., Seifried, B., Moquin, P., Grandfield, K., \& Cranston, E. D. (2018). Morphology of cross-linked cellulose nanocrystal aerogels : cryo-templating versus pressurized gas expansion processing. Journal of Materials Science, 53(13), 9829-9847. https://doi.org/10.1007/s10853-018-2235-2

Österberg, M., Vartiainen, J., Lucenius, J., Hippi, U., Seppälä, J., Serimaa, R., \& Laine, J. (2013). A fast method to produce strong NFC films as a platform for barrier and functional materials. ACS Applied Materials and Interfaces, 5(11), 4640-4647. https://doi.org/10.1021/am401046x

Ougiya, H., Watanabe, K., Morinaga, Y., \& Yoshinaga, F. (1997). Emulsion-stabilizing Effect of Bacterial Cellulose. Bioscience, Biotechnology and Biochemistry, 61(9), 1541-1545. https://doi.org/https://doi.org/10.1271/bbb.61.1541

Ouzas, A., Niinivaara, E., Cranston, E. D., \& Dubé, M. A. (2018). In Situ Semibatch Emulsion Polymerization of 2-Ethyl Hexyl Acrylate/n-Butyl Acrylate/Methyl Methacrylate/Cellulose Nanocrystal Nanocomposites for Adhesive Applications. Macromolecular Reaction 
Engineering, 12(3), 1-10. https://doi.org/10.1002/mren.201700068

Ouzas, A., Niinivaara, E., Cranston, E. D., \& Dubé, M. A. (2019). Synthesis of poly(isobutyl acrylate/n-butyl acrylate/methyl methacrylate)/CNC nanocomposites for adhesive applications via in situ semi-batch emulsion polymerization. Polymer Composites, 40(4), 1365-1377. https://doi.org/10.1002/pc.24869

Pääkko, M., Ankerfors, M., Kosonen, H., Nykänen, A., Ahola, S., Österberg, M., Ruokolainen, J., Laine, J., Larsson, P. T., Ikkala, O., Lindström, T., Pääkkö, M., Ankerfors, M., Kosonen, H., Nykänen, A., Ahola, S., Österberg, M., Ruokolainen, J., Laine, J., ... Lindström, T. (2007). Enzymatic hydrolysis combined with mechanical shearing and high-pressure homogenization for nanoscale cellulose fibrils and strong gels. Biomacromolecules, $8(6)$, 1934-1941. https://doi.org/10.1021/bm061215p

Pakdel, A. S., Gabriel, V., Berry, R. M., Fraschini, C., Cranston, E. D., \& Dubé, M. A. (2020). A sequential design approach for in situ incorporation of cellulose nanocrystals in emulsionbased pressure sensitive adhesives. Cellulose, 6. https://doi.org/10.1007/s10570-020-030606

Pan, J., Hamad, W., \& Straus, S. K. (2010). Parameters Affecting the Chiral Nematic Phase of Nanocrystalline Cellulose Films. Macromolecules, 43(8), 3851-3858. https://doi.org/10.1021/ma902383k

Parker, R. M., Frka-Petesic, B., Guidetti, G., Kamita, G., Consani, G., Abell, C., \& Vignolini, S. (2016). Hierarchical Self-Assembly of Cellulose Nanocrystals in a Confined Geometry. ACS Nano, 10(9), 8443-8449. https://doi.org/10.1021/acsnano.6b03355

Parker, R. M., Guidetti, G., Williams, C. A., Zhao, T., Narkevicius, A., Vignolini, S., \& FrkaPetesic, B. (2018). The Self-Assembly of Cellulose Nanocrystals: Hierarchical Design of Visual Appearance. Advanced Materials, 30(19), 1704477. https://doi.org/10.1002/adma.201704477

Paulraj, T., Riazanova, A. V., \& Svagan, A. J. (2018). Bioinspired capsules based on nanocellulose, xyloglucan and pectin - The influence of capsule wall composition on permeability properties. Acta Biomaterialia, 69, 196-205. https://doi.org/10.1016/j.actbio.2018.01.003

Peng, Y., Gardner, D. J., \& Han, Y. (2012). Drying cellulose nanofibrils : in search of a suitable method. Cellulose, 19(2012), 91-102. https://doi.org/10.1007/s10570-011-9630-z

Peng, Y., Gardner, D. J., \& Han, Y. (2015). Characterization of mechanical and morphological properties of cellulose reinforced polyamide 6 composites. Cellulose, 22(5), 3199-3215. https://doi.org/10.1007/s10570-015-0723-y

Peng, Y., Gardner, D. J., Han, Y., Kiziltas, A., Cai, Z., \& Tshabalala, M. a. (2013). Influence of drying method on the material properties of nanocellulose I: Thermostability and crystallinity. Cellulose, 20(5), 2379-2392. https://doi.org/10.1007/s10570-013-0019-z

Peng, Y., Han, Y., \& Gardner, D. J. (2012). Spray-drying cellulose nanofibrils: Effect of drying process parameters on particle morphology and size distribution. Wood and Fiber Science, 44(4), 1-14. 
Ping, Y., Chodavarapu, V. P., Kirk, A. G., \& Andrews, M. P. (2013). Sensors and Actuators B : Chemical Structured color humidity indicator from reversible pitch tuning in self-assembled nanocrystalline cellulose films. Sensors \& Actuators: B. Chemical, 176, 692-697. https://doi.org/10.1016/j.snb.2012.09.100

Rajala, S., Siponkoski, T., Sarlin, E., Mettänen, M., Vuoriluoto, M., Pammo, A., Juuti, J., Rojas, O. J., Franssila, S., \& Tuukkanen, S. (2016). Cellulose Nanofibril Film as a Piezoelectric Sensor Material. ACS Applied Materials and Interfaces, 8(24), 15607-15614. https://doi.org/10.1021/acsami.6b03597

Reid, M. S., Villalobos, M., \& Cranston, E. D. (2016). Cellulose nanocrystal interactions probed by thin film swelling to predict dispersibility. Nanoscale, 8(24), 12247-12257. https://doi.org/10.1039/c6nr01737a

Reid, M. S., Villalobos, M., \& Cranston, E. D. (2017). Benchmarking Cellulose Nanocrystals: From the Laboratory to Industrial Production. Langmuir, 33(7), 1583-1598. https://doi.org/10.1021/acs.langmuir.6b03765

Richard-Lacroix, M., \& Pellerin, C. (2013). Molecular orientation in electrospun fibers: From mats to single fibers. Macromolecules, 46(24), 9473-9493. https://doi.org/10.1021/ma401681m

Rofouie, P., Alizadehgiashi, M., Mundoor, H., Smalyukh, I. I., \& Kumacheva, E. (2018). SelfAssembly of Cellulose Nanocrystals into Semi-Spherical Photonic Cholesteric Films. Advanced Functional Materials, 1803852, 1803852. https://doi.org/10.1002/adfm.201803852

Rol, F., Belgacem, M. N., Gandini, A., \& Bras, J. (2019). Recent advances in surface-modified cellulose nanofibrils. Progress in Polymer Science, 88, 241-264. https://doi.org/10.1016/j.progpolymsci.2018.09.002

Roman, M. (2015). Toxicity of Cellulose Nanocrystals: A Review. Industrial Biotechnology, 11(1), 25-33. https://doi.org/10.1089/ind.2014.0024

Saha, P., Ansari, N., Kitchens, C. L., Ashurst, W. R., \& Davis, V. A. (2018). Microelectromechanical Systems from Aligned Cellulose Nanocrystal Films [Researcharticle]. ACS Applied Materials \& Interfaces, 10, 24116-24123. https://doi.org/10.1021/acsami.8b04985

Sani, A., \& Dahman, Y. (2010). Improvements in the production of bacterial synthesized biocellulose nanofibres using different culture methods. Journal of Chemical Technology and Biotechnology, 85(2), 151-164. https://doi.org/10.1002/jctb.2300

Schubert, D. W., \& Dunkel, T. (2003). Spin coating from a molecular point of view: its concentration regimes, influence of molar mass and distribution. Materials Research Innovations, 7(5), 314-321. https://doi.org/10.1007/s10019-003-0270-2

Sehaqui, H., Zhou, Q., Ikkala, O., \& Berglund, L. A. (2011). Strong and Tough Cellulose Nanopaper with High Specific Surface Area and Porosity. Biomacromolecules, 12(10), 3638-3644. https://doi.org/10.1021/bm2008907

Shanmugam, K., Doosthosseini, H., Varanasi, S., Garnier, G., \& Batchelor, W. (2018). Flexible 
spray coating process for smooth nanocellulose film production. Cellulose, 25(3), 17251741. https://doi.org/10.1007/s10570-018-1677-7

Shanmugam, K., Doosthosseini, H., Varanasi, S., Garnier, G., \& Batchelor, W. (2019). Nanocellulose films as air and water vapour barriers: A recyclable and biodegradable alternative to polyolefin packaging. Sustainable Materials and Technologies, 22. https://doi.org/10.1016/j.susmat.2019.e00115

Shanmugam, K., Varanasi, S., Garnier, G., \& Batchelor, W. (2017). Rapid preparation of smooth nanocellulose films using spray coating. Cellulose, 24(7), 2669-2676. https://doi.org/10.1007/s10570-017-1328-4

Shi, Q., Zhou, C., Yue, Y., Guo, W., Wu, Y., \& Wu, Q. (2012). Mechanical properties and in vitro degradation of electrospun bio-nanocomposite mats from PLA and cellulose nanocrystals. Carbohydrate Polymers, 90(1), 301-308.

https://doi.org/10.1016/j.carbpol.2012.05.042

Sixta, H., Michud, A., Hauru, L., Asaadi, S., Ma, Y., King, A. W. T., Kilpeläinen, I., \& Hummel, M. (2015). Ioncell-F: A high-strength regenerated cellulose fibre. Nordic Pulp and Paper Research Journal, 30(1), 43-57. https://doi.org/10.3183/npprj-2015-30-01-p043-057

Stiernstedt, J., Nordgren, N., Wågberg, L., Brumer, H., Gray, D. G., \& Rutland, M. W. (2006). Friction and forces between cellulose model surfaces: A comparison. Journal of Colloid and Interface Science, 303(1), 117-123. https://doi.org/10.1016/j.jcis.2006.06.070

Sugiyama, J., Chanzy, H., \& Maret, G. (1992). Orientation of Cellulose Microcrystals by Strong Magnetic Fields. Macromolecules, 25(16), 4232-4234. https://doi.org/10.1021/ma00042a032

Sun, X., Wu, Q., Zhang, X., Ren, S., Lei, T., Li, W., Xu, G., \& Zhang, Q. (2018). Nanocellulose films with combined cellulose nanofibers and nanocrystals: tailored thermal, optical and mechanical properties. Cellulose, 25, 1103-1115.

Supramaniam, J., Rohana, A., Haida, N. K. M., \& Bushra, R. (2018). Magnetic nanocellulose alginate hydrogel beads as potential drug delivery system. International Journal of Biological Macromolecules, 118, 640-648. https://doi.org/https://doi.org/10.1016/j.ijbiomac.2018.06.043

Svagan, A. J., Bender Koch, C., Hedenqvist, M. S., Nilsson, F., Glasser, G., Baluschev, S., \& Andersen, M. L. (2016). Liquid-core nanocellulose-shell capsules with tunable oxygen permeability. Carbohydrate Polymers, 136, 292-299. https://doi.org/10.1016/j.carbpol.2015.09.040

Svagan, A. J., Musyanovych, A., Kappl, M., Bernhardt, M., Glasser, G., Wohnhaas, C., Berglund, L. A., Risbo, J., \& Landfester, K. (2014). Cellulose nanofiber/nanocrystal reinforced capsules: A fast and facile approach toward assembly of liquid-core capsules with high mechanical stability. Biomacromolecules, 15(5), 1852-1859. https://doi.org/10.1021/bm500232h

Teramoto, Y. (2020). Material development using the inherent features of nano-cellulose and nano-chitin: Necessity of simple processes and cross-disciplinary collaboration. Advanced 
Powder Technology, 31(2), 528-532. https://doi.org/10.1016/j.apt.2019.11.009

Tran, A., Boott, C. E., \& MacLachlan, M. J. (2020). Understanding the Self-Assembly of Cellulose Nanocrystals - Toward Chiral Photonic Materials. Advanced Materials, 1905876, 1-15. https://doi.org/10.1002/adma.201905876

Tumarkin, E., \& Kumacheva, E. (2009). Microfluidic generation of microgels from synthetic and natural polymers. Chemical Society Reviews, 38(8), 2161-2168.

https://doi.org/10.1039/b809915b

Uddin, A. J., Araki, J., \& Gotoh, Y. (2011). Toward "Strong” sreen nanocomposites: Polyvinyl alcohol reinforced with extremely oriented cellulose whiskers. Biomacromolecules, 12(3), 617-624. https://doi.org/10.1021/bm101280f

Uetani, K., \& Yano, H. (2013). Self-organizing capacity of nanocelluloses via droplet evaporation $\dagger$. Soft Matter, 9(12), 3396-3401. https://doi.org/10.1039/c3sm27822k

Ure, E. E., Ao, G., Davis, V. A., \& Kitchens, C. L. (2011). Rheology and Phase Behavior of Lyotropic Cellulose Nanocrystal Suspensions. Macromolecules, 44(22), 8990-8998. https://doi.org/10.1021/ma201649f

Vallejos, M. E., Peresin, M. S., \& Rojas, O. J. (2012). All-Cellulose Composite Fibers Obtained by Electrospinning Dispersions of Cellulose Acetate and Cellulose Nanocrystals. Journal of Polymers and the Environment, 20(4), 1075-1083. https://doi.org/10.1007/s10924-0120499-1

Vehring, R. (2008). Pharmaceutical particle engineering via spray drying. Pharmaceutical Research, 25(5), 999-1022. https://doi.org/10.1007/s11095-007-9475-1

Verwey, E. J. W., \& Overbeek, J. T. G. (1955). Theory of the stability of lyophobic colloids. In Journal of Colloid Science (Vol. 10, Issue 2). Elsevier. https://doi.org/10.1016/00958522(55)90030-1

Villares, A., Moreau, C., Dammak, A., Capron, I., \& Cathala, B. (2015). Kinetic aspects of the adsorption of xyloglucan onto cellulose nanocrystals. Soft Matter, 11(32), 6472-6481. https://doi.org/10.1039/c5sm01413a

Voisin, H., Bergström, L., Liu, P., \& Mathew, A. P. (2017). Nanocellulose-based materials for water purification. Nanomaterials, 7(3). https://doi.org/10.3390/nano7030057

Wågberg, L., Decher, G., Norgren, M., Lindström, T., Ankerfors, M., \& Axnäs, K. (2008). The build-up of polyelectrolyte multilayers of microfibrillated cellulose and cationic polyelectrolytes. Langmuir, 24(3), 784-795. https://doi.org/10.1021/la702481v

Walther, A., Timonen, J. V. I., Díez, I., Laukkanen, A., \& Ikkala, O. (2011). Multifunctional high-performance biofibers based on wet-extrusion of renewable native cellulose nanofibrils. Advanced Materials, 23(26), 2924-2928. https://doi.org/10.1002/adma.201100580

Wang, H., Kong, L., \& Ziegler, G. R. (2019). Fabrication of starch - Nanocellulose composite fibers by electrospinning. Food Hydrocolloids, 90(November 2018), 90-98. https://doi.org/10.1016/j.foodhyd.2018.11.047 
Wang, K., Nune, K. C., \& Misra, R. D. K. (2016). Acta Biomaterialia The functional response of alginate-gelatin-nanocrystalline cellulose injectable hydrogels toward delivery of cells and bioactive molecules. Acta Biomaterialia, 36, 143-151.

https://doi.org/10.1016/j.actbio.2016.03.016

Wang, Y., \& Chen, L. (2011). Impacts of nanowhisker on formation kinetics and properties of all-cellulose composite gels. Carbohydrate Polymers, 83(4), 1937-1946. https://doi.org/10.1016/j.carbpol.2010.10.071

Wei, B., Li, H., Li, Q., Wen, Y., Sun, L., Wei, P., Pu, W., \& Li, Y. (2017). Stabilization of Foam Lamella Using Novel Surface-Grafted Nanocellulose-Based Nanofluids. Langmuir, 33(21), 5127-5139. https://doi.org/10.1021/acs.langmuir.7b00387

Wei, J., Chen, Y., Liu, H., Du, C., Yu, H., \& Zhou, Z. (2016). Thermo-responsive and compression properties of TEMPO-oxidized cellulose nanofiber-modified PNIPAm hydrogels. Carbohydrate Polymers, 147, 201-207. https://doi.org/10.1016/j.carbpol.2016.04.015

Wicklein, B., Kocjan, A., Salazar-Alvarez, G., Carosio, F., Camino, G., Antonietti, M., \& Bergström, L. (2015). Thermally insulating and fire-retardant lightweight anisotropic foams based on nanocellulose and graphene oxide. Nature Nanotechnology, 10(3), 277-283. https://doi.org/10.1038/nnano.2014.248

Winuprasith, T., \& Suphantharika, M. (2015). Properties and stability of oil-in-water emulsions stabilized by microfibrillated cellulose from mangosteen rind. Food Hydrocolloids, 43, 690-699. https://doi.org/10.1016/j.foodhyd.2014.07.027

Xhanari, K., Syverud, K., Chinga-Carrasco, G., Paso, K., \& Stenius, P. (2011). Structure of nanofibrillated cellulose layers at the $\mathrm{o} / \mathrm{w}$ interface. Journal of Colloid and Interface Science, 356(1), 58-62. https://doi.org/10.1016/j.jcis.2010.12.083

Xu, M., Li, W., Ma, C., Yu, H., Wu, Y., Wang, Y., Chen, Z., Li, J., \& Liu, S. (2018). Multifunctional chiral nematic cellulose nanocrystals/glycerol structural colored nanocomposites for intelligent responsive films, photonic inks and iridescent coatings. Journal of Materials Chemistry C, 6(20), 5391-5400. https://doi.org/10.1039/c8tc01321g

Xu, S., Nie, Z., Seo, M., Lewis, P., Kumacheva, E., Stone, H. A., Garstecki, P., Weibel, D. B., Gitlin, I., \& Whitesides, G. M. (2005). Generation of Monodisperse Particles by Using Microfluidics: Control over Size, Shape, and Composition. Angewandte Chemie, 117(5), 734-738. https://doi.org/10.1002/ange.200462226

Xu, X., Zhou, J., Jiang, L., Lubineau, G., Ng, T., Ooi, B. S., Liao, H. Y., Shen, C., Chen, L., \& Zhu, J. Y. (2016). Highly transparent, low-haze, hybrid cellulose nanopaper as electrodes for flexible electronics. Nanoscale, 8(24), 12294-12306. https://doi.org/10.1039/c6nr02245f

Yang, J., Han, C. R., Duan, J. F., Ma, M. G., Zhang, X. M., Xu, F., \& Sun, R. C. (2013). Synthesis and characterization of mechanically flexible and tough cellulose nanocrystalspolyacrylamide nanocomposite hydrogels. Cellulose, 20(1), 227-237.

https://doi.org/10.1007/s10570-012-9841-y

Yang, J., Han, C. R., Xu, F., \& Sun, R. C. (2014). Simple approach to reinforce hydrogels with 
cellulose nanocrystals. Nanoscale, 6(11), 5934-5943. https://doi.org/10.1039/c4nr01214c

Yang, X., \& Cranston, E. D. (2014). Chemically cross-linked cellulose nanocrystal aerogels with shape recovery and superabsorbent properties. Chemistry of Materials, 26(20), 6016-6025. https://doi.org/10.1021/cm502873c

Yang, X., Shi, K., Zhitomirsky, I., \& Cranston, E. D. (2015). Cellulose Nanocrystal Aerogels as Universal 3D Lightweight Substrates for Supercapacitor Materials. Advanced Materials, 27(40), 6104-6109. https://doi.org/10.1002/adma.201502284

Ye, C., Malak, S. T., Hu, K., Wu, W., \& Tsukruk, V. V. (2015). Cellulose Nanocrystal Microcapsules as Tunable Cages for Nano- and Microparticles. ACS Nano, 9(11), 1088710895. https://doi.org/10.1021/acsnano.5b03905

Yoo, Y., Martinez, C., \& Youngblood, J. P. (2017). Sustained Dye Release Using Poly(ureaurethane)/Cellulose Nanocrystal Composite Microcapsules. Langmuir, 33(6), 1521-1532. https://doi.org/10.1021/acs.langmuir.6b04628

Zhang, H., Lyu, S., Zhou, X., Gu, H., Ma, C., Wang, C., Ding, T., Shao, Q., Liu, H., \& Guo, Z. (2019). Super light 3D hierarchical nanocellulose aerogel foam with superior oil adsorption. Journal of Colloid and Interface Science, 536, 245-251. https://doi.org/10.1016/j.jcis.2018.10.038

Zhang, K., \& Liimatainen, H. (2018). Hierarchical Assembly of Nanocellulose-Based Filaments by Interfacial Complexation. Small, 14(38), 1-9. https://doi.org/10.1002/smll.201801937

Zhang, Y., Zhao, Q., Wang, H., Jiang, X., \& Cha, R. (2017). Preparation of green and gelatinfree nanocrystalline cellulose capsules. Carbohydrate Polymers, 164, 358-363. https://doi.org/10.1016/j.carbpol.2017.01.096

Zheng, G., Cui, Y., Karabulut, E., Wågberg, L., Zhu, H., \& Hu, L. (2013). Nanostructured paper for flexible energy and electronic devices. MRS Bulletin, 38(4), 320-325. https://doi.org/10.1557/mrs.2013.59

Zhou, Q., Malm, E., Nilsson, H., Larsson, P. T., Iversen, T., Berglund, L. A., \& Bulone, V. (2009). Nanostructured biocomposites based on bacterial cellulosic nanofibers compartmentalized by a soft hydroxyethylcellulose matrix coating. Soft Matter, 5(21), 4124-4130. https://doi.org/10.1039/b907838j

Zhou, Yiming, Fu, S., Zhang, L., \& Zhan, H. (2013). Superabsorbent nanocomposite hydrogels made of carboxylated cellulose nanofibrils and CMC-g-p(AA-co-AM). Carbohydrate Polymers, 97(2), 429-435. https://doi.org/10.1016/j.carbpol.2013.04.088

Zhou, Yiming, Fu, S., Zhang, L., Zhan, H., \& Levit, M. V. (2014). Use of carboxylated cellulose nanofibrils-filled magnetic chitosan hydrogel beads as adsorbents for $\mathrm{Pb}(\mathrm{II})$. Carbohydrate Polymers, 101(1), 75-82. https://doi.org/10.1016/j.carbpol.2013.08.055

Zhou, Yinhua, Fuentes-Hernandez, C., Khan, T. M., Liu, J. C., Hsu, J., Shim, J. W., Dindar, A., Youngblood, J. P., Moon, R. J., \& Kippelen, B. (2013). Recyclable organic solar cells on cellulose nanocrystal substrates. Scientific Reports, 3(1), 24-26.

https://doi.org/10.1038/srep01536 
Zhu, H., Yang, X., Cranston, E. D., \& Zhu, S. (2016). Flexible and Porous Nanocellulose Aerogels with High Loadings of Metal-Organic-Framework Particles for Separations Applications. Advanced Materials, 28(35), 7652-7657.

https://doi.org/10.1002/adma.201601351

Zhu, Z., Fu, S., \& Lucia, L. A. (2019). Tuning the Morphology of Microparticles from Spray Drying of Cellulose Nanocrystal Suspensions by Hydrophobic Lignin [Research-article]. ACS Sustainable Chemistry and Engineering, 7(5), 5376-5384. https://doi.org/10.1021/acssuschemeng.8b06399

Zoppe, J. O., Larsson, P. A., \& Cusola, O. (2020). Surface Modification of Nanocellulosics and Functionalities. In I. Filpponen, M. S. Peresin, \& T. Nypelö (Eds.), Lignocellulosics Renewable Feedstock for (Tailored) Functional Materials and Nanotechnology (pp. 17-63). Elsevier. 
a) Spray dried CNC powder from suspension

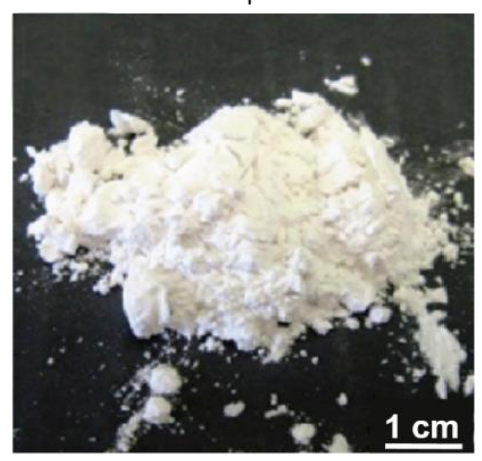

d) Freeze dried CNC flakes from suspension

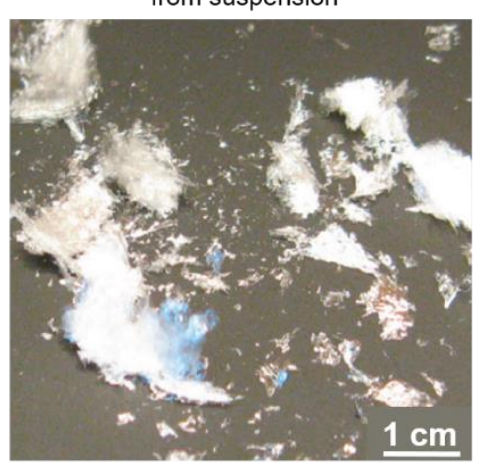

b) Spray dried CNC powder

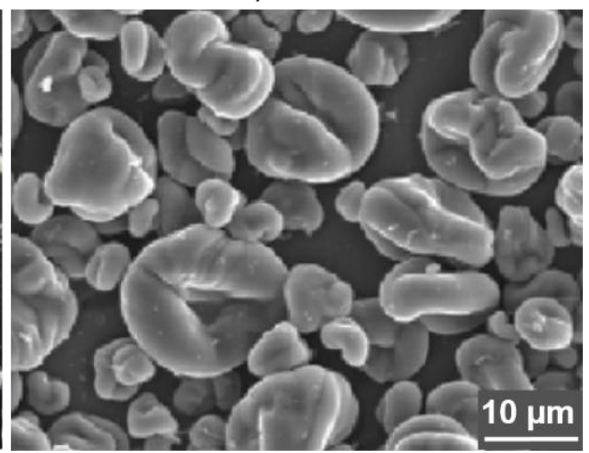

e) Formation of CNC droplets in microfluidic device c) Spray dried CNF powder

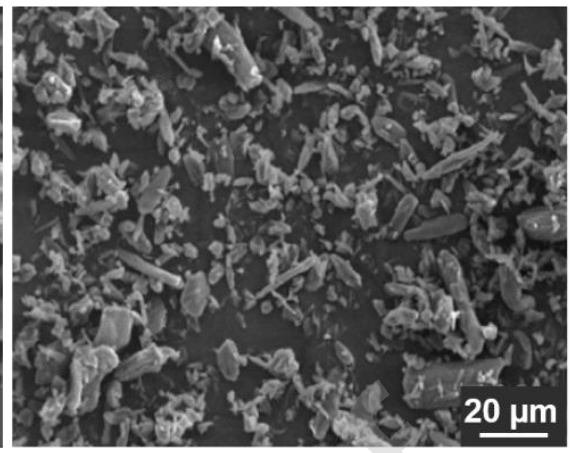

f) Dried CNF

bead

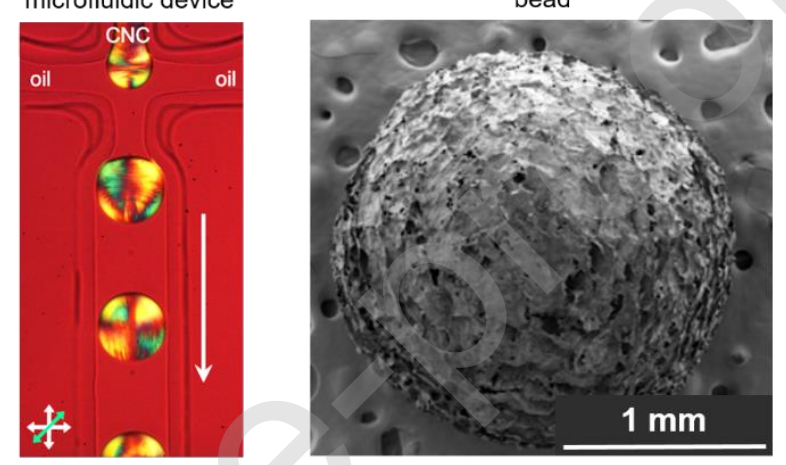

Figure 1. Photograph of a) a spray-dried CNC powder (dried from suspension) and scanning electron micrographs of spray dried b) CNC powder (Reprinted (adapted) with permission from (Beck et al., 2012). Copyright 2012 American Chemical Society), and c) CNF power (Reprinted (adapted) from (Peng, Han, et al., 2012). A photograph of d) freeze- dried CNC flakes (dried from suspension) (Reprinted (adapted) with permission from (Beck et al., 2012). Copyright 2012 American Chemical Society). Microfluidic devices are a common way to confine nanocellulose into droplets as shown in e) where CNC droplets are generated in a continuous oil phase inducing orientation of CNCs visible as blue and yellow domains in the polarized optical microscope (Reprinted (adapted) with permission from (Parker et al., 2016). Copyright 2016 American Chemical Society). Droplets of CNF suspensions can be dried to form $\mathrm{f}$ ) dried beads (Reprinted from (Erlandsson et al., 2016), Copyright 2016, with permission from Elsevier). 
a) Schematic CNC capsule

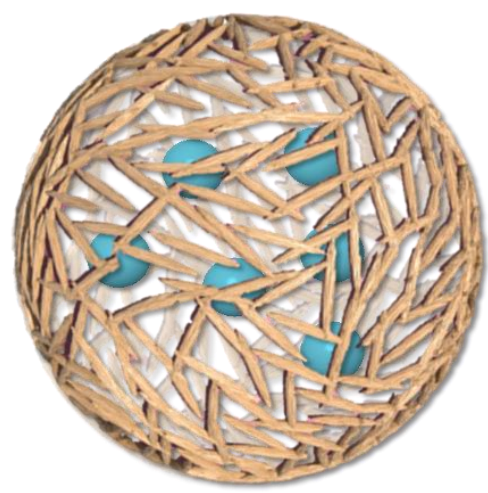

b) CNC nanocomposite capsule

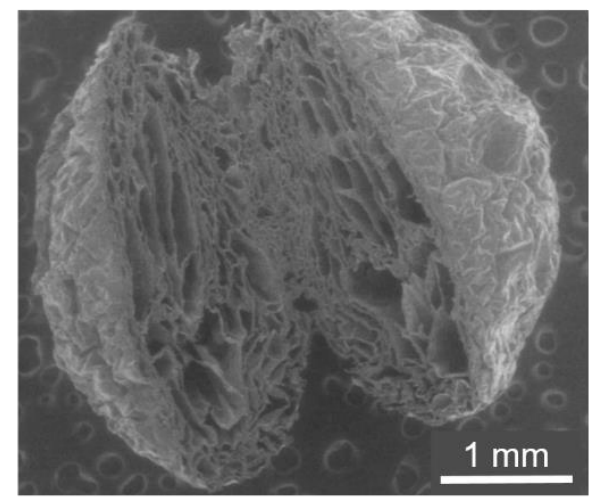

c) CNF/CNC nanocomposite capsule

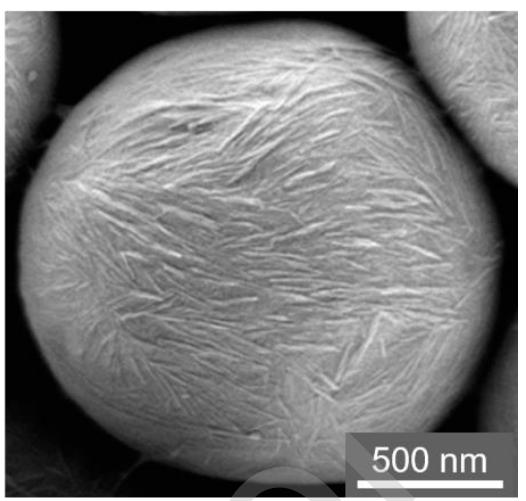

Figure 2. a) Schematic representation of a CNC capsule; scanning electron micrographs of b) an alginate/CNC nanocomposite capsule (adapted from reference (Lemahieu et al., 2011) Copyright (C) 2011 WILEY - VCH Verlag GmbH \& Co. KgaA, Weinheim) and c) a CNF/CNC nanocomposite capsule (Reprinted (adapted) with permission from (Svagan et al., 2014) Copyright 2014 American Chemical Society). 

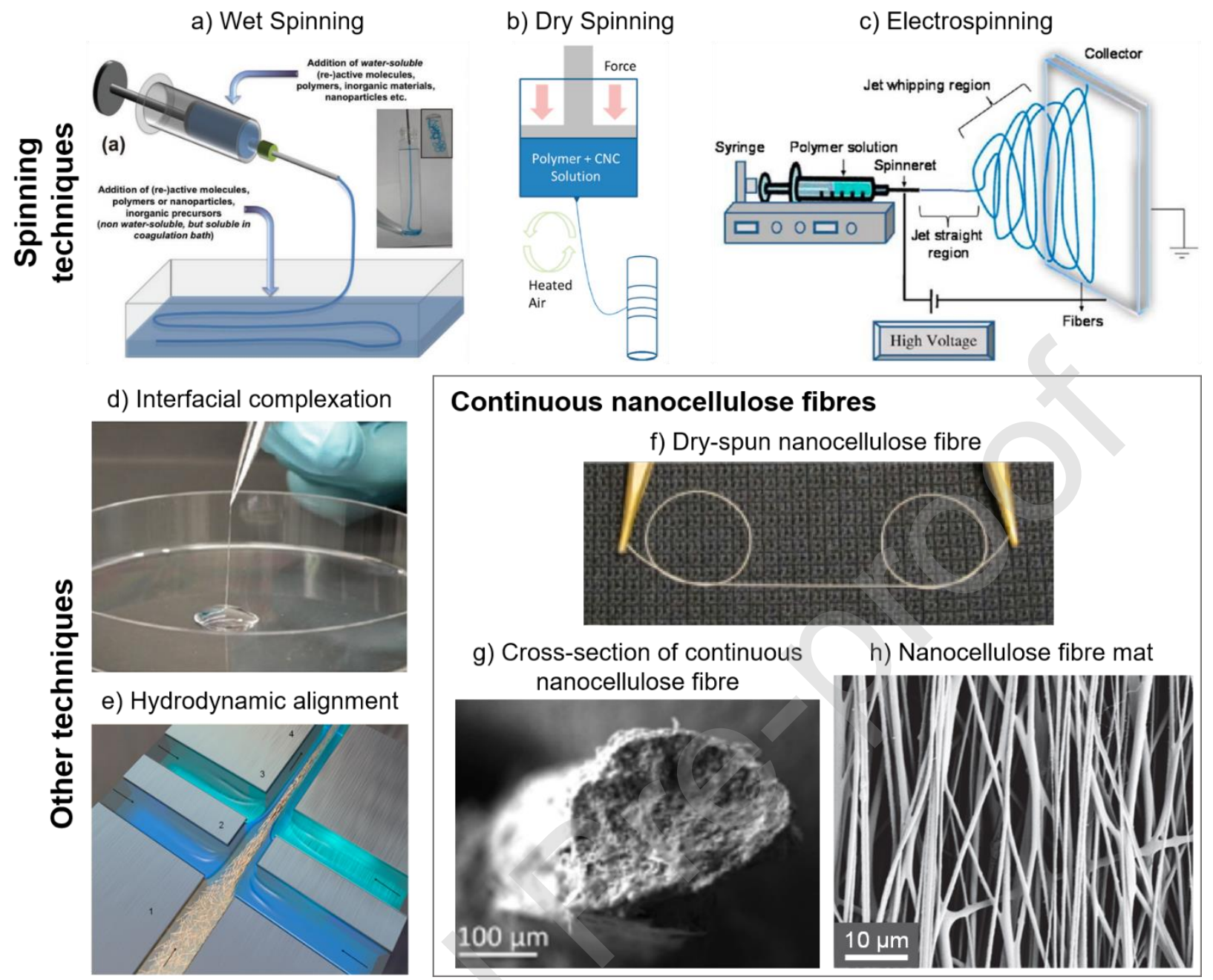

g) Cross-section of continuous

h) Nanocellulose fibre mat
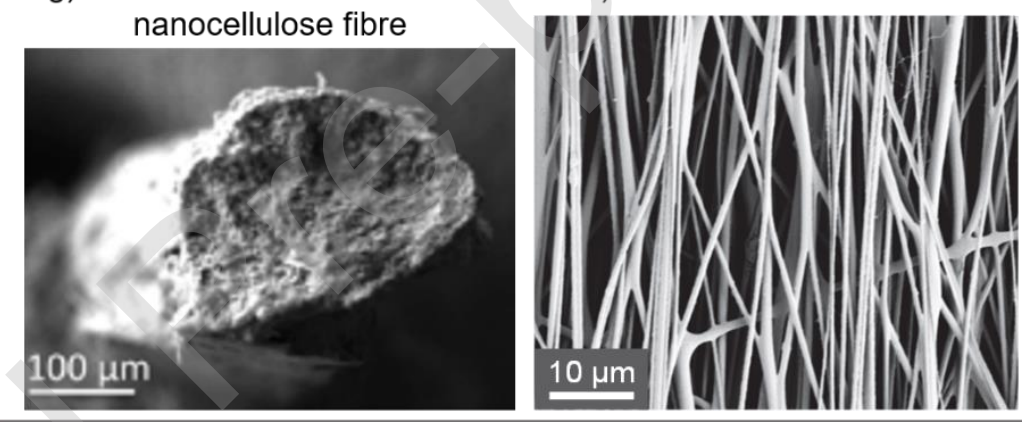

Figure 3. Schematic representations of three main spinning techniques a) wet spinning (adapted from reference (Walther et al., 2011) Copyright (C) 2011 WILEY- VCH Verlag GmbH \& Co. KgaA, Weinheim), b) dry spinning (Reprinted (adapted) with permission from (S. Chen et al., 2014) Copyright 2014 American Chemical Society), and c) electrospinning (Reprinted (adapted) with permission from (Richard-Lacroix \& Pellerin, 2013) Copyright 2013 American Chemical Society), d) a photograph of the pulling of a fibre through interfacial complexation (adapted from reference (K. Zhang \& Liimatainen, 2018) (C) 2018 WILEY- VCH Verlag GmbH \& Co. KgaA, Weinheim), and e) hydrodynamic alignment (Reprinted (adapted) with permission from (Mittal et al., 2018) Copyright 2015 American Chemical Society) used to prepare nanocellulose-based continuous fibres. Along with $\mathrm{f}$ ) a photograph of a dry spun continuous nanocellulose fibre,g) a scanning electron micrograph of its cross-section (Reprinted (adapted) with permission from (Hooshmand et al., 2015) Copyright 2018 American Chemical Society) and h) a scanning electron micrograph of an electrospun nanocellulose fibre mat (This work is licensed under the Creative Commons Attribution 4.0 International License. To view a copy of this license, visit http://creativecommons.org/licenses/by/4.0/ or send a letter to Creative Commons, PO Box 1866, Mountain View, CA 94042, USA) (Clemons, 2016). 
a) Dip coating

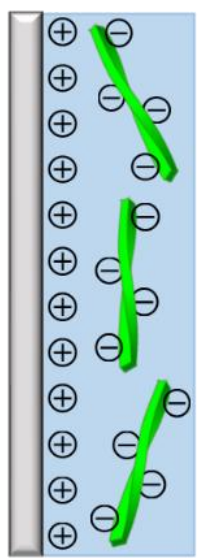

c) Spin coating b) Langmuir deposition

Horizontal Langmuir-Schaefer Deposition
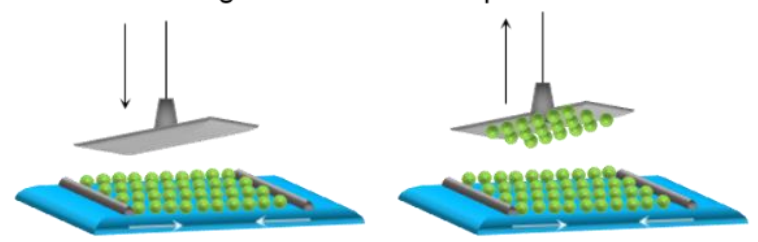

Vertical Langmuir-Blodgett Deposition

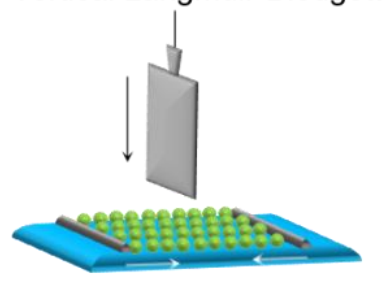

d) Bar coating

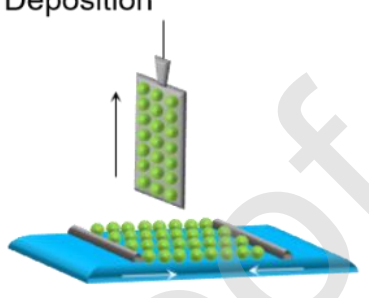

Direction of coating

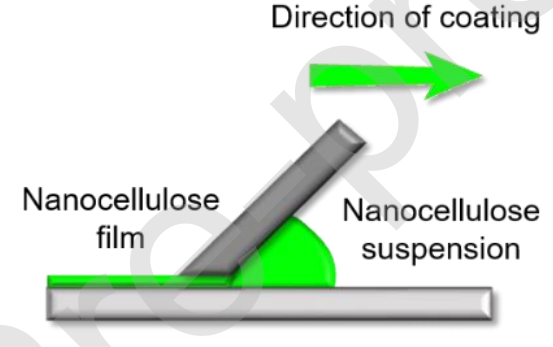

Substrate

Figure 4. Schematic representation of nanocellulose thin film deposition on to a substrate through a) dip coating, b) horizontal Langmuir deposition (Langmuir-Schaefer deposition) and vertical Langmuir deposition (Langmuir-Blodgett deposition) (Reprinted from (Niinivaara, Wilson, et al., 2016), Copyright 2015, with permission from Elsevier), c) spin coating (Reprinted from (Niinivaara, 2016)), and d) bar coating. 
a) Transparent polished

CNF film

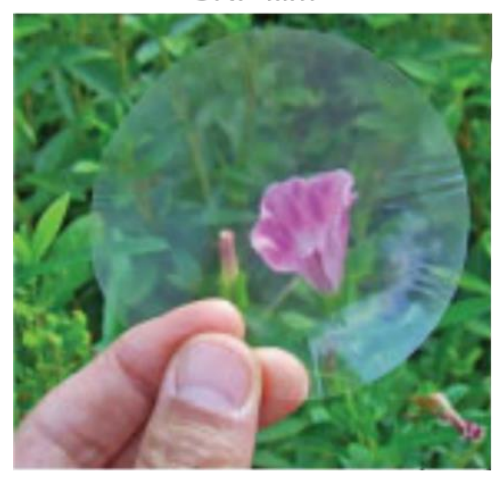

d) Spin coated supported CNF and $\mathrm{CNC}$ thin films b) Cross-sectional micrograph of CNF film

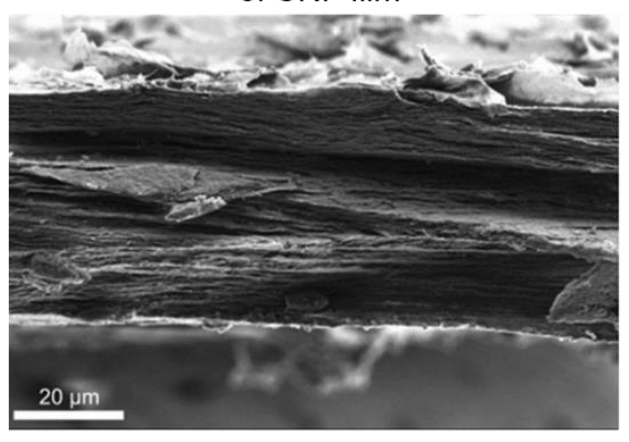

c) Flexible $\mathrm{CNC} /$ polyethylene glycol composite film

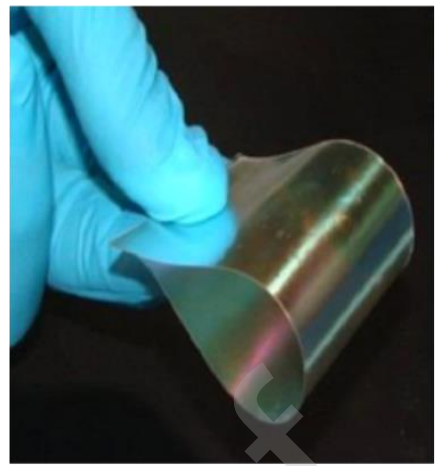

e) Chiral nematic CNC butterflies with crosssectional micrograph of self-assembled CNC film

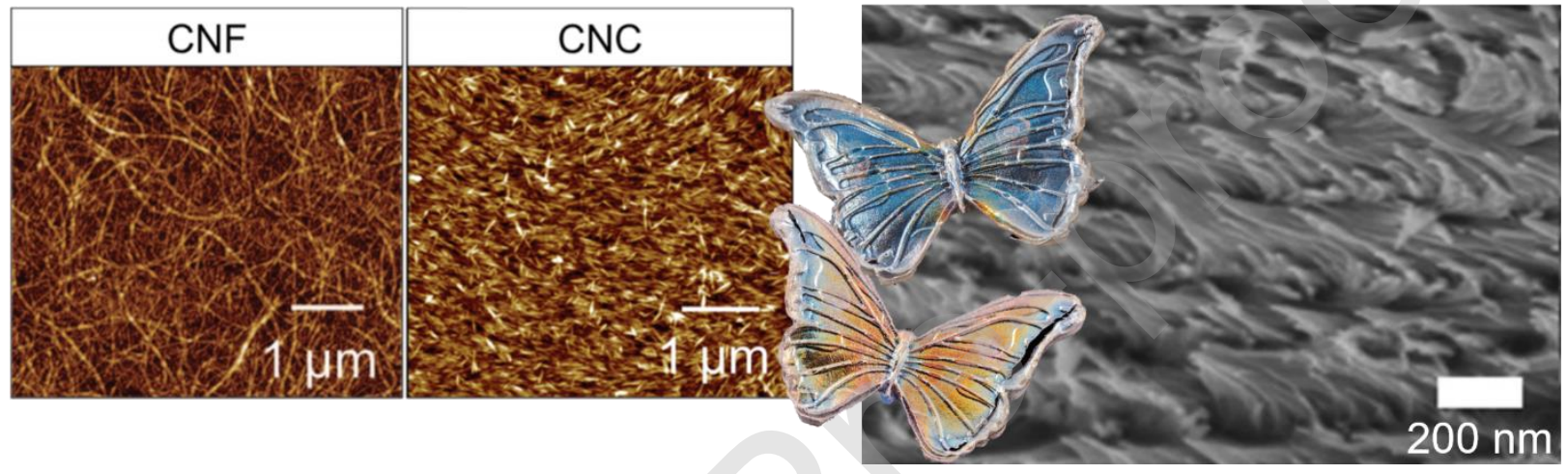

Figure 5. a) Photograph of a transparent polished CNF film (adapted from reference (Nogi et al., 2009) Copyright (C) 2009 WILEY- VCH Verlag GmbH \& Co. KgaA, Weinheim), b) scanning electron micrograph of the cross section of a representative CNF film (Reprinted (adapted) with permission from (Rajala et al., 2016) Copyright 2015 American Chemical Society), c) photograph of a flexible CNC/polyethylene glycol composite film (Reprinted (adapted) with permission from (Bardet et al., 2015) Copyright 2015 American Chemical Society), d) atomic force microscopy topography images of representative spin coated CNF and CNC films (Reprinted with permission of Royal Society of Chemistry, from (Foster et al., 2018) 2018; permission conveyed through Copyright Clearance Center, Inc.) and e) scanning electron micrograph of a self-assembled chiral nematic CNC film (adapted from reference (Guidetti et al., 2016) (C) 2016 The Authors. Published by WILEY - VCH Verlag GmbH \& Co. KgaA, Weinheim) with photographs of iridescent butterflies made from chiral nematic CNC films (adapted from (Blonder et al., 2017)). 


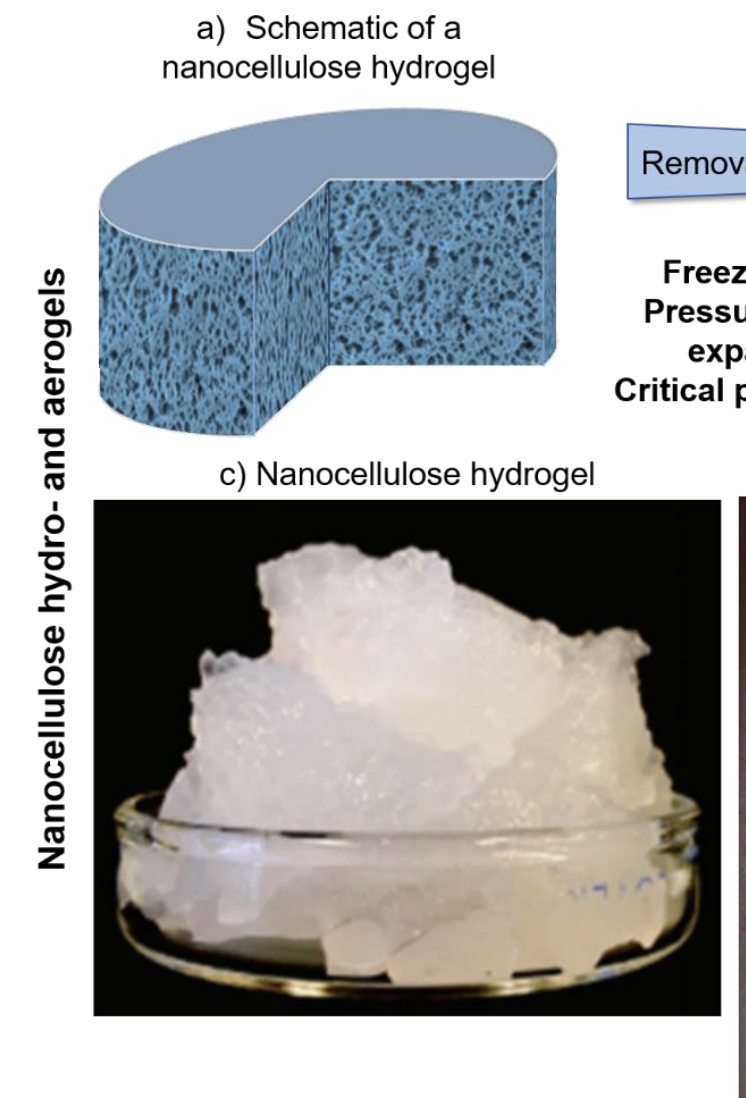

a) Schematic of a nanocellulose hydrogel

을

g) Dry nanocellulose foam

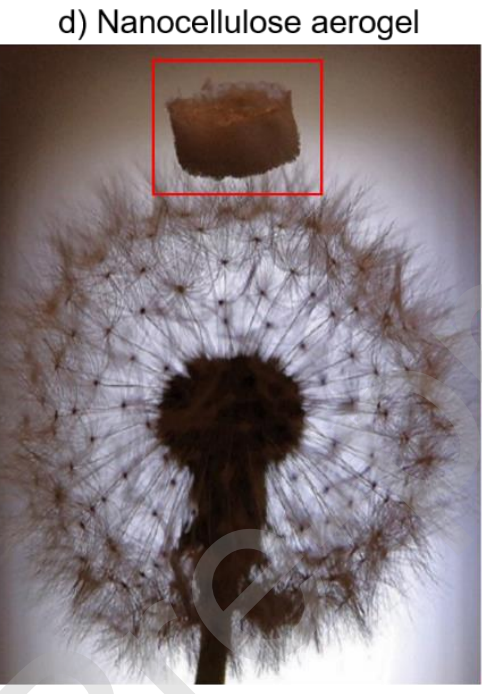

e) Cross-sectional view of nanocellulose aerogel

b) Schematic of a

nanocellulose aerogel
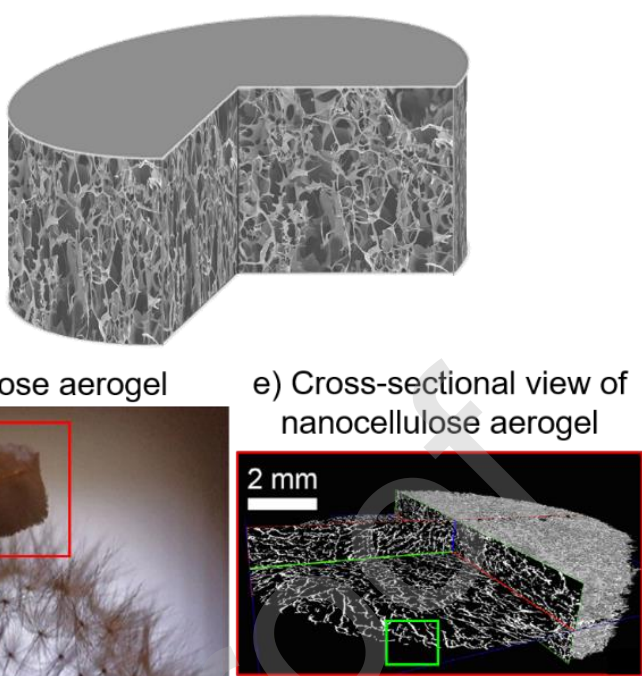

f) Micrograph of aerogel mesopore structure

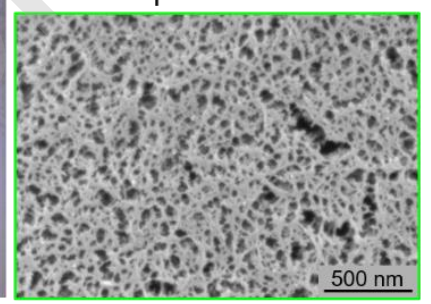

h) Wet nanocellulose foam
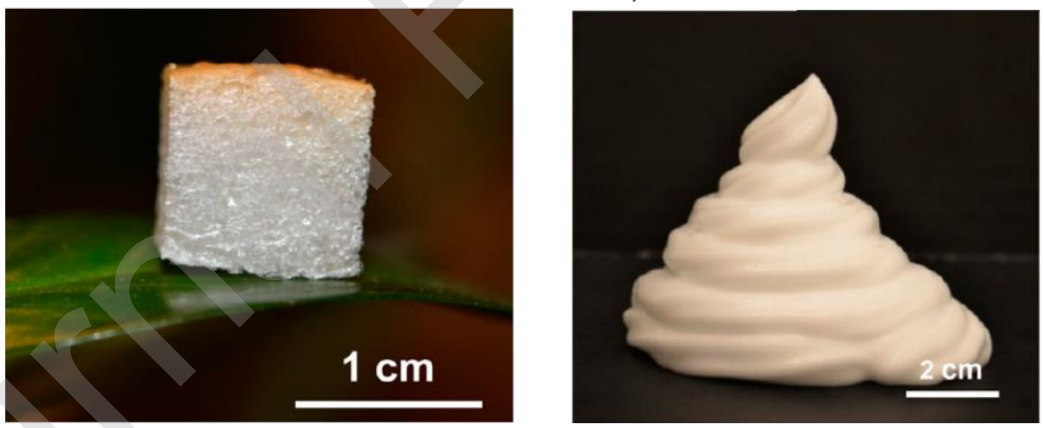

Figure 6. Schematic representation of a) a nanocellulose hydrogel and b) a nanocellulose aerogel listing methods to remove water from a hydrogel, and photographs of c) a nanocellulose hydrogel of high solids content (Republished with permission of Royal Society of Chemistry, from (Foster et al., 2018) 2018; permission conveyed through Copyright Clearance Center, Inc.) and d) a nanocellulose aerogel resting on a dandelion (Reprinted (adapted) with permission from (X. Yang \& Cranston, 2014) Copyright 2014 American Chemical Society). Panel e) shows a xray micro computed tomography scan of a nanocellulose aerogel (Reprinted from (Osorio et al., 2019), Copyright 2019, with permission from Elsevier) and f) a scanning electron micrograph of the mesopore structure of a nanocellulose aerogel sheet. Also shown are photographs of a g) dried nanocellulose foam and $\mathrm{h}$ ) a wet nanocellulose foam (or aqueous precursor foam) 
(Reprinted (adapted) with permission from (Cervin et al., 2016) Copyright 2014 American Chemical Society). 
Table 1. Bottom-up assembled nanocellulose-only (or primarily nanocellulose) structures: ordered from discrete particles to bulk nanostructured materials including their most common characteristic dimension and approximate size, methods of assembly, current research directions and potential applications. ${ }^{* * *}$

\begin{tabular}{|c|c|c|c|}
\hline $\begin{array}{l}\text { Assembled } \\
\text { Structure }\end{array}$ & $\begin{array}{l}\text { Characteristic } \\
\text { Dimension }\end{array}$ & Methods of Assembly & $\begin{array}{l}\text { Current Research Directions } \\
\text { and Potential Applications }\end{array}$ \\
\hline $\begin{array}{l}\text { 1. Powders, } \\
\text { beads, } \\
\text { droplets }\end{array}$ & $\begin{array}{l}\text { Radius } \\
(\mu \mathrm{m})\end{array}$ & $\begin{array}{l}\text { Spray drying, spray freeze } \\
\text { drying, super } \\
\text { critical/expanded gas drying, } \\
\text { microfluidics }\end{array}$ & $\begin{array}{l}\text { Understanding drying/redispersion of } \\
\text { nanocellulose, self-assembly in } \\
\text { confined geometries, hybrid/composite } \\
\text { materials, master batching, plastic } \\
\text { microbeads, chromatography, } \\
\text { controlled release, sorbents, } \\
\text { components for energy devices }\end{array}$ \\
\hline 2. Capsules & $\begin{array}{l}\text { Radius } \\
(\mathrm{nm}-\mathrm{mm})\end{array}$ & $\begin{array}{l}\text { Interfacial reactions or } \\
\text { heterogeneous } \\
\text { polymerization, layer-by-layer } \\
\text { deposition, biofabrication }\end{array}$ & $\begin{array}{l}\text { Controlled drug release, cell scaffolds, } \\
\text { pharmaceutical encapsulation, } \\
\text { separation technologies }\end{array}$ \\
\hline $\begin{array}{l}\text { Contir } \\
\text { fibres }\end{array}$ & $\begin{array}{l}\text { Cross-section } \\
(\mu \mathrm{m})\end{array}$ & $\begin{array}{l}\text { Microfluidic devices, flow- } \\
\text { focusing channel systems, } \\
\text { electrospinning/spraying, } \\
\text { wet-spinning, dry spinning, } \\
\text { wet-extrusion }\end{array}$ & $\begin{array}{l}\text { Super-strong fibre assemblies, } \\
\text { reinforcing fibres for composite } \\
\text { materials, textiles }\end{array}$ \\
\hline 4. Films & $\begin{array}{l}\text { Thickness } \\
\text { Supported } \\
(\mathrm{nm}-\mu \mathrm{m}) \\
\text { Free-standing } \\
(\mu \mathrm{m}-\mathrm{mm})\end{array}$ & $\begin{array}{l}\text { Drop casting, dip coating, } \\
\text { Langmuir deposition, bar } \\
\text { coating, spin coating, } \\
\text { (ultra)filtration }\end{array}$ & $\begin{array}{l}\text { Model surfaces, chiral nematic films } \\
\text { and templates, barrier and coating } \\
\text { materials, advanced functional } \\
\text { materials, optical devices, sensors, } \\
\text { packaging, templates, membranes, } \\
\text { filters }\end{array}$ \\
\hline $\begin{array}{l}\text { 5. Hydrogels } \\
\text { (wet) }\end{array}$ & $\begin{array}{l}\text { Crosslink } \\
\text { density } \\
\left(\mathrm{mol} / \mathrm{m}^{3}\right)\end{array}$ & $\begin{array}{l}\text { Physical entanglement, } \\
\text { forced gelation, } \\
\text { physical/chemical } \\
\text { crosslinking }\end{array}$ & $\begin{array}{l}\text { Drug delivery systems, cell and } \\
\text { biomolecule transportation systems, } \\
\text { biomimetic scaffolds, absorbents, } \\
\text { biomedical devices, rheological } \\
\text { modifiers for oil and gas extraction, } \\
\text { food, cosmetics }\end{array}$ \\
\hline $\begin{array}{l}\text { 6. Aerogels } \\
\text { and foams } \\
\text { (dry) }\end{array}$ & $\begin{array}{l}\text { Pore size } \\
(\mu \mathrm{m})\end{array}$ & $\begin{array}{l}\text { Freeze drying, critical point } \\
\text { drying (CPD), cryo- } \\
\text { templating, pressurized gas } \\
\text { expansion (PGX) processing, } \\
\text { oven drying }\end{array}$ & $\begin{array}{l}\text { Support/template structures, sorbents, } \\
\text { sound and thermal insulators, hygiene } \\
\text { products, components for energy } \\
\text { devices, tissue engineering scaffolds }\end{array}$ \\
\hline
\end{tabular}

"Comprehensive references are provided below in the individual sections as this table is intended as a general overview only. ${ }^{* *}$ The 'nanocellulose' in the schematics represents either CNCs or CNFs.

Table 2. Summary of dominant interactions in discrete nanocellulose particles (i.e., assembled powders, droplets and beads) and some key properties. 


\begin{tabular}{|c|c|c|c|c|c|}
\hline $\begin{array}{l}\text { Preparation } \\
\text { Method }\end{array}$ & $\begin{array}{l}\text { Particle } \\
\text { Type }\end{array}$ & $\begin{array}{l}\text { Forces/Interactions } \\
\text { during Preparation }\end{array}$ & $\begin{array}{l}\text { Forces Holding Dry } \\
\text { Particles Together }\end{array}$ & $\begin{array}{l}\text { Internal } \\
\text { structure }\end{array}$ & $\begin{array}{l}\text { Average } \\
\text { Particle } \\
\text { Size }\end{array}$ \\
\hline Spray drying ${ }^{1}$ & Powder & $\begin{array}{l}\text { - Water } \\
\text { evaporation and } \\
\text { water diffusion } \\
\text { - Capillary forces }\end{array}$ & $\begin{array}{l}\text { - van der Waals } \\
\text { forces } \\
\text { - Hydrogen bonding } \\
\text { - Possible } \\
\text { hornification }\end{array}$ & $\begin{array}{l}\text { Solid or } \\
\text { hollow } \\
\text { depending } \\
\text { on process } \\
\text { parameters }\end{array}$ & 5 to $30 \mu \mathrm{m}$ \\
\hline $\begin{array}{l}\text { Freeze } \\
\text { drying }^{2}\end{array}$ & $\begin{array}{l}\text { Flaky } \\
\text { structure } \\
\text { (sometimes } \\
\text { ground to } \\
\text { powder) }\end{array}$ & $\begin{array}{l}\text { - Cryo-gelation/ } \\
\text { aggregation } \\
\text { - Ice crystals } \\
\text { prevent hydrogen } \\
\text { bonding between } \\
\text { lamellae } \\
\text { - Minimal capillary } \\
\text { forces }\end{array}$ & $\begin{array}{l}\text { - van der Waals } \\
\text { forces } \\
\text { - Hydrogen bonding } \\
\text { - Hydrophobic } \\
\text { interactions } \\
\text { between lamellar } \\
\text { sheets }\end{array}$ & $\begin{array}{l}\text { Lamellar } \\
\text { (flaky) with } \\
\text { large pores }\end{array}$ & $\begin{array}{l}<1 \mu \mathrm{m} \\
\text { (lamellae } \\
\text { thickness) }\end{array}$ \\
\hline $\begin{array}{l}\text { Freeze spray } \\
\text { drying }^{3}\end{array}$ & $\begin{array}{l}\text { Beads or } \\
\text { foam }\end{array}$ & $\begin{array}{l}\text { - Cryo-gelation/ } \\
\text { aggregation } \\
\text { - Minimal capillary } \\
\text { forces }\end{array}$ & $\begin{array}{l}\text { - van der Waals } \\
\text { forces } \\
\text { - Hydrogen bonding } \\
\text { - Optional: chemical } \\
\text { crosslinking }\end{array}$ & $\begin{array}{l}\text { Meso and } \\
\text { macropores }\end{array}$ & $\begin{array}{l}60 \text { to } 120 \\
\mu \mathrm{m} \text { (beads) }\end{array}$ \\
\hline $\begin{array}{l}\text { Supercritical } \\
\text { drying, or } \\
\text { critical point } \\
\text { drying } \\
(\text { CPD })^{4}\end{array}$ & $\begin{array}{l}\text { Foam } \\
\text { (sometimes } \\
\text { ground to } \\
\text { powder) }\end{array}$ & $\begin{array}{l}\text { - No capillary } \\
\text { forces or surface } \\
\text { tension }\end{array}$ & $\begin{array}{l}\text { - van der Waals } \\
\text { forces } \\
\text { - Hydrogen bonding } \\
\text { - Optional: chemical } \\
\text { crosslinking }\end{array}$ & $\begin{array}{l}\text { Highly } \\
\text { porous }\end{array}$ & N/A \\
\hline Microfluidics $^{5}$ & $\begin{array}{l}\text { Droplets/ } \\
\text { Beads } \\
\text { (solid and } \\
\text { aerogel } \\
\text { beads) }\end{array}$ & $\begin{array}{l}\text { - Shear } \\
\text { - Liquid } \\
\text { confinement can } \\
\text { induce liquid } \\
\text { crystal self- } \\
\text { assembly (CNCs) } \\
\text { - Upon drying: } \\
\text { capillary forces }\end{array}$ & $\begin{array}{l}\text { - van der Waals } \\
\text { forces } \\
\text { - Hydrogen bonding } \\
\text { - Optional: chemical } \\
\text { crosslinking }\end{array}$ & $\begin{array}{l}\text { Randomly } \\
\text { aligned/ } \\
\text { chiral } \\
\text { nematic } \\
\text { (CNCs) or } \\
\text { porous }\end{array}$ & $\begin{array}{l}>50 \mu \mathrm{m} \\
\text { (droplets) } \\
30 \text { to } 200 \\
\mu \mathrm{m} \text { (beads) }\end{array}$ \\
\hline $\begin{array}{l}\text { Droplet } \\
\text { deposition/ } \\
\text { cryogelation } 6\end{array}$ & $\begin{array}{l}\text { Beads } \\
\text { (aerogel } \\
\text { beads) }\end{array}$ & $\begin{array}{l}\text { - Cryo-gelation/ } \\
\text { aggregation } \\
\text { - Minimal capillary } \\
\text { forces due to } \\
\text { solvent exchange }\end{array}$ & $\begin{array}{l}\text { - Entanglement } \\
\text { (CNFs) } \\
\text { - Crosslinking } \\
\text { - van der Waals } \\
\text { forces } \\
\text { - Hydrogen bonding }\end{array}$ & $\begin{array}{l}\text { Intercon- } \\
\text { nected } \\
\text { macropores }\end{array}$ & 1 to $2 \mathrm{~mm}$ \\
\hline
\end{tabular}

${ }^{1}$ Peng et al., 2012; Vehring, 2008; Beck et al., 2012; Khoshkava \& Kamal, 2014a; Z. Zhu et al., 2019

${ }^{2}$ Peng et al., 2012

${ }^{3}$ Cai et al., 2014; Jimenez-Saelices et al., 2016

${ }^{4}$ Peng et al., 2012, 2013; Osorio et al., 2018

${ }^{5}$ Y. Li et al., 2016; Parker et al., 2016, 2018; Levin et al., 2018

${ }^{6}$ Z. Liu et al., 2012; Martin et al., 2013;Mohammed et al., 2015; M. Li et al., 2016; Supramaniam et al., 2018 
Table 3. Summary of dominant interactions and mechanisms in the formation of capsules.

\begin{tabular}{|c|c|c|c|}
\hline Preparation Method & $\begin{array}{l}\text { Forces/Interactions } \\
\text { during Preparation }\end{array}$ & $\begin{array}{l}\text { Examples of How } \\
\text { Nanocellulose Shells are "Set" }\end{array}$ & Sizes \\
\hline Layer-by-layer deposition & $\begin{array}{ll}\text { - } & \text { Electrostatic } \\
& \text { interactions } \\
\text { - } & \text { Cellulose-cellulose } \\
\text { interactions }\end{array}$ & $\begin{array}{l}\text { - Annealing with heat to } \\
\text { induce hydrogen bonding } \\
\text { - Chemical crosslinking }\end{array}$ & $\begin{array}{l}\text { Hundreds of } \\
\mathrm{nm} \text { to } \mu \mathrm{m}\end{array}$ \\
\hline $\begin{array}{l}\text { Interfacial polymerization } \\
\text { or complexation }{ }^{8}\end{array}$ & $\begin{array}{l}\text { Ability of } \\
\text { nanocellulose to } \\
\text { partition at water-oil } \\
\text { interfaces } \\
\text { (intermediate } \\
\text { wettability) }\end{array}$ & $\begin{array}{l}\text { - Physical entrapment within } \\
\text { polymer } \\
\text { - Added complexation/ } \\
\text { crosslinking agents that } \\
\text { react with nanocellulose }\end{array}$ & $\begin{array}{l}\text { Hundreds of } \\
\mathrm{nm} \text { to } \mu \mathrm{m}\end{array}$ \\
\hline Biofabrication $^{9}$ & $\begin{array}{l}\text { - Hydrogen bonding } \\
\text { - van der Waals } \\
\text { forces }\end{array}$ & $\begin{array}{l}\text { - Inherent intra- and } \\
\text { intermolecular bonding in } \mathrm{BC} \\
\text { mat }\end{array}$ & $\mu \mathrm{m}$ to $\mathrm{cm}$ \\
\hline
\end{tabular}

Table 4. Summary of the typical preparation methods for nanocellulose-based continuous fibres, the external forces causing nanocellulose alignment, the structural forces at play in the resulting assemblies and the typical diameters of fibres resulting from each method.

\begin{tabular}{|l|l|l|l|}
\hline Preparation Method & $\begin{array}{l}\text { External forces } \\
\text { causing nanocellulose } \\
\text { alignment }\end{array}$ & $\begin{array}{l}\text { Forces/Interactions during } \\
\text { Preparation }\end{array}$ & $\begin{array}{l}\text { Typical diameter } \\
\text { of fibres }\end{array}$ \\
\hline $\begin{array}{l}\text { Solution (wet and dry) } \\
\text { spinning }\end{array}$ & $\begin{array}{l}\text { - Shear forces from } \\
\text { filament extrusion } \\
\text { and pulling }\end{array}$ & $\begin{array}{l}\text { - Physical entanglement } \\
\text { - Hydrogen bonding }\end{array}$ & 100 to $500 \mu \mathrm{m}$ \\
\hline Electrospinning $^{11}$ & $\begin{array}{l}\text { - Electrostatic fields } \\
\text { - Shear forces } \\
\text { - Physical } \\
\text { confinement }\end{array}$ & $\begin{array}{l}\text { - Physical entanglement } \\
\text { - Hydrogen bonding }\end{array}$ & $100 \mathrm{~nm}$ to $\mu \mathrm{m}$ \\
\hline Interfacial complexation & $\begin{array}{l}\text { 12 } \\
\text { Shear forces }\end{array}$ & $\begin{array}{l}\text { - Electrostatic } \\
\text { interactions } \\
\text { (complexation) }\end{array}$ & $\leq 1 \mu \mathrm{m}$ \\
\hline $\begin{array}{l}\text { Hydrodynamic } \\
\text { alignment }\end{array}$ & $\begin{array}{l}\text { - Hydrodynamic } \\
\text { flow }\end{array}$ & $\begin{array}{l}\text { - Hydrogen bonding } \\
\text { Electrostatic } \\
\text { interactions (gelation) }\end{array}$ & $<50 \mu \mathrm{m}$ \\
\hline
\end{tabular}

\footnotetext{
${ }^{7}$ Mohanta et al., 2014; Ye et al., 2015; Paulraj et al., 2018

${ }^{8}$ Svagan et al., 2014, 2016; Yoo et al., 2017)

${ }^{9}$ Greca et al., 2018

${ }^{10}$ Iwamoto et al., 2011; Walther et al., 2011; Håkansson et al., 2014; S. Chen et al., 2014; Hooshmand et al., 2015; Lundahl et al., 2016

${ }^{11}$ Ago, Jakes, et al., 2012; Ago, Okajima, et al., 2012; H. Dong et al., 2012; Vallejos et al., 2012; He et al., 2014; H. Wang et al., 2019;

${ }^{12} \mathrm{~K}$. Zhang \& Liimatainen, 2018;

${ }^{13}$ Håkansson et al., 2014; Mittal et al., 2017, 2018, 2019; Nechyporchuk et al., 2019
} 
- Electrostatic

repulsion

Table 5. Summary of dominant interactions in nanocellulose films and their properties.

\begin{tabular}{|c|c|c|c|c|c|}
\hline & $\begin{array}{l}\text { Forces/Interactions } \\
\text { during Preparation }\end{array}$ & $\begin{array}{l}\text { Forces Holding } \\
\text { Dry Films } \\
\text { Together }\end{array}$ & Appearance & Thickness & $\begin{array}{l}\text { Surface } \\
\text { Roughness }\end{array}$ \\
\hline $\begin{array}{l}\text { Drop } \\
\text { coating }{ }^{14}\end{array}$ & $\begin{array}{ll}\text { - } & \text { Solvent } \\
\text { evaporation } \\
\text { - } & \text { Nanocellulose } \\
& \text { self-assembly } \\
\text { - } & \text { Dewetting }\end{array}$ & $\begin{array}{l}\text { - Hydrogen } \\
\text { bonding } \\
\text { - van der Waals } \\
\text { forces }\end{array}$ & $\begin{array}{l}\text { Transparent } \\
\text { or iridescent } \\
\text { (from CNC } \\
\text { liquid crystal } \\
\text { ordering) }\end{array}$ & $<100 \mu \mathrm{m}$ & $<50 \mathrm{~nm}$ \\
\hline $\begin{array}{l}\text { Dip } \\
\text { coating }{ }^{15}\end{array}$ & $\begin{array}{ll}\text { - } & \text { Electrostatics } \\
\text { - Specific } \\
\text { substrate- } \\
\text { cellulose } \\
\text { interactions } \\
\end{array}$ & $\begin{array}{l}\text { - Electrostatics } \\
\text { - Hydrogen } \\
\text { bonding } \\
\text { - van der Waals } \\
\text { forces }\end{array}$ & Transparent & $\begin{array}{l}\text { Monolayer: } \\
<20 \mathrm{~nm} \\
\text { Multilayer: } \\
5 \mathrm{~nm} \text { to } 10 \\
\mu \mathrm{m}\end{array}$ & $<50 \mathrm{~nm}$ \\
\hline $\begin{array}{l}\text { Langmuir } \\
\text { deposition } \\
16\end{array}$ & $\begin{array}{l}\text { Nanocellulose } \\
\text { assembly at air- } \\
\text { water interface } \\
\text { - Electrostatics/ } \\
\text { specific } \\
\text { interactions with } \\
\text { substrate } \\
\end{array}$ & $\begin{array}{l}\text { - Electrostatics } \\
\text { - Hydrogen } \\
\text { bonding } \\
\text { - van der Waals } \\
\text { forces }\end{array}$ & Transparent & $<100 \mathrm{~nm}$ & $<10 \mathrm{~nm}$ \\
\hline $\begin{array}{l}\text { Spin } \\
\text { coating }{ }^{17}\end{array}$ & $\begin{array}{ll}\text { - } & \begin{array}{l}\text { Shear forces } \\
\text { (radial) }\end{array} \\
\text { - Solvent } \\
\text { evaporation }\end{array}$ & $\begin{array}{l}\text { - Hydrogen } \\
\text { bonding } \\
\text { - van der Waals } \\
\text { forces }\end{array}$ & $\begin{array}{l}\text { Transparent } \\
\text { or iridescent } \\
\text { (from thin } \\
\text { film } \\
\text { interference) }\end{array}$ & $\begin{array}{l}5 \mathrm{~nm} \text { to } 1 \\
\mu \mathrm{m}\end{array}$ & $<10 \mathrm{~nm}$ \\
\hline $\begin{array}{l}\text { Bar } \\
\text { coating }{ }^{18}\end{array}$ & $\begin{array}{ll}\text { - } & \text { Shear forces } \\
\text { - Solvent } \\
\text { evaporation }\end{array}$ & $\begin{array}{l}\text { - Hydrogen } \\
\text { bonding } \\
\text { - van der Waals } \\
\text { forces } \\
\end{array}$ & $\begin{array}{l}\text { Transparent } \\
\text { to hazy }\end{array}$ & $<1 \mathrm{~mm}$ & $<10 \mathrm{~nm}$ \\
\hline Filtration $^{19}$ & $\begin{array}{l}\text { - Solvent } \\
\text { evaporation }\end{array}$ & $\begin{array}{l}\text { - Hydrogen } \\
\text { bonding } \\
\text { - Physical } \\
\text { entanglement } \\
\text { - van der Waals } \\
\text { forces }\end{array}$ & $\begin{array}{l}\text { Transparent, } \\
\text { hazy, or } \\
\text { white }\end{array}$ & $\begin{array}{l}10 \mu \mathrm{m} \text { to } 1 \\
\mathrm{~mm}\end{array}$ & $<10 \mathrm{~nm}$ \\
\hline
\end{tabular}

\footnotetext{
${ }^{14}$ Beck et al., 2011

${ }^{15}$ Cranston, 2013

${ }^{16}$ Habibi et al., 2007; Habibi, Hoeger, et al., 2010; Xhanari et al., 2011; Bertsch et al., 2018

${ }^{17}$ Edgar \& Gray, 2003; Kontturi et al., 2003, 2007; Notley, Eriksson, Wågberg, Beck-Candanedo, et al., 2006; Ahola et al., 2008

${ }^{18}$ Hoeger et al., 2011; Lavoine et al., 2014

${ }^{19}$ Henriksson et al., 2008; Österberg et al., 2013; Q. Chen et al., 2014
} 


\begin{tabular}{|c|c|c|c|c|c|}
\hline $\begin{array}{l}\text { Spray } \\
\text { Coating } 20\end{array}$ & $\begin{array}{l}\text { - Shear forces } \\
\text { - Solvent } \\
\text { evaporation }\end{array}$ & $\begin{array}{l}\text { - Hydrogen } \\
\text { bonding } \\
\text { - Physical } \\
\text { entanglement } \\
\text { - van der Waals } \\
\text { forces } \\
\end{array}$ & $\begin{array}{l}\text { White, } \\
\text { optically } \\
\text { uniform }\end{array}$ & $\begin{array}{l}50-300 \\
\mu \mathrm{m}\end{array}$ & $<20 \mathrm{~nm}$ \\
\hline
\end{tabular}

Table 6. Summary of dominant interactions in nanocellulose-only hydrogels, aerogels and foams, and some examples of added crosslinking chemistries (similar to those reviewed by (Liang et al., 2020)).

\begin{tabular}{|c|c|c|c|c|}
\hline & $\begin{array}{l}\text { Preparation } \\
\text { Method }\end{array}$ & $\begin{array}{l}\text { Forces/Interactions during } \\
\text { Preparation }\end{array}$ & $\begin{array}{l}\text { Forces Holding } \\
\text { Aerogel/Hydrogel } \\
\text { Together }\end{array}$ & $\begin{array}{l}\text { Eg. of Covalent } \\
\text { Crosslinking } \\
\text { Chemistries }\end{array}$ \\
\hline \multirow{5}{*}{ 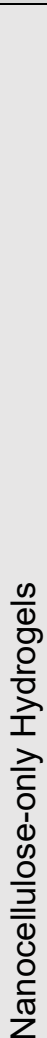 } & $\begin{array}{l}\text { Concentrating } \\
\text { CNC/CNF } \\
\text { suspension }\end{array}$ & $\begin{array}{l}\text { - Surpassing nanocellulose } \\
\text { percolation/entanglement } \\
\text { threshold }\end{array}$ & $\begin{array}{l}\text { - Entanglement } \\
\text { - van der Waals } \\
\text { forces }\end{array}$ & N/A \\
\hline & $\begin{array}{l}\text { Electrostatic } \\
\text { destabilization } \\
\text { of CNC/CNF } \\
\text { suspension }(\mathrm{pH} \text {, } \\
\text { salt, temp. })^{22}\end{array}$ & $\begin{array}{l}\text { - DLVO destabilization } \\
\text { - Decrease in percolation/ } \\
\text { entanglement threshold }\end{array}$ & $\begin{array}{l}\text { - Entanglement } \\
\text { - van der Waals } \\
\text { forces }\end{array}$ & $\begin{array}{l}\text { Amine or carboxyl } \\
\text { functionalization ( } \mathrm{pH} \\
\text { responsive) }\end{array}$ \\
\hline & $\begin{array}{l}\text { Ion-mediated } \\
\text { gelation } 23\end{array}$ & $\begin{array}{l}\text { - DLVO destabilization } \\
\text { - Decrease in percolation/ } \\
\text { entanglement threshold } \\
\text { - lonic bridging }\end{array}$ & $\begin{array}{l}\text { - lonic bridging (with } \\
\text { multi-valent ions) }\end{array}$ & $\mathrm{N} / \mathrm{A}$ \\
\hline & $\begin{array}{l}\text { Crosslinking } \\
\text { agents or } \\
\text { surface } \\
\text { functionalization } \\
\text { of CNCs/CNFs }{ }^{24}\end{array}$ & $\begin{array}{l}\text { - Chemical crosslinking } \\
\text { - Decrease in percolation } \\
\text { threshold }\end{array}$ & $\begin{array}{l}\text { - Covalent/ionic } \\
\text { bonds }\end{array}$ & $\begin{array}{l}\text { - Hydrazone } \\
\text { crosslinking, } \\
\text { - paper wet-strength } \\
\text { additives (e.g. PAE, } \\
\text { Kymene) } \\
\text { - Butanetetracarboxylic } \\
\text { acid } \\
\text { - Maleimide } \\
\text { - Epichlorohydrin }\end{array}$ \\
\hline & $\begin{array}{l}\text { In situ } \\
\text { polymerization } \\
\text { around } \\
\mathrm{CNCs} \mathrm{CNFs}^{25}\end{array}$ & - Chemical crosslinking & $\begin{array}{l}\text { - Covalent bonds } \\
\text { - Physical } \\
\text { entrapment } \\
\text { - Entanglement } \\
\end{array}$ & $\begin{array}{l}\text { Free radical } \\
\text { polymerization }\end{array}$ \\
\hline
\end{tabular}

\footnotetext{
${ }^{20}$ Beneventi et al., 2014, 2015; Shanmugam et al., 2017, 2018

${ }^{21}$ Pääkko et al., 2007; Ure et al., 2011

${ }^{22}$ Fall et al., 2011; Nordenström et al., 2017; Lewis et al., 2016

${ }^{23}$ Chau et al., 2015

${ }^{24}$ Osorio et al., 2018; X. Yang \& Cranston, 2014; Köhnke et al., 2014; McKee et al., 2014; Domingues et al., 2015; García-Astrain et al., 2016; Chau et al., 2016

${ }^{25}$ J. Yang et al., 2013; J. Wei et al., 2016
} 


\begin{tabular}{|c|c|c|c|c|}
\hline \multirow{4}{*}{ 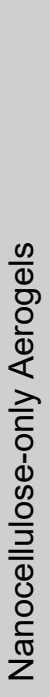 } & Freeze drying 26 & $\begin{array}{l}\text { - Cryo-gelation/ } \\
\text { aggregation } \\
\text { - Ice crystals prevent } \\
\text { hydrogen bonding } \\
\text { between lamellae } \\
\text { - Minimal capillary forces }\end{array}$ & $\begin{array}{l}\text { - van der Waals } \\
\text { forces } \\
\text { - Hydrogen bonding } \\
\text { - Hydrophobic } \\
\text { interactions }\end{array}$ & $\begin{array}{l}\text { - Hydrazone } \\
\text { crosslinking } \\
\text { - Acetal formation } \\
\text { - Citric acid crosslinking }\end{array}$ \\
\hline & $\begin{array}{l}\text { Critical point } \\
\text { drying }^{27}\end{array}$ & $\begin{array}{l}\text { - Rapid dehydration } \\
\text { - Hydrogel structure locked } \\
\text { into place }\end{array}$ & $\begin{array}{l}\text { - van der Waals } \\
\text { forces } \\
\text { - Hydrogen bonding } \\
\text { - Hydrophobic } \\
\text { interactions }\end{array}$ & $\begin{array}{l}\text { - Hydrazone } \\
\text { crosslinking } \\
\text { - Acetal formation } \\
\text { - Citric acid crosslinking }\end{array}$ \\
\hline & $\begin{array}{l}\text { Pressurized gas } \\
\text { expansion } \\
(P G X)^{28}\end{array}$ & $\begin{array}{l}\text { - Rapid dehydration } \\
\text { - Hydrogel structure locked } \\
\text { into place }\end{array}$ & $\begin{array}{l}\text { - van der Waals } \\
\text { forces } \\
\text { - Hydrogen bonding }\end{array}$ & - Hydrazone crosslinks \\
\hline & $\begin{array}{l}\text { Spray freeze } \\
\text { drying } 29\end{array}$ & $\begin{array}{l}\text { - Cryo-gelation/ } \\
\text { aggregation } \\
\text { - Minimal capillary forces }\end{array}$ & $\begin{array}{l}\text { - van der Waals } \\
\text { forces } \\
\text { - Hydrogen bonding }\end{array}$ & - Kymene \\
\hline 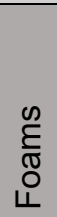 & $\begin{array}{l}\text { Homogenization } \\
\text { (aqueous } \\
\text { foams) with } \\
\text { drying (dry } \\
\text { foams) }\end{array}$ & $\begin{array}{l}\text { - Ability of nanocellulose to } \\
\text { partition at air-water } \\
\text { interfaces (with surfactant } \\
\text { additives needed) }\end{array}$ & $\begin{array}{l}\text { - Hydrogen bonds } \\
\text { - Hydrophobic } \\
\text { interactions }\end{array}$ & N/A \\
\hline
\end{tabular}

${ }^{26}$ Lavoine \& Bergström, 2017

${ }^{27}$ Heath \& Thielemans, 2010; Liebner et al., 2010

${ }^{28}$ Osorio et al., 2018

${ }^{29}$ Cai et al., 2014; Jimenez-Saelices et al., 2016

${ }^{30}$ Cervin et al., 2013, 2016; Gordeyeva et al., 2016; Z. Hu, Xu, et al., 2016; B. Wei et al., 2017; Mariano et al., 2018 